\title{
Air Pollution in the Hindu Kush Himalaya
}

\section{Coordinating Lead Authors}

Eri Saikawa, Emory University, Atlanta, GA, USA, e-mail: eri.saikawa@emory.edu Arnico Panday, ICIMOD, Kathmandu, Nepal, e-mail: arnico.panday@icimod.org (corresponding author) Shichang Kang, State Key Laboratory of Cryosphere Science, Northwest Institute of Eco-Environment and Resources, Chinese Academy of Science, Lanzhou, China, e-mail: Shichang.kang@1zb.ac.cn

\section{Lead Authors}

Ritesh Gautam, Indian Institute of Technology Bombay, Mumbai, India, e-mail: rgautam.Iitb@gmail.com Eric Zusman, Institute for Global Environmental Strategies, Hayama, Japan, e-mail: zusman@iges.or.jp Zhiyuan Cong, Institute of Tibetan Plateau Research, Chinese Academy of Science, Beijing, China, e-mail: zhiyuancong@Itpcas.ac.cn

E. Somanathan, Economics and Planning Unit, Indian Statistical Institute, Delhi, India, e-mail: som@isid.acin

Bhupesh Adhikary, ICIMOD, Kathmandu, Nepal, email: bhupesh.adhikary@icimod.org

\section{Contributing Authors}

Robert E. Yokelson, University of Montana, Missoula, MT, USA, e-mail: bob.yokelson@mso.umt.edu James H. Crawford, NASA Langley Research Center, Hamton, VA, USA, e-mail: james.h.crawford@nasa.gov Maheswar Rupakheti, Institute for Advanced Sustainability Studies, Potsdam, Germany, e-mail: maheswar. rupakheti@iass-potsdam.de

Wenlu Ye, Emory University, Atlanta, GA, USA, e-mail: wenlu.ye@emory.edu

Md. Golam Saroar, Scientific Officer (Modelling), Clean Air and Sustainable Environment (CASE) Project, Department of Environment Ministry of Environment and Forest, Bangladesh, e-mail: saroar82@gmail.com

\section{Review Editor}

Nguyen Thi Kim Oanh, Asian Institute of Technology, Bangkok, Thailand, e-mail: kimoanh@ait.asia

\section{Corresponding Author}

Arnico Panday, ICIMOD, Kathmandu, Nepal, e-mail: arnico.panday@icimod.org 


\section{Contents}

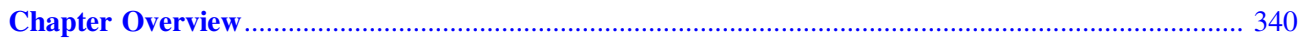

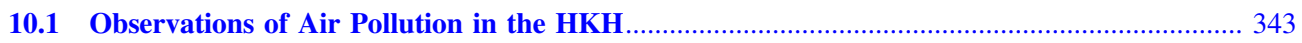

10.1.1 Air Pollution Time-Series and Seasonality in the HKH ................................................ 343

10.1.2 Air Pollution Diurnal Cycle in the HKH..................................................................... 345

10.1.3 Air Pollution Observations in High Mountain Areas ...................................................... 347

10.1.4 Assessment of Existing Observational Networks and Gaps in the HKH for Air Quality ... 348

10.2 Worsening Haze and Winter Fog in and Near the HKH.................................................. 349

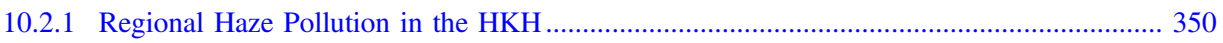

10.2.2 State of Current Knowledge About Haze in the HKH .................................................... 351

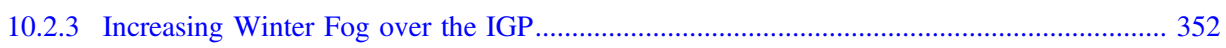

10.2.4 Causes and Impacts of Haze and Winter Fog ............................................................ 353

10.3 Emission Sources and Transport Processes in the HKH..................................................... 354

10.3.1 The Major Air Pollutant Emissions Source Sectors in the HKH ...................................... 355

10.3.2 Source Regions and Transport Pathways for Pollution Reaching and Crossing the High

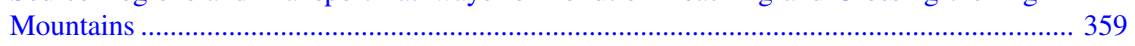

10.3.3 Assessment of Our Knowledge About Emissions and Processes in the HKH..................... 361

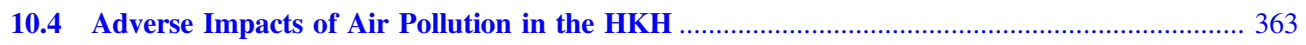

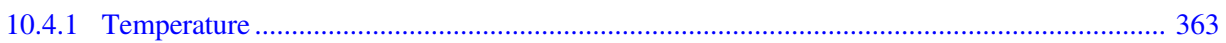

10.4.2 Precipitation and Monsoon (Cloud Microphysics to Regional Scale) .................................. 364

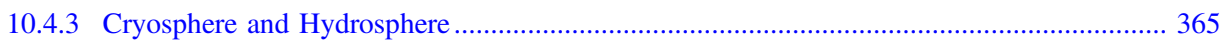

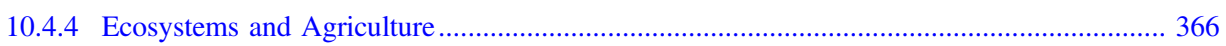

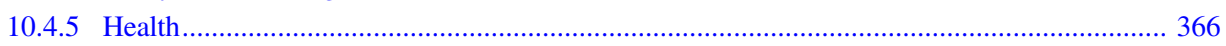

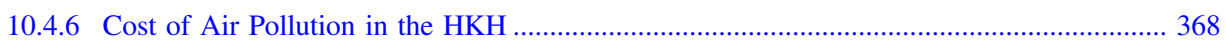

10.5 Mitigation Efforts for Improving Air Quality in the HKH ................................................. 369

10.5.1 Mitigation Options in the HKH to Reduce Emissions .................................................... 369

10.5.2 Incentives and Behaviour Change for Improving Air Quality in the HKH ....................... 371

10.5.3 Planning, Policies, and Institutions for Air Quality Management in the HKH.................. 371

10.5.4 National Ambient Air Quality Standards and Air Quality Management in the HKH ........ 372

10.6 Key Challenges in Reducing Air Pollution in the HKH ................................................... 375

10.6.1 Recognition of Air Pollution as a Problem and Co-benefits of Mitigation ......................... 375

10.6.2 Transboundary Pollution Flows, Collaborations, and Cooperation......................................... 376

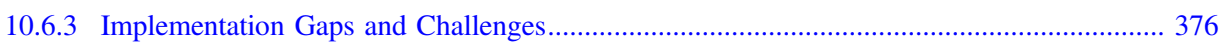

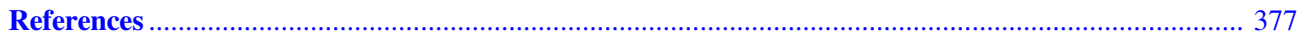

\section{Chapter Overview}

\section{Key Findings}

1. Air pollution in the Hindu Kush Himalaya (HKH) is on the rise and regional air quality has worsened in the past two decades, with the adjacent Indo-Gangetic Plains (IGP) having become one of the most polluted regions in the world. The causes include rapid urbanization and population growth, with emissions from diverse pollutant sources - cookstoves, brick kilns, other industries, power plants, and transport. However, major gaps in our understanding remain due to the scarcity of air quality monitoring stations.

2. Persistent winter fog and haze have increased across the Indo-Gangetic Plains (IGP), leading to reduced visibility and elevated air pollution just south of the HKH and affecting air quality in the HKH as well as in the IGP. The winter fog reduces crop yields and affects tourism, impacting the lives of millions of people.

3. The HKH is sensitive to climate change-air pollutants originating within and near the $\mathrm{HKH}$ 
amplify the effects of greenhouse gases and accelerate the melting of the cryosphere through the deposition of black carbon and dust, the circulation of the monsoon, and the distribution of rainfall over Asia.

\section{Policy Messages}

1. To mitigate air pollution and its severe socio-economic impacts, investment in clean technologies and infrastructure is essential. The $\mathrm{HKH}$ should focus on leapfrogging directly to environmentally-friendly technologies and energy options in households, agriculture, industry, transport and

2. Dedicated national institutions are required to address air pollution across multiple sectors and scales and implement air pollution mitigation policies. These institutions also need to be mandated to cooperate and collaborate regionally to address trans-boundary air pollution.

3. Education is essential-the HKH needs more mechanisms to enhance knowledge sharing, to increase responsiveness to scientific evidence, and to promote awareness and behavioural change.

Air pollution has large impacts on the Hindu Kush Himalaya (HKH), affecting not just the health of people and ecosystems, but also climate, the cryosphere, monsoon patterns, water availability, agriculture, and incomes (established but incomplete). Although the available data are not comprehensive, they clearly show that the $\mathrm{HKH}$ receives significant amounts of air pollution from within and outside of the region, including the Indo-Gangetic Plain (IGP), a region where many rural areas are severely polluted. In addition, the HKH receives trans-boundary pollution from other parts of Asia. This chapter surveys the evidence on regional air pollution and considers options for reducing it, while underlining the need for regional collaboration in mitigation efforts. As described in Chap. 1, the HKH region is fragile and rapidly changing; while the outcome of the interplay of complex drivers is difficult to predict, it will have major consequences. That holds true for air pollution as well.

The past decade has seen a rapid rise not only in air pollution affecting the HKH (well-established), but also in our understanding of it. An increasing number of atmospheric monitoring stations have been installed throughout the $\mathrm{HKH}$ and the nearby plains, while several important field campaigns have contributed significant knowledge about atmospheric processes. Many collect time series data on particulate matter with a diameter of $10 \mu \mathrm{m}$ or less $\left(\mathrm{PM}_{10}\right)$ and with a diameter of $2.5 \mu \mathrm{m}$ or less $\left(\mathrm{PM}_{2.5}\right)$. Data from these monitoring stations show that air quality has strong seasonal and diurnal cycles in most parts of the HKH, with both meteorology and emission patterns playing important roles in determining concentrations.

Air pollution varies by season: Ground-level particulate matter pollutant concentrations in the $\mathrm{HKH}$ are highest during the winter months from December to February, and lowest during the summer monsoon months from June to August (well-established). Pollution also varies diurnally, though in different ways for different pollutants. In many plain and valley locations, meteorology and emissions patterns cause morning and evening peaks in $\mathrm{PM}_{10}$ and $\mathrm{PM}_{2.5}$ - while ozone $\left(\mathrm{O}_{3}\right)$ peaks during the daytime and sinks to low levels at night, as a result of dry deposition and titration by nitric oxide (NO). Mountaintop and high-altitude locations show an afternoon peak in PM caused by the up-slope arrival of polluted air masses from lower elevations; these higher locations do not exhibit the night-time drop in $\mathrm{O}_{3}$ levels found in the plains and valleys.

Despite recent improvements in data collection, major gaps in $\mathrm{HKH}$ air quality networks persist, with many large cities and even more rural areas within and surrounding the HKH (i.e., IGP) still lack monitoring. These data gaps reflect several challenges. First, the topographical heterogeneity and thus fine-scale atmospheric variations in the $\mathrm{HKH}$ means that improved air quality monitoring would require a denser network of stations than is required in flat plains. Second, the current use of different instruments or protocols at different sites means that data from these sites urgently needs to be compared and validated to produce harmonized data bases. Third, in addition to the ground-based observation of air pollution, a full picture would also require the measurement of pollutants' vertical variation. In addition, more advanced instruments with higher sensitivity are essential for advancing our understanding of air pollution.

One of the worsening pollution problems now facing the southern edges of the HKH and the nearby IGP is regional haze during the dry season, augmented by increasing instances of persistent winter fog in the past two decades (well-established). In winter months, temperatures over the IGP are cold enough for frequent temperature inversion episodes - a layer of cool air is trapped near the ground under a layer of warm air. This condition suppresses the normal tendency of pollutants to rise and disperse over a wide area, trapping them instead in a relatively shallow boundary layer and causing winter haze to be optically thick (as often seen in satellite imagery). Winter air pollution is 
also exacerbated by increased biofuel burning for heating, combined with increased open biomass burning: Higher winter-time concentrations have been found at several locations in the IGP for carbonaceous aerosols (black carbon, BC and organic carbon, OC), for sulphate, as well as for nitrate. Finally, dense persistent haze and fog can be self-reinforcing: by reducing the sun's ability to warm the land surface, they can further lower surface temperatures and perpetuate the inversion effect. For all these reasons, poor visibility days can rise as high as $90 \%$ during winter throughout the IGP.

The HKH is sensitive to global climate change through its impacts on atmospheric dynamics and thermal forcing (established but incomplete). Research also indicates that snow and glacier melt are accelerated by absorbing aerosols by up to $20 \%$. In addition, several climate modeling studies have suggested the importance of aerosol solar absorption in modulating summer monsoon circulation and rainfall distribution over Asia. Water from seasonal snow and glacial melt provides significant resources for regional livelihoods, and monsoon rainfall—particularly over southern Asia-is a crucial freshwater resource for the region (constituting over $70 \%$ of annual rainfall). Thus, as aerosol radiative effects and regional warming perturb monsoon circulation and the Himalayan cryosphere, the resulting shifts in rainfall dynamics have critical socio-economic as well as environmental implications.

Air pollutant mitigation is urgently needed in the $\mathrm{HKH}$, given the severe impacts of deteriorating air quality and increasing haze and winter fog across the region - on health, climate, the cryosphere, water resources, agriculture, ecosystems, and livelihoods (established but incomplete). Such mitigation will require three elements:

- Investment in clean technologies and green infrastructure.

- Dedicated institutions and policies, at the local and national levels, but also for regional and trans-boundary collaboration and cooperation.

- Behavioural change, supported by knowledge sharing and responsiveness to scientific evidence.

Promising clean technologies exist for mitigation in the household, industrial, transport, and energy sectors. At the household level, steps include chimney installation and the use of cleaner cook stoves - whether with liquefied petroleum gas (LPG), biogas, or electricity. Households may be more likely to adopt these cleaner fuels and technologies with help from government subsidies and credit, as well as through effective awareness building and marketing. At the industry level, brick producers can reduce fuel consumption and mitigate $\mathrm{CO}_{2}$ and air pollutant emissions by shifting from intermittent or inefficient kilns (such as clamp kilns or bull's trench kilns) to more efficient types (such as zigzag or Vertical Shaft). Finally, green infrastructure policies could significantly reduce short-lived climate pollutants (SLCPs) and greenhouse gases through structural changes to energy and transport systems: For example, the HKH countries could adopt tighter vehicle emissions and fuel quality standards or design cities that promote public and non-motorized transport.

Dedicated institutions and policies are needed, both within countries and across national borders. Because air pollution in the HKH is regional, its mitigation is - critically - a regional responsibility. The region urgently requires institutional arrangements that will enable inter-agency coordination on air pollution, actively engaging multiple stakeholders. To begin with, two constraints need to be removed: the lack of a clear division of labour among government institutions, and the lack of coordinating mechanisms to break down agency silos.

Public awareness and behavioural change are also essential for emissions reduction. For example, people who lack adequate solid waste collection services commonly burn their trash, generating emissions that can be linked to health problems. Raising awareness of these problems can help to build public support and pressure for improving services in urban areas - and for adopting alternative waste disposal methods, such as composting.

\section{Air Pollution and the Sustainable Development Goals}

Air pollution mitigation must be part of any effort to meet the Sustainable Development Goals (SDGs), especially three: those on health (SDG 3), sustainable energy (SDG 7), and climate action (SDG 13). To make the connection explicit, we propose three calls to action on air pollutants in the HKH:

- For SDG 3 (Ensure healthy lives and promote wellbeing for all at all ages): Take urgent measures to reduce household air pollution from cook stoves in the HKH.

- For SDG 7 (Ensure access to affordable, reliable, sustainable, and modern energy for all): Ensure access to affordable, sustainable, and improved clean fuel for all people in the HKH.

- For SDG 13 (Take urgent action to combat climate change and its impacts): Reduce emissions of short-lived climate pollutants (SLCPs) - especially black carbon (BC) - by reducing emissions from brick kilns, cook stoves, open biomass burning, and diesel engines in the HKH. 


\subsection{Observations of Air Pollution in the $\mathrm{HKH}$}

Photographs of snowy peaks against blue skies can give the impression that the Hindu Kush Himalaya (HKH) has pristine air quality. Unfortunately, days when such photographs can be taken are becoming increasingly rare. Recent decades have seen much of the HKH suffering from major air pollution problems. Three urban cities in the HKH, including Peshawar (Pakistan), Mazar-e-Sharif (Afghanistan), and Kabul (Afghanistan), are on the list of the 20 most polluted cities in the world (World Health Organization 2016). During a big fraction of the dry season (see Box 10.1 for definition of seasons), the heavily populated Indo-Gangetic Plain (IGP) just south of the HKH is covered by a thick aerosol haze that reduces visibility and obscures sunlight. The haze often penetrates deep into Himalayan valleys and at times even crosses the Himalaya to reach the Tibetan Plateau.

Across the region, particulate matter (PM) - both primary and secondary aerosols - as well as tropospheric ozone $\left(\mathrm{O}_{3}\right)$ - a secondary pollutant-have increased. As illustrated in Fig. 10.1, many cities in the HKH have an annual average $\mathrm{PM}_{2.5}$ concentration higher than the World Health Organization (WHO) guideline of $10 \mu \mathrm{g} / \mathrm{m}^{3}$ (WHO 2005). Furthermore, in 12 cities (Allahabad, India; Patna, India; Dehradun, India; Delhi, India; Luchnow, India; Ludhiana, India; Peshawar, Pakistan; Amritsar, India; Rawalpindi, Pakistan; Narayangonj, Bangladesh; Agra, India; Jaipur, India), the annual average concentrations are more than 10 times higher than the guideline value. Meanwhile the IGP has seen an increase in persistent winter fog during the past two decades that is at least partly driven by increased air pollution, in addition to changes in moisture availability. The historical trends of black carbon (BC) reconstructed from lake sediment and ice cores at high altitude sites also show a dramatic increase in recent decades, starting in the 1960s. This section presents our understanding of air pollution in the region based on available observations. Throughout the section, the focus will be on PM and gaseous air pollutants, including carbon monoxide $(\mathrm{CO})$, nitrogen oxides $\left(\mathrm{NO}_{x}\right)$, sulphur oxides $\left(\mathrm{SO}_{x}\right)$, and $\mathrm{O}_{3}$.

\section{Box 10.1 Seasons in the HKH}

When discussing air pollution in the HKH, we generally talk about two seasons: dry period (OctoberJune) and wet period (June-September), which also corresponds to the monsoon season. The dry period can be further divided into three separate seasons: winter (December-February), pre-monsoon (Marchmid-June), and post-monsoon (October-November). These definitions (illustrated in Fig. 10.2) are used throughout this chapter.
In recent years, stations to monitor air pollution have been established at a number of key places within and near the $\mathrm{HKH}$, both in urban and rural areas. In addition, short-duration field campaigns have collected valuable first glimpses into pollution levels and temporal patterns of pollutants that are otherwise not monitored in those locations. While many time-series are short and most datasets do not go back more than a few years, they provide some important observations:

- Air quality in most places has strong seasonal and diurnal cycles, with an important role played by meteorology and emission patterns.

- Air pollution levels are generally high outside of the rainy season.

- Air pollution is very much a regional issue, with widespread haze extending across much of the urban and rural parts of the IGP and southern HKH foothills during the dry season.

\subsubsection{Air Pollution Time-Series and Seasonality in the HKH}

Many places in the HKH and surrounding regions suffer from unhealthy levels of air pollution. In Bangladesh, we find PM levels more than twice the national annual average ambient air quality standards for $\mathrm{PM}_{10}\left(50 \mu \mathrm{g} / \mathrm{m}^{3}\right.$ annual average) and more than 4.5 times higher for $\mathrm{PM}_{2.5}$ $\left(15 \mu \mathrm{g} / \mathrm{m}^{3}\right.$ annual average) (Clean Air Asia 2016). Figure 10.3 shows monthly average levels of $\mathrm{PM}_{10}$ and $\mathrm{PM}_{2.5}$ collected by the only continuous monitoring station in Dhaka, Bangladesh, between 2002 and 2010. We see in the figure a distinct seasonal pattern, with highest concentrations during the winter months from December to February, and lowest concentrations during the summer monsoon months of June to August. A similar seasonal pattern was also found in $\mathrm{PM}_{10}$ concentrations in Kathmandu, Nepal (Aryal et al. 2008), while in Varanasi, India, $\mathrm{PM}_{10}$ and $\mathrm{PM}_{2.5}$ were found to decrease from January to March (Kumar et al. 2015).

Although detailed seasonal data are lacking in many places, the levels of PM are very high in many cities in the region for which data exists, including Islamabad, Pakistan (Parekh et al. 2001) and Delhi and Kolkata, India (Gurjar et al. 2016). A large population in the region is exposed to air pollution that is higher than the WHO annual standard of $20 \mu \mathrm{g} / \mathrm{m}^{3}$ for $\mathrm{PM}_{10}$ and $10 \mu \mathrm{g} / \mathrm{m}^{3}$ for $\mathrm{PM}_{2.5}$ (WHO 2005). Putero et al. (2015) reported annual $\mathrm{PM}_{10}$ concentration of $169 \pm 113 \mu \mathrm{g} / \mathrm{m}^{3}$ for Kathmandu during the year 2013 . Kathmandu, Nepal has annual average $\mathrm{PM}_{2.5}$ concentrations of $49 \mu \mathrm{g} / \mathrm{m}^{3}$ in 2013, exceeding Nepal's own 24-h ambient standard of $40 \mu \mathrm{g} / \mathrm{m}^{3}$ (http://www.who.int/phe/health_ topics/outdoorair/databases/cities/en/). 


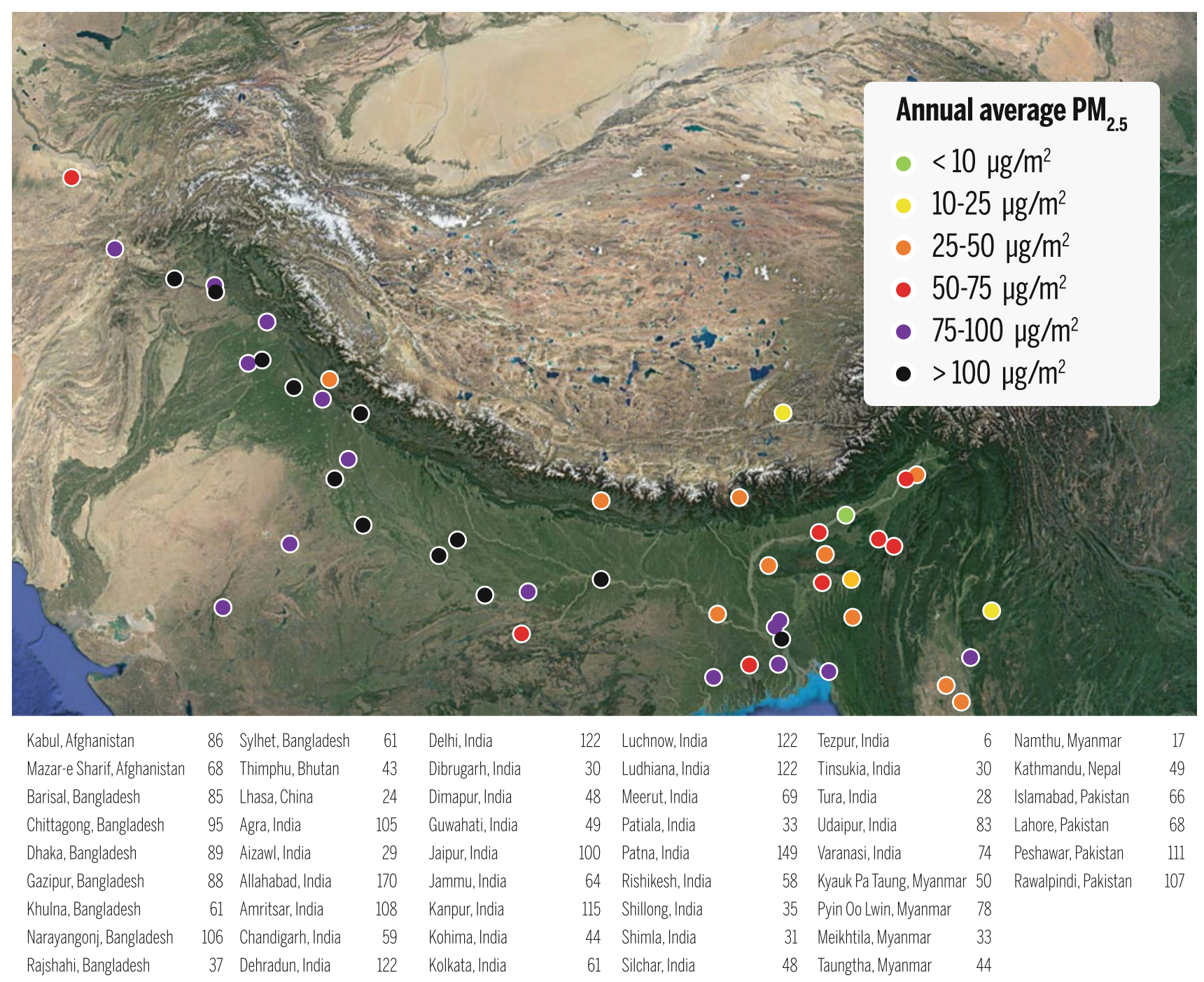

Fig. 10.1 Annual average $\mathrm{PM}_{2.5}$ concentrations in the HKH (Data source WHO 2016, http://www.who.int/phe/health_topics/outdoorair/ databases/cities/en/)

\begin{tabular}{|c|c|c|c|c|c|c|c|c|c|c|c|c|c|c|c|c|c|c|c|c|c|c|c|c|}
\hline \multirow{2}{*}{$\begin{array}{l}\text { Season' } \\
"\end{array}$} & \multicolumn{2}{|c|}{ January' } & \multicolumn{2}{|c|}{ February' } & \multicolumn{2}{|c|}{ March' } & \multicolumn{2}{|c|}{ April' } & \multicolumn{2}{|c|}{ May' } & \multicolumn{2}{|c|}{ June' } & \multicolumn{2}{|c|}{ July' } & \multicolumn{2}{|c|}{ August' } & \multicolumn{2}{|c|}{ September' } & \multicolumn{2}{|c|}{ October' } & \multicolumn{2}{|c|}{ November' } & \multicolumn{2}{|c|}{ December' } \\
\hline & ' & & & & & & & & & & & & & & & & & & & & & & & $"$ \\
\hline Winter' & $" 1$ & $" 1$ & $"$ & " & $"$ & " & $"$ & 11 & $"$ & $" 1$ & 11 & " & $" 1$ & $" 1$ & $"$ & " & $"$ & " & " & " & $" 1$ & $" 1$ & $" 1$ & $" 1$ \\
\hline Pre)monsoon' & ' & & & & $"$ & " & " & " & " & $"$ & 11 & ' & & & & & & & & & & & & " \\
\hline Monsoon' & ' & & & & & & & & & & & $"$ & $"$ & " & $" 1$ & $"$ & $"$ & $"$ & ' & & & & & " \\
\hline Post)monsoon' & " & $"$ & $"$ & $"$ & $"$ & $"$ & " & $"$ & " & $"$ & $"$ & " & $"$ & " & $"$ & " & $"$ & $"$ & $"$ & $"$ & $" 1$ & $"$ & $"$ & $"$ \\
\hline$" 1$ & ' & & & & & & & & & & & & & & & & & & & & & & & $" 1$ \\
\hline Dry'period" & " & " & " & $"$ & " & " & $"$ & $"$ & " & " & " & ' & & & & & & & " & " & " & " & $"$ & " \\
\hline Wet'period' & " & $"$ & $"$ & $"$ & $"$ & $"$ & $"$ & $"$ & $"$ & $"$ & $" 1$ & $"$ & $"$ & $" 1$ & $"$ & $"$ & $"$ & $"$ & $"$ & $"$ & $" 1$ & $"$ & $"$ & $"$ \\
\hline
\end{tabular}

Fig. 10.2 Illustration of seasons for the HKH (Sources Bollasina et al. 2002; Hindman et al. 2002; Bonasoni et al. 2012)

$\mathrm{PM}_{2.5}$ is usually dominated by smoke particles and secondary aerosols, while $\mathrm{PM}_{10}$ is more affected by natural soil dust (Wilson and Suh 1997). Data from both Dhaka and Delhi show a dominated by fine particles- $-\mathrm{PM}_{2.5}$ is a large fraction of $\mathrm{PM}_{10}$ (Gadi et al. 2000). In contrast, Karachi,
Pakistan, in the arid south-western corner of the IGP, had $\mathrm{PM}_{2.5}$ concentrations of $75 \mu \mathrm{g} / \mathrm{m}^{3}$ but $\mathrm{PM}_{10}$ concentrations of $437 \mu \mathrm{g} / \mathrm{m}^{3}$ in March-April 2009 (Shahid et al. 2016). In addition, it is not only the cities in the region that have high levels of air pollution; rural places in the IGP are also 


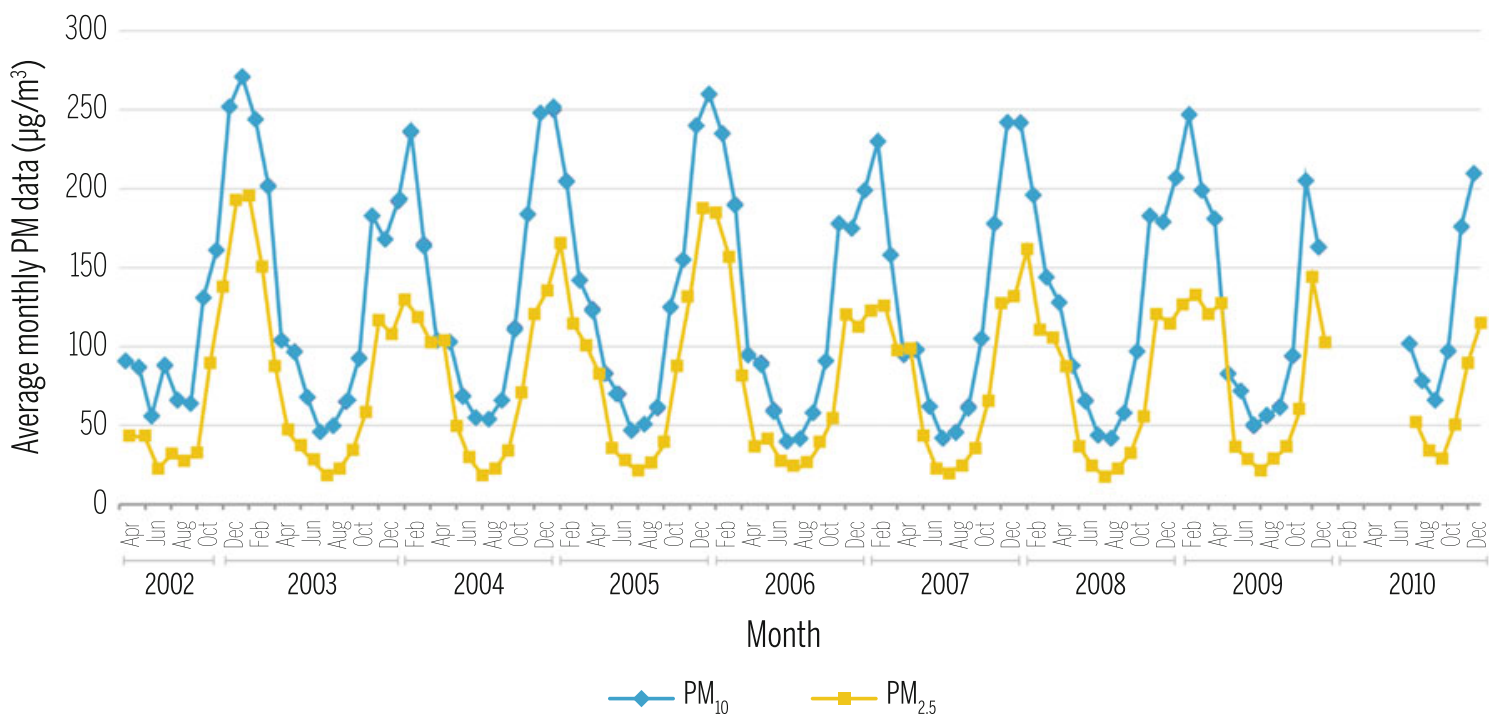

Fig. 10.3 Average monthly PM data in Dhaka, Bangladesh, 2002-2010 (Data source Clean Air and Sustainable Environment (CASE), case.doe. gov.bd)

affected, such as Lumbini, Nepal (Rupakheti et al. 2017). In places with a lot of dirty fuel combustion, a significant fraction of $\mathrm{PM}_{2.5}$ is composed of $\mathrm{BC}$, the light-absorbing soot that is emitted during incomplete combustion (Shindell et al. 2013).

Although few cities have long enough records to allow us to see trends, the satellite data in Fig. 10.4 shows the increasing aerosol optical depth in the region over time. In Delhi, while levels of PM and $\mathrm{NO}_{x}$ have slightly increased over the past decade, levels of sulphur dioxide $\left(\mathrm{SO}_{2}\right)$ and $\mathrm{CO}$ have come down as a result of converting public vehicles to

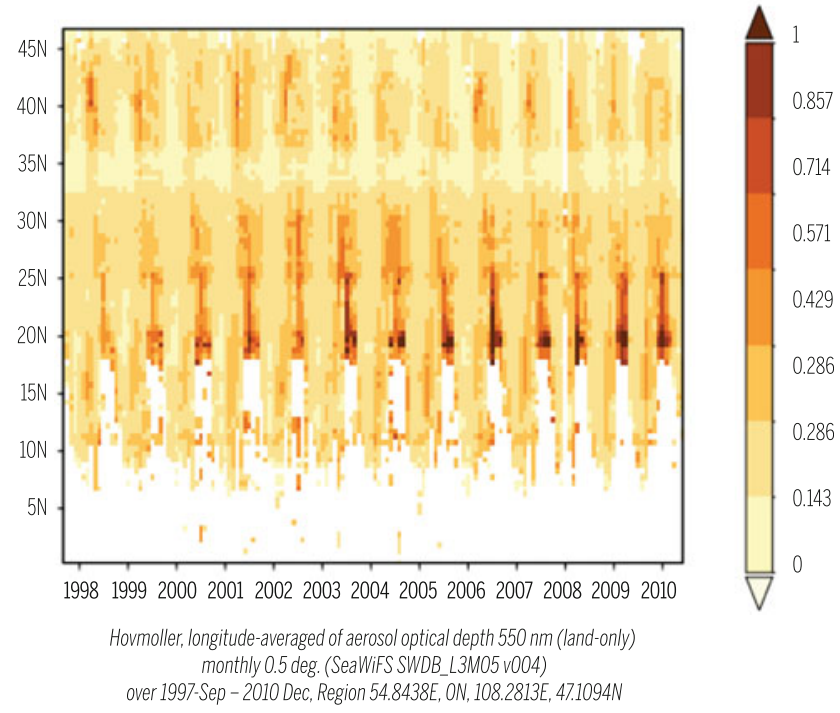

Fig. 10.4 Longitude-averaged aerosol optical depth between 54.8 and 108 E (Data source SeaWiFS using NASA's online Giovanni tool (https://giovanni.gsfc.nasa.gov/giovanni/)) compressed natural gas (CNG) (Firdaus and Ahmad 2011; Gurjar et al. 2016). A study on the health effects of the measures found improvements in the respiratory health of people who spent the most time outdoors (Foster and Kumar 2011). Lhasa, Tibet, meanwhile, has seen CO levels remain flat from 1998 to 2012, while $\mathrm{NO}_{2}$ and $\mathrm{SO}_{2}$ have increased substantially as a result of a growing vehicle fleet but decreasing biomass combustion (Ran et al. 2014).

\subsubsection{Air Pollution Diurnal Cycle in the HKH}

In the Kathmandu Valley, Nepal, $\mathrm{PM}_{10}$ and $\mathrm{PM}_{2.5}$ have been found to exhibit morning and evening peaks that are influenced by a combination of emissions patterns and meteorology (Aryal et al. 2009; Panday and Prinn 2009; Panday et al. 2009). The pattern of morning and evening peaks is also found in $\mathrm{CO}$ concentrations in Kathmandu (Panday and Prinn 2009), as shown in Fig. 10.5. CO is another product of incomplete combustion. The fact that the same pattern appeared on weekends and festival days illustrates that emission patterns (such as rush hour) alone cannot explain the observed pattern, which depended on the formation and dissipation of a cold-air pool over the bowl-shaped valley (Panday et al. 2009). Similar diurnal patterns have also been found in $\mathrm{CO}$ and $\mathrm{NO}_{x}$ concentrations in Lhasa, Tibet (Ran et al. 2014) and in BC in Kanpur, India (Tripathi et al. 2005) and in Kharagpur, India (Beegum et al. 2009).

Figure 10.6 shows the diurnal cycle of $\mathrm{BC}$ during four different seasons in Pantnagar, a semi-urban site at the northern edge of the IGP in Uttarakhand, India, as well as in the city centre of Kathmandu, Nepal (Putero et al. 2015; Joshi et al. 2016). Both places exhibit clear morning and 
Fig. 10.5 $\mathrm{CO}$ in the Kathmandu Valley in October (a) and January (b) 2005. Weekends are marked in orange and festival days in dark yellow shading (Adapted from Panday and Prinn 2009)

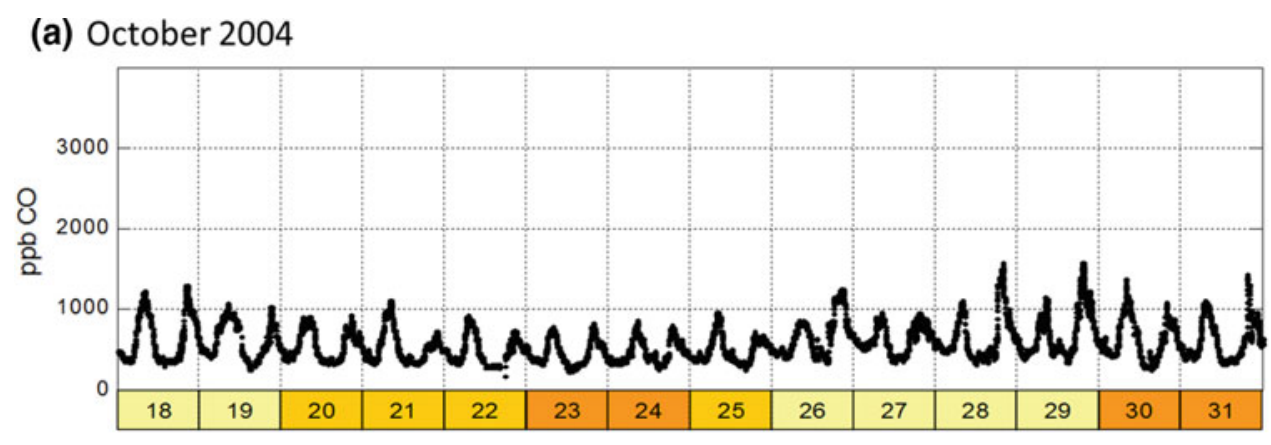

(b) January 2005

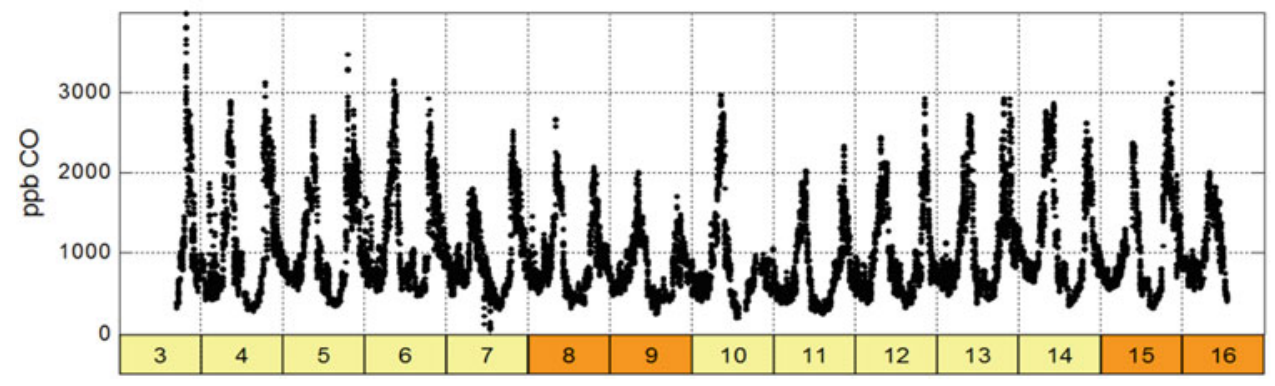

evening peaks in BC. Rupakheti et al. (2017) reported that the evening peak pollution (BC, $\mathrm{CO}$ ) concentration values In the Kathmandu Valley during the pre-monsoon season in the northern IGP was stronger than morning peak values. Similar patterns were also found in Kullu Valley in India (Sharma et al. 2013). The impact of pollution transport due to wind patterns in mountains and valleys was also observed in the diurnal cycle of the measured aerosol number concentration in the pre-monsoon season, with minimum in the afternoon in central Nepal (Shrestha et al. 2010).

The pollutant gas $\mathrm{O}_{3}$, in contrast, shows a very different pattern in many cities in and near the HKH (Bonasoni et al. 2012). Tropospheric $\mathrm{O}_{3}$ is produced by catalytic reactions of $\mathrm{NO}_{x}$ and volatile organic compounds (VOCs) under sunlight. In a number of urban areas, $\mathrm{O}_{3}$ was found to peak during the day and to sink to low levels at night as a result of dry deposition and titration by NO (Panday and Prinn 2009; Putero et al. 2014; Ran et al. 2014). The daytime peak was a result of replenishment from higher altitudes as well as photochemical production (Sillman 1999; Panday and Prinn 2009). Such patterns have been studied in Kathmandu (Panday 2006; Pudasainee et al. 2010; Putero et al. 2014), as well as in many other cities around the world (Imhoff et al. 1995). In Chandigarh, $\mathrm{O}_{3}$ was found to exceed India's national ambient air quality standard on all except one day in May 2012 (Sarkar et al. 2016). $\mathrm{O}_{3}$ diurnal patterns are different on mountain tops and at high elevations, as seen in Fig. 10.7. In Nagarkot, Nepal (Panday and Prinn 2009), as well as in Lhasa, Tibet (Ran et al. 2014) and Nainital, India (Kumar et al. 2010; Sarangi et al. 2013), however, $\mathrm{O}_{3}$ values stay high at night. That is because they have fewer local NO
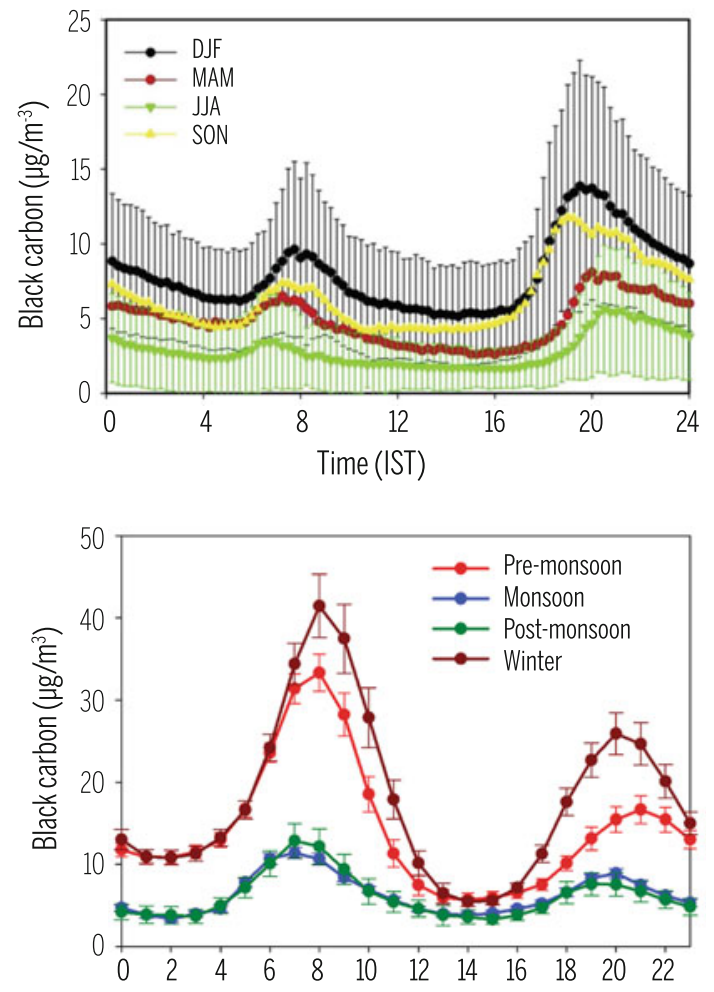

Fig. 10.6 Diurnal concentrations of $\mathrm{BC}$ during each season at Pantnagar, Uttarakhand, India (top; source Joshi et al. 2016) and at Paknajol, Kathmandu, Nepal (bottom; source Putero et al. 2015)

sources and receive $\mathrm{O}_{3}$ from the air far off the ground. High-altitude locations also receive $\mathrm{O}_{3}$ from stratospheric intrusions (Kumar et al. 2010; Cristofanelli et al. 2010). 


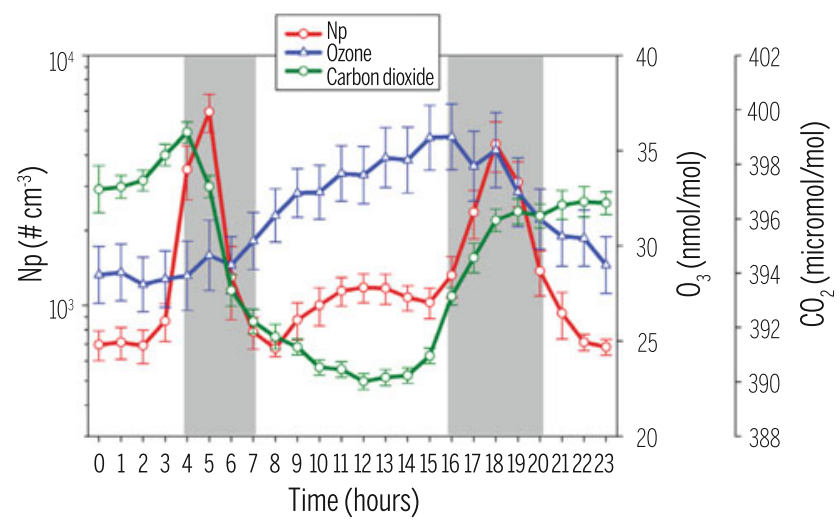

Fig. 10.7 Diurnal variations for aerosol particle number concentration $(\mathrm{Np})$, surface $\mathrm{O}_{3}$, and $\mathrm{CO}_{2}$ at Askole in northern Pakistan $(3,015 \mathrm{~m}$ asl) (Source Putero et al. 2014)

\subsubsection{Air Pollution Observations in High Mountain Areas}

While high-altitude sites in the HKH don't exhibit the same alarming levels of air pollution as lowland cities, they are by no means unaffected by the regional pollution. Despite the lack of significant local pollution sources of their own, high mountain areas of HKH receive substantial air pollution from the IGP, as seen in data from stations established along the Himalaya. On the south side of the Himalaya, comprehensive air pollution observations have been carried out at several high-altitude sites, such as Nepal Climate Observatory-Pyramid (NCO-P, 5,079 m asl) in Khumbu, Nepal (Bonasoni et al. 2010), Manora Peak (1,950 m asl) in North India (Ram et al. 2010), and Jomsom (2,900 $\mathrm{m}$ asl) in Nepal (Dhungel et al. 2016). To the north of the Himalaya, long-term observations of air pollution include the Qomolangma Station (QOMS) (South Tibetan Plateau, 4,276 m asl) (Cong et al. 2015), Lulang Station (Southeast Tibetan Plateau, 3,326 m asl) (Liu et al. 2013), and Nam Co (inland Tibetan Plateau, 4,730 m asl) (e.g., Wang et al. 2015; Kang et al. 2016; Yin et al. 2017). Parameters monitored at these sites include $\mathrm{BC}$ and $\mathrm{PM}$ mass concentrations, aerosol optical depth (AOD), $\mathrm{CO}$ and $\mathrm{O}_{3}$ mixing ratios, as well as aerosol and precipitation compositions (OC/elemental carbon [EC], ions, elements, and organic tracers).

Figure 10.8 shows the diurnal cycle of the aerosol number concentrations at Manora Peak (1,954 m asl) near Nainital, India, overlooking the IGP, and depicts an afternoon peak in pollution as aerosols from the IGP travel upslope to reach the site over the course of the day (Pant et al. 2006a). BC in Nainital follows the same diurnal pattern (Beegum et al. 2009). This is another common pattern at mountaintop sites except during the monsoon season (Dumka et al. 2015).

Seasonal patterns are different over the Tibetan Plateau: Illustrating the unusual elevation of coarse particle loading

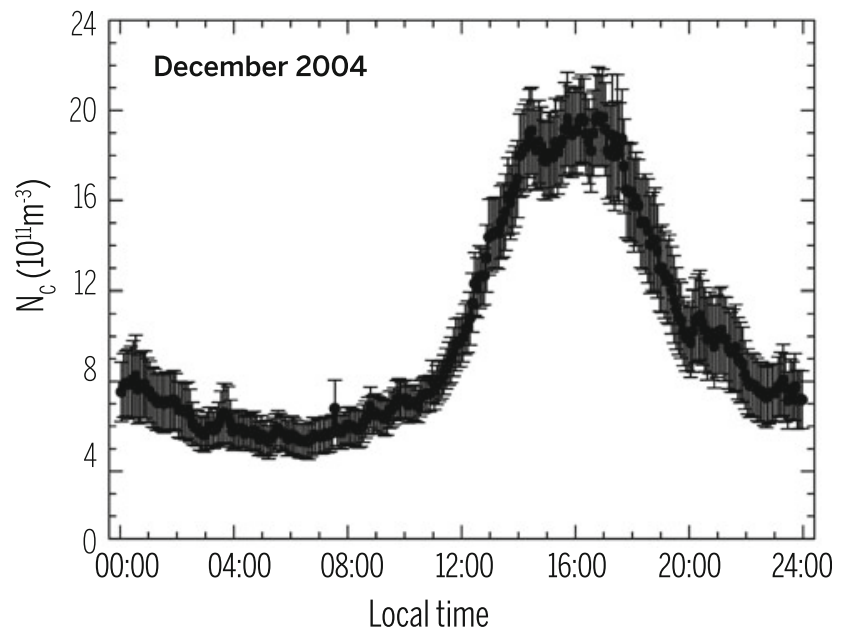

Fig. 10.8 Diurnal cycle of aerosol number concentrations at Manora Peak, Nainital, India (Source Pant et al. 2006a)

in high mountain areas, high aerosol optical depth (AOD)-an indication of significant presence of aerosols in an atmospheric column-was even observed during monsoon season at NCO-P (median $500 \mathrm{~nm}$ AOD was 0.08 compared to 0.04 over winter). Such enhancement is in stark contrast to AOD over Gandhinagar, an IGP site, where AOD during monsoon was at its minimum (Gobbi et al. 2010). As illustrated in Fig. 10.9, during the pre-monsoon season aerosols over the IGP pile up against the slopes of the Himalaya at elevated altitudes. Both in the Kathmandu Valley in the middle hills, and at NCO-P near Mount Everest, $\mathrm{O}_{3}$ concentrations peak during the pre-monsoon season and are the lowest during monsoon (Fig. 10.10).

Glacial ice cores and lake sediments from alpine areas of the HKH serve as archives for the long-term changes of air pollution (Xu et al. 2009). Kaspari et al. (2011) analysed a Mount Everest ice core spanning 1860-2000. They found that BC concentrations had increased approximately threefold by 1975-2000 compared to 1860-1975, indicating that $\mathrm{BC}$ from anthropogenic sources is being transported to high elevation regions of the Himalaya. The timing of the increase in $\mathrm{BC}$ is consistent with $\mathrm{BC}$ emission inventory data from South Asia and the Middle East. Furthermore, Cong et al. (2013) have reported the atmospheric BC history over the past 150 years using the lake sediments from Nam Co Lake (Tibetan Plateau). The results show that BC was relatively constant until 1900, then began to gradually increase, with a sharp rise beginning around 1960 with a 2.5 -fold increase compared to the background level. Clearly, the historical records in both ice core and lake sediment in the $\mathrm{HKH}$ reflect an evidently increasing impact of anthropogenic emissions in recent decades, especially from 1960s. Impacts of $\mathrm{BC}$ on melting of $\mathrm{HKH}$ snow and ice is discussed in Sect. 10.4.3. 

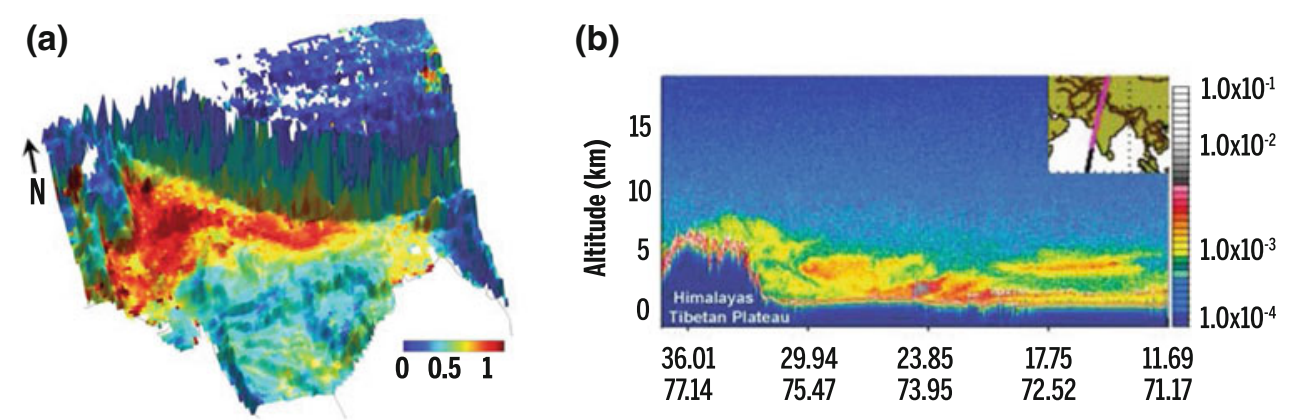

Fig. 10.9 Mean MODIS AOD during pre-monsoon season between 2003 and 2006, projected as a function of surface topography (left) and CALIPSO back-scatter profile from southern India to the Himalaya (right) (Source Gautam et al. 2009a)

Fig. 10.10 Mean cycle of ozone mixing ratios in Kathmandu (top) and at NCO-P (bottom) (Sources Putero et al. 2015; Bonasoni et al. 2010)
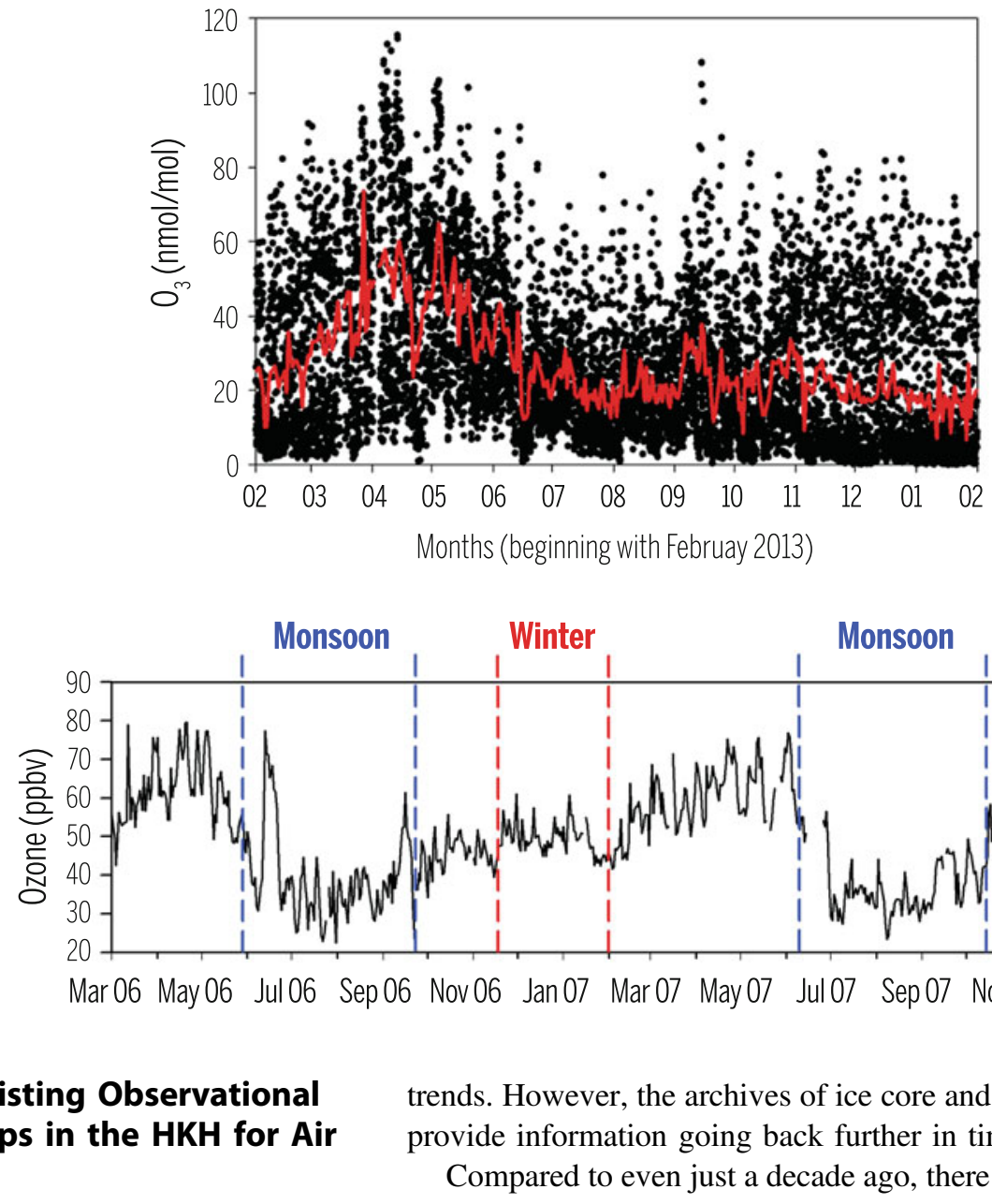

Observations to date have provided valuable information on air quality to assess the anthropogenic influences and evaluate the effects of radiative forcing on the cryosphere. Modellers have also used the observational data to validate model performance. Because most of the high-altitude sites were set up relatively recently (mostly less than 10 years ago), it is still difficult to determine clear long-term temporal trends. However, the archives of ice core and lake sediments provide information going back further in time.

Compared to even just a decade ago, there are many more atmospheric monitoring stations in the HKH and on the nearby plains, while several important field campaigns have increased knowledge about atmospheric processes. There are, however, still major gaps in the air quality networks: Many large cities in the IGP lack air quality monitoring stations, as do smaller urban centres and rural areas in the $\mathrm{HKH}$, as well as many of the fast-growing urban centres in confined valleys within the HKH. There is also an urgent 
need to compare and validate the monitoring data among different sites that currently have different instruments or protocols to generate a harmonized regional dataset. In addition to ground-based observation of air pollution, measurement of the vertical variation of such pollutants is also necessary to depict the whole picture.

Box 10.2 Chinese Academy of Sciences (CAS)coordinated monitoring network of atmospheric pollution and cryospheric changes (APCC) over the HKH and surroundings

Discrete and fragmented monitoring based on individual sites has been the source for reporting the status of atmospheric pollution and glacier changes over the $\mathrm{HKH}$ region, while a continuous and coordinated monitoring network remains deficient. The resulting gaps limit our understanding of the distribution and origin of atmospheric pollutants and their potential impacts on cryospheric changes over the HKH region.

In early 2013, a coordinated monitoring network was initiated to obtain continuous observational data and systematic samples from cross-sectional regions over the HKH-TP (see Fig. 10.11). The aim was to study the distribution, variation, and transport of atmospheric pollutants and to assess their impacts on cryospheric changes over the region. The network has been completed gradually, covering the large spatial scale of the HKH-TP.

To monitor atmospheric pollutants at each site, the Chinese Academy of Sciences (CAS) operates a total suspended particle $(\mathrm{TSP}<100 \mu \mathrm{m})$ auto sampler, loaded with a quartz fibre filter $(\Phi 90 \mathrm{~mm})$, running at a flow rate of $100 \mathrm{~L} / \mathrm{min}$ (LPM) for 24-48 h every six days. During pre-monsoon (from March to May), when the IGP haze reaches higher altitudes, sampling frequency is increased to every two to three days. After transport to the laboratory, filters are punched into small pieces for analysis of multiple parameters including elemental carbon (EC)/OC, soluble ions, elements, and other organic matters. Real time observation (e.g., $\mathrm{BC}, \mathrm{PM}, \mathrm{O}_{3}$ ) has been operated at some superstations (e.g., QOMS, Nam Co, Southeast Tibet). Note that the terms EC and BC both refer to the most refractory and light-absorbing component of carbonaceous particles emitted from combustion. The measurement of elemental carbon (EC) is usually through thermal evolution and $\mathrm{BC}$ is determined by optical light-absorption.

Benchmark glaciers have been chosen for pointing observation and periodic sampling to investigate preserved atmospheric pollutants, with special focus on light-absorbing impurities (e.g., BC, OC, and mineral dust) and other relevant snow chemistry. Glacier mass balance and meteorological data are recorded for the assessment of the impacts of light-absorbing impurities on glacier melt. The sites are shown in Fig. 10.11.

\section{Box 10.3 Observatories initiated by ICIMOD in Bhutan and Nepal}

Working closely with governments and academic institutions in Bhutan and Nepal, ICIMOD has contributed to establishing a network of observatories across data-sparse regions of the two countries. At the time of writing, this network consisted of air quality stations in Thimphu, Pasakha, and Phuentsholing in Bhutan, and in Lumbini, Chitwan, Ratnapark (central Kathmandu), Pulchowk, and Dhulikhel in Nepal. In addition, a BC observatory was established on Yala Glacier in Nepal In 2016, and its twin was installed at Chele La in Bhutan in 2018. Two comprehensive ridgetop climate and environmental observatories were in preparation in Ichhyakamana, Nepal, and Gedu, Bhutan that, together with Manora Peak in India, form a network of three ridgetop observatories overlooking the IGP.

\subsection{Worsening Haze and Winter Fog in and Near the HKH}

Before the 1950s, Europe and North America were the largest sources of air pollutant emissions, and they had the haziest skies with significant adverse health impacts (Bell and Davis 2001; Helfland et al. 2001). Since then, the tropics and eastern Asia have dominated (Ramanathan and Carmichael 2008). Two regions in close proximity to the HKH experience particularly heavy haze: eastern China and the IGP (Ramanathan and Carmichael 2008). The IGP stretches out south and west of the Himalaya and is a big source of pollution reaching the high mountains. It is an extensive stretch of highly fertile agricultural plains covering an area of $700,000 \mathrm{~km}^{2}$. It is also among the world's most densely populated regions, inhabited by over 900 million people, which is $\sim 1 / 7$ th of the world's population. Over the past several decades, the IGP has experienced increasing aerosol haze and winter fog. Data going back to 1982 show haze increasing across much of northern India (Sarkar et al. 2006). This section discusses the worsening haze and winter fog in the region.

In recent years, many studies have analysed regional haze in the $\mathrm{HKH}$, using remote sensing data as described below. More attention is also being paid to the recent winter fog occurrences in the region. While a lot of the necessary 


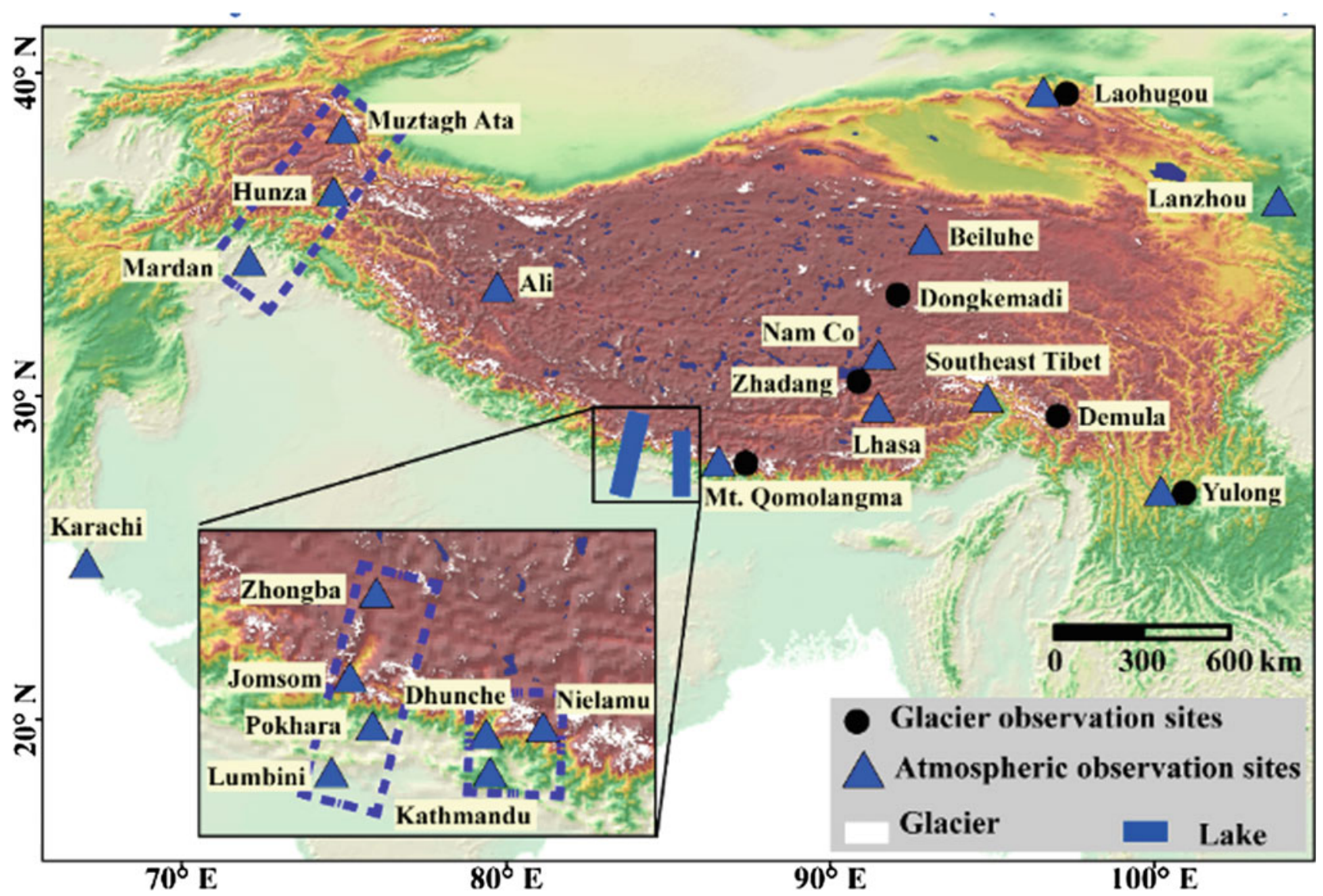

Fig. 10.11 The spatial distribution of observation sites in the APCC network

measurement data are still lacking, the existing data provide some important observations:

- As air pollution worsens in many cities in the HKH and across the IGP (WHO 2016), increased regional haze and winter fog episodes, as well as increased $\mathrm{O}_{3}$, have been observed in the HKH.

- Many adverse impacts (e.g., visibility, temperature, and health) are associated with regional haze and winter fog.

\subsubsection{Regional Haze Pollution in the HKH}

During the past decade and a half, the aerosol haze that covers much of the IGP during the dry season has been studied extensively. Measurements of column-integrated aerosol loading retrieved from satellite measurements show the annual build-up of haze over the IGP (Di Girolamo et al. 2004; Jethva et al. 2005; Gautam et al. 2007). Figure 10.12 shows satellite imagery from Terra MODIS, taken on 1 December 2010, with the pollution haze extending across parts of Pakistan, India, Nepal, Bhutan, and Bangladesh.
The build-up of the haze, which is sometimes referred to as atmospheric brown cloud (ABC), starts in the post-monsoon season when, after the rice harvest, paddy residue is burned across large parts of the region. It then intensifies in December and January (Dey and Di Girolamo 2010). Winter temperatures are sufficiently cold within and surrounding the HKH to allow frequent temperature inversion episodes - atmospheric conditions in which a layer of warm air traps a layer of cool air below it close to the ground. This condition suppresses the buoyant vertical transport of pollutants that would otherwise have dispersed over a wider area. Temperature inversion episodes result in the trapping of pollutants within the shallow boundary layer with low wind speeds (Tare et al. 2006). As a result, an optically thick haze layer builds up (as often seen in satellite imagery), with pollution dominated by anthropogenic emissions from vehicles, industries, and open biomass burning, as well as biofuel burning for residential heating and cooking. Elevated concentrations of carbonaceous aerosols (BC and $\mathrm{OC}$ ), sulphate, and nitrate have been reported over several locations in the IGP (Ganguly et al. 2006). The suppressed vertical mixing in winter leads to plumes of haze getting blown far out over the Bay of 


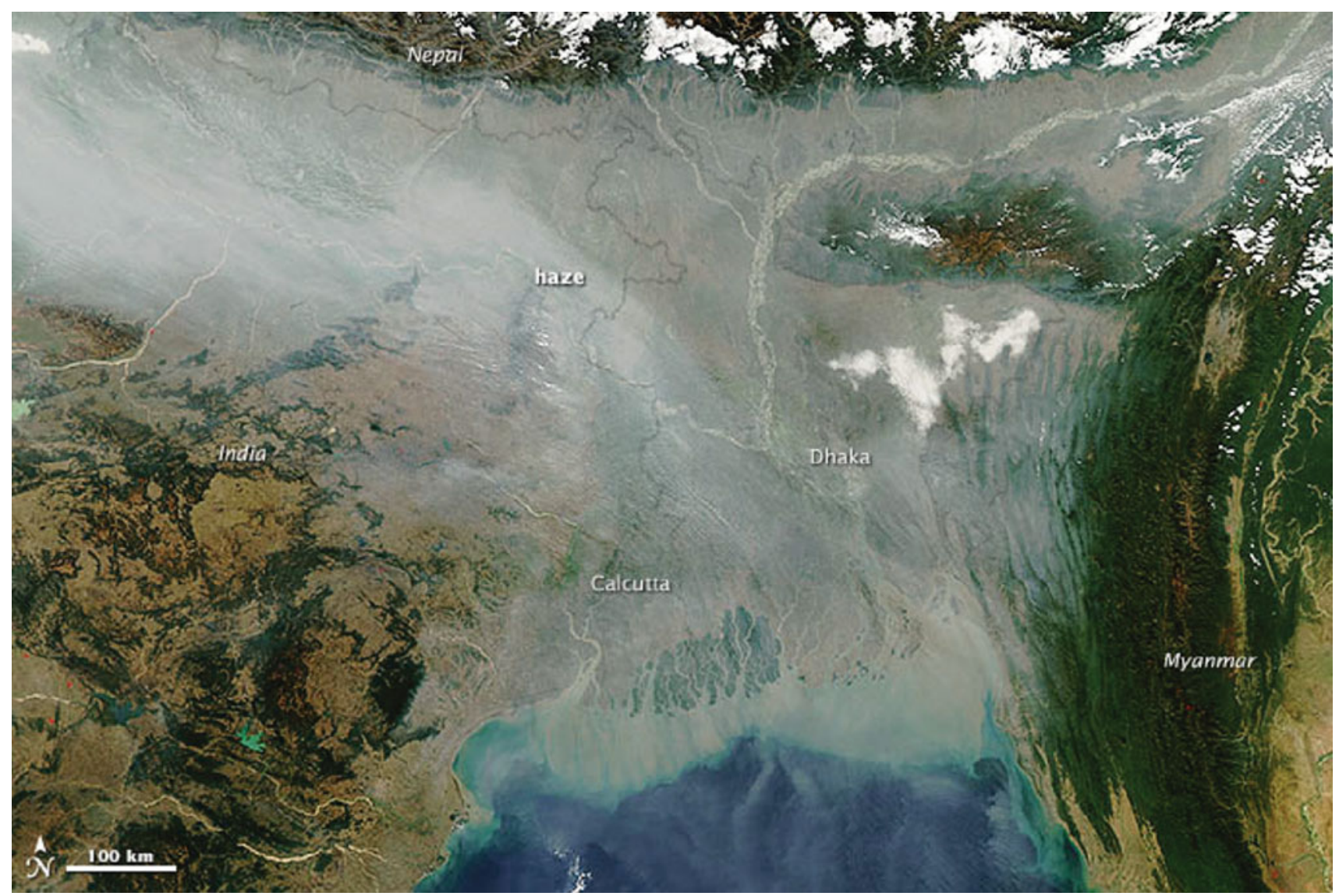

Fig. 10.12 Winter haze blanketing the entire IGP, including regions of Pakistan, India, Nepal, and Bangladesh, south of the Himalaya (right) (Source NASA MODIS imagery)

Bengal by low-level westerly winds (Dey and Di Girolamo 2010).

The haze becomes denser in the pre-monsoon months, when there are additional contributions from wind-blown desert dust (Dey and Di Girolamo 2010), most of which originates in the Thar Desert (Gautam et al. 2009b), as well as from extensive agricultural and forest fires. In Delhi, both the total aerosol loading and the proportion due to dust have been found to increase over the course of the pre-monsoon from March to June (Pandithurai et al. 2008). Throughout the dry season, biomass-based cooking fires and increasing amounts of emissions from transport and industries also contribute to the haze. Vertical profile measurements during the pre-monsoon have found high levels of $\mathrm{BC}$ up to $4.5 \mathrm{~km}$ altitude; layers of enhanced $\mathrm{BC}$ have been observed as high as $8 \mathrm{~km}$ above sea level (Babu et al. 2011a). Even during the rainy season, significant aerosol build-ups happen during monsoon breaks (Dey and Di Girolamo 2010); however, decreases of $55-70 \%$ in season-average aerosol concentrations have been found in India during the monsoon compared to the pre-monsoon (Hyvärinen et al. 2011a). While at a mountain location the combination of cloud and fog droplet activation and rain scavenging was found to remove particles across all sizes; at an urban site near Delhi, where only rain scavenging took place, the finest accumulation mode particles were not removed (Hyvärinen et al. 2011b).

\subsubsection{State of Current Knowledge About Haze in the HKH}

The Indian Ocean Experiment (INDOEX) field campaign in 1999 discovered the broad extent of regional haze over the Indian Ocean, and in subsequent years there was a realization that the haze was also very widespread over the IGP (UNEP 2002). This realization was further cemented with the advent of NASA's satellite sensors, MODIS and MISR (Mehta 2015), which provided daily views from space (Di Girolamo et al. 2004). In the almost two decades since then, hundreds of papers have been published on various aspects of the haze over India, and a smaller number on the haze over Bangladesh, Nepal and Pakistan. As a result, we have a fairly good understanding of its temporal variations and horizontal extent, chemical composition, and physical and 
Fig. 10.13 Fog frequency from 82 stations over India and Pakistan from 1976 to 2010 (Syed et al. 2012). The regimes are defined using a mean fog fraction during the time period. Regime-1: $6.1 \%$, Regime- 2 : $10.1 \%$, Regime-3: $19.5 \%$

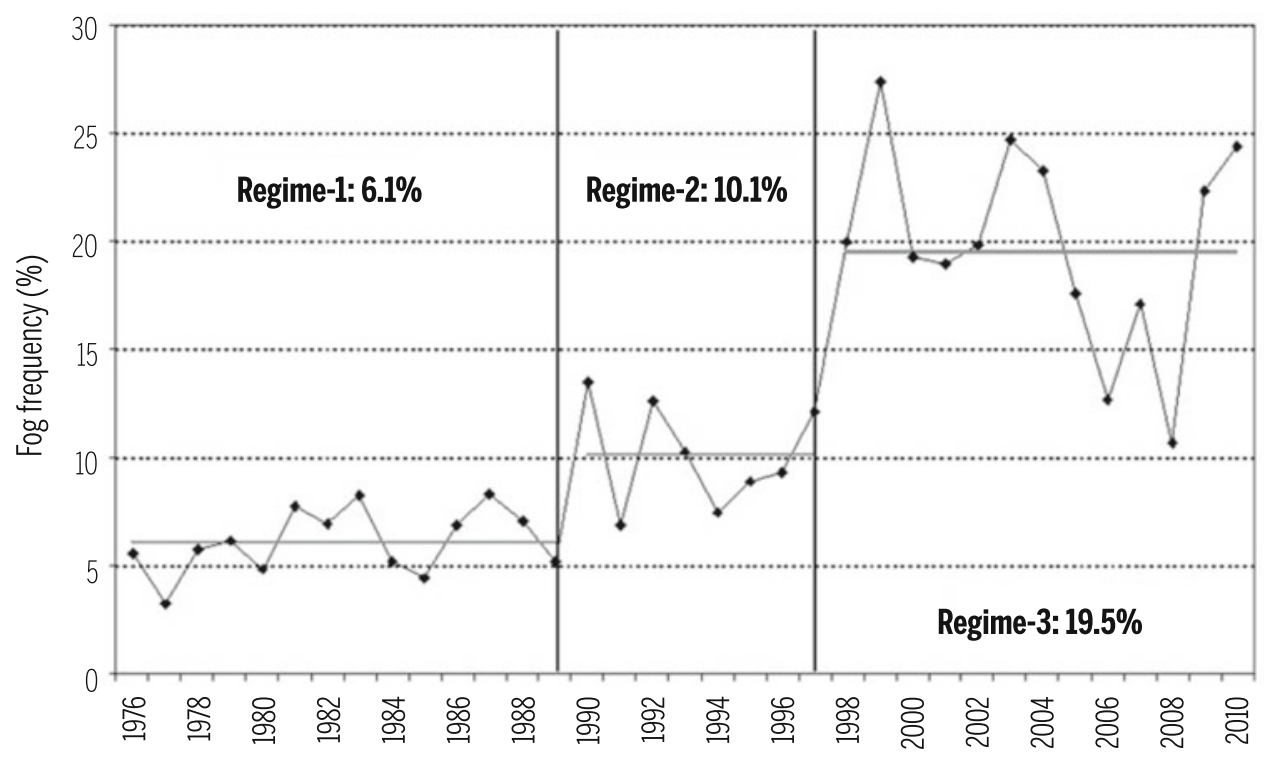

optical properties, as well as its radiative impacts. We have some hints, but not yet a good understanding of its impacts on gas-phase photochemistry and its role in changing monsoon precipitation patterns. There is still very little understanding among the general population and policy makers about the causes and costs of the haze.

While the increase in aerosol haze across the IGP has received a lot of attention, there have been far fewer studies about the increase in $\mathrm{O}_{3}$, which already exceeds air quality standards during the spring in many places in the IGP (Lal et al. 2000; Mittal et al. 2007; Ojha et al. 2012; Sinha et al. 2014). There are only a few papers from a handful of higher-altitude locations including Kullu (1,154 m) (Sharma et al. 2013), Nainital (1,954 m) (Kumar et al. 2010), and NCO-P (5,079 m) (Cristofanelli et al. 2010), as well as several places along the northern side of Mount Everest (Semple and Moore 2008) and Nam Co, Tibetan Plateau (Yin et al. 2017). They all found relatively high levels of $\mathrm{O}_{3}$ in the spring, with higher altitudes also affected occasionally by stratospheric intrusions.

\subsubsection{Increasing Winter Fog over the IGP}

Often coinciding with the winter haze is the widespread and persistent occurrence of severe winter fog episodes along the IGP. Note that while haze is commonly defined as an atmospheric condition with reduced visibility, but with visibility remaining above $1 \mathrm{~km}$, fog is defined to have visibility less than $1 \mathrm{~km}$. The majority of the fog episodes last from mid-December into January and result in poor visibility conditions that cause major disruptions to the air and rail transportation sectors, as well as a significant number of deaths in vehicular accidents (Hameed et al. 2000; Ghude et al. 2017). The fraction of days with fog has increased threefold in a 35-year period across the IGP (Ghude et al. 2017; Jenamani 2007; Syed et al. 2012), and tenfold in five decades in Delhi (Mohan and Payra 2014). Figure 10.13 shows that increase has not been linear, but with distinct "regime changes" (Syed et al. 2012). Within each regime, and especially within the third regime, there have been large interannual variations, with a low in 2007-08 of just above $10 \%$ and highs exceeding $27 \%$.

Fog conditions usually also vary within each day: At Delhi airport, fog is denser at night than during the day (Jenamani and Tyagi 2011); it appears to be the case across the IGP that visibility improves over the course of the afternoon. MODIS images also show distinct day-to-day variations, with growing, shrinking, and lateral shifting of the IGP fog deck from one day to the next, as shown in Fig. 10.14.

To date there is still a lack of scientific consensus to explain why persistent winter fog has increased across the IGP. The key ingredients needed for fog to form anywhere in the world are well known: Sufficient moisture, airborne surfaces that moisture can condense onto (cloud condensation nuclei, or $\mathrm{CCN}$ ), and a drop in temperature that allows water vapour to condense (Gultepe et al. 2007). Most of the fog over northern India, and presumably the rest of the IGP, is radiation fog (Syed et al. 2012). This occurs when moist near-surface air cools under clear skies in stagnant, stable air. The available literature points to the role played by synoptic-scale processes in creating conditions that allow the formation of large-scale radiation fog across the IGP within a short time period. The fog not only forms simultaneously over large regions, but inter-annual variations in fog are also coupled across wide areas (Syed et al. 2012).

For a regional-scale fog episode to occur, a high dew point temperature is needed on a regional scale (Sawaisarje 

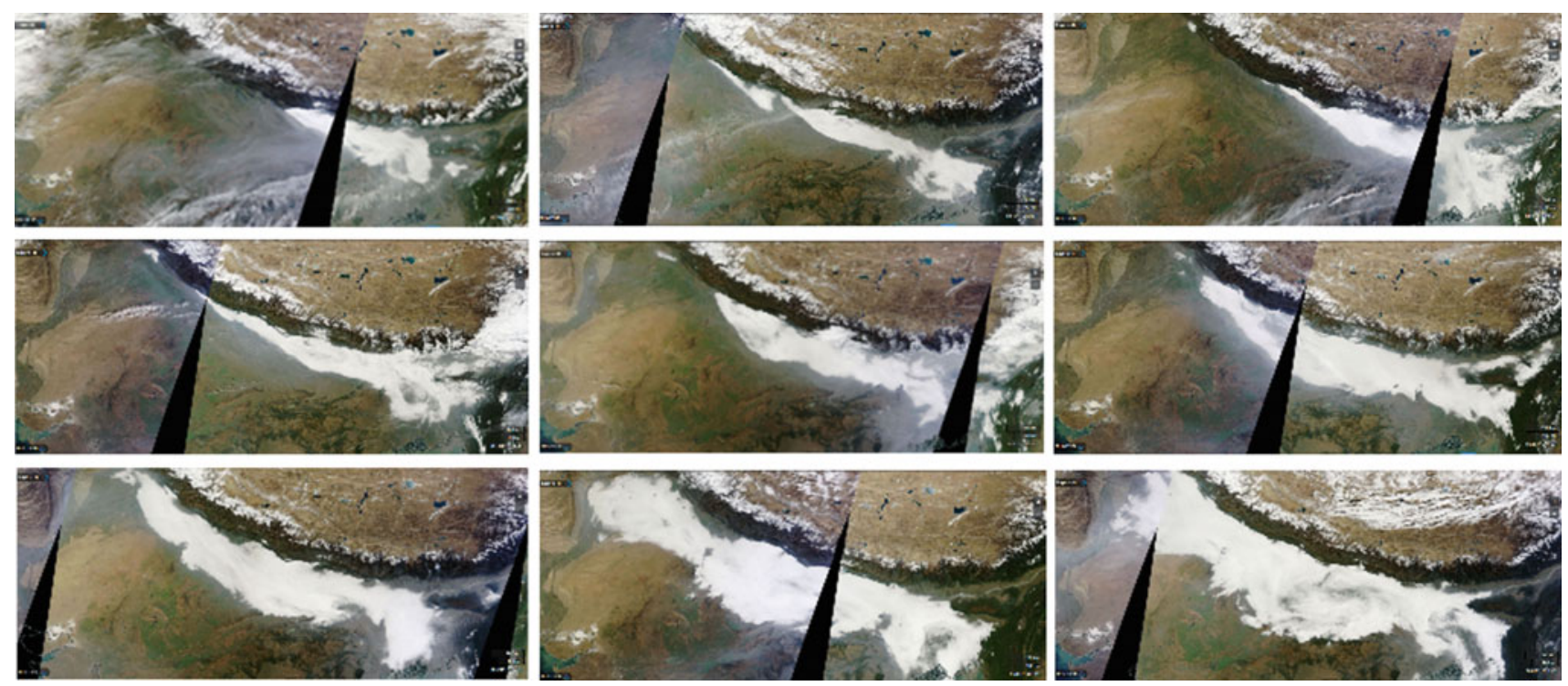

Fig. 10.14 Terra MODIS images of the IGP on 17, 18, 19 (top row), 20, 21, 22 (middle row), and 23, 24, 25 (bottom row) December 2012

et al. 2014) — in other words, a large amount of water vapour needs to be present over a broad region. During the winter season, much of the IGP is subjected to a regional characteristic weather phenomenon known as western disturbances, a series of alternate low- and high-pressure systems. First, a low-pressure system results in enhanced moisture content in the boundary layer; this is subsequently replaced by a high-pressure system with low winds, radiative cooling of the ground, and temperature inversions (Pasricha et al. 2003). The resulting anomalous cold conditions are generally referred to as sheet lahar (cold waves) in many parts of the IGP. In addition to western disturbances, it is also possible that the moisture needed for fog in some parts of the IGP could originate in the agricultural fields of Uttar Pradesh, Haryana, and Punjab, where large areas are irrigated in winter (Jenamani 2007).

Moisture and cold temperatures alone are insufficient to form fog if there are no particle surfaces for the fog droplets to condense onto. Los Angeles has seen a decrease in fog as it cleaned up its air pollution problem and as its ambient aerosol concentrations dropped (LaDochy 2013). Cities in many other parts of the world have seen the reverse: They have denser and more persistent fog due to increases in air pollution and thus in the availability of condensation nuclei, resulting in larger numbers of smaller drops with higher optical depth (Syed et al. 2012). Central and eastern China have seen a doubling of fog frequency over the past three decades, as aerosol concentrations have increased (Niu et al. 2010).

Across the IGP the increase in fog appears to be associated with the increasing trends of anthropogenic air pollution (Habib et al. 2006; Sarkar et al. 2006). In Delhi, the onset of fog has been found to match with times of high aerosol number concentration (Mohan and Payra 2014), as well as with high concentrations of CO (Mohan and Payra 2009), a tracer of incomplete combustion. A field campaign at Delhi airport in winter 2015-16 found that fog occurred in a highly polluted environment dominated by combustion and vehicular emissions (Ghude et al. 2017). During winter, aerosols over the IGP are dominated by emissions from biomass burning and agricultural waste burning (Gustafsson et al. 2009; Ram et al. 2012). In Kanpur, a large fraction of measured organic aerosols were found to be from biomass burning. The composition of organic aerosols was different during foggy events, with higher oxygen-to-carbon ratios during foggy events (Chakraborty et al. 2015). Burning of post-harvest paddy residue produces carcinogenic benzenoids that can partition into aerosol phase and oxidize into hydrophilic phenolics and cresols that have increased water vapour uptake and contribute to fog formation (Sarkar et al. 2013).

Analysis of filter samples collected in Hissar and Allahabad, India, found that secondary inorganic aerosol constituents (ammonia, nitrate, sulphate) increased by a factor of two to three during foggy or hazy days compared to clear days (Ram et al. 2012); unfortunately, the study did not distinguish between foggy and hazy days. Acidic gases and ammonia are taken up by fog, as found in a study in Lahore in winter 2005-06 (Biswas et al. 2008). Fog water in Delhi has been found to have a higher concentration of ions than rainwater (Ali et al. 2004).

\subsubsection{Causes and Impacts of Haze and Winter Fog}

The persistent and dense winter haze and fog reduce the solar insolation available to warm the land surface, which can act to further lower surface temperatures, in turn 
providing a positive feedback to the persistence of foggy and cold conditions (Gautam 2014). Trends in poor visibility days due to haze and fog during the winter season have been significantly increasing over the IGP, reaching $90 \%$ of winter days (De and Dandekar 2001), with serious impacts on air, rail, road, and water-based transportation systems, as well as on agriculture and tourism.

The IGP haze has been found to have increased in the winter and post-monsoon season over the time period from 2001 to 2013 (Mehta 2015), and along with it, global short-wave radiation has been found to have decreased in many cities in India since 1990 (Porch et al. 2007). In China, the increase in haze has been associated with the simultaneous decrease in both cloud cover and solar radiation at the surface (Qian et al. 2006, 2007).

The aerosol haze over the IGP has significant impacts on local and regional climate. It reduces the solar radiation reaching the surface and warms the atmosphere due to absorption of sunlight by BC (Ramanathan and Ramana 2005; Tripathi et al. 2005; Ramanathan and Carmichael 2008). Fifty to $70 \%$ of the warming by absorbing aerosols over the IGP takes place above clouds (Satheesh et al. 2008). Based on the observational data, the solar-absorption efficiency has positive correlation with the ratio of absorbing BC to scattering sulphate aerosols (Ramana et al. 2010). While BC from biomass-burning cookstoves was found to directly contribute to regional climate forcing over the IGP (Praveen et al. 2012), fossil fuel-dominated BC plumes have been found to be twice as efficient in their effect on net warming of the atmosphere compared to biomassburning-dominated plumes (Ramana et al. 2010). A study using multiple sun photometers around Kanpur, India, found that emissions from Kanpur city contributed only 10-15\% of the aerosol optical depth observed in Kanpur (Giles et al. 2011), implying a regional origin of the observed haze. Although current state-of-the-art chemical transport models are able to capture seasonality of the pollution haze over low-lying plains, they are still limited in their ability to capture observed seasonality over valleys and mountains (Adhikary et al. 2007). Current mesoscale numerical weather models are not able to adequately predict persistent winter fog over IGP and the foothills area. Thus, more in situ observations are needed in the region to understand the phenomenon and to constrain numerical weather and chemistry models.

Although there seems to be a consensus in the scientific community that winter haze and fog are a strongly coupled system, there is a lack of in-depth and quantitative understanding about the impact of air pollution on fog variability and long-term trends. At a fundamental level, aerosol particles (especially hydrophilic aerosols) act as efficient cloud condensation nuclei, favouring the formation of fog.
However, given the complex aerosol composition over the IGP from a wide range of emission sources, the microphysical, chemical, and radiative interactions between aerosols and fog or low-level stratus clouds requires more detailed studies. In this respect, recent ongoing field studies have focused on the winter fog characterization in the IGP led by the Indian Institute of Tropical Meteorology with detailed characterization of fog in Delhi, the Winter Fog Experiment (Ghude et al. 2017), as well as multi-institutional efforts led by ICIMOD at several locations across the IGP. In addition, there are other factors which may be linked to the long-term variability/trends in fog occurrence, such as changes in land use/land cover patterns, increase in the density of irrigation canals, and regional meteorological changes over the IGP.

\subsection{Emission Sources and Transport Processes in the HKH}

Major emission sources of air pollutants within and upwind of the HKH include cooking and heating fires, open burning of agricultural residue and garbage, forest fires, motor vehicles, and thermal power generation (including with diesel generator sets), as well as brick kilns and other industries. While most of the region's inhabitants still live in homes severely polluted by emissions from traditional biomass cookstoves, outdoor air quality has deteriorated in many urban and rural areas, on mountains, in valleys, and in the IGP. Source regions affecting the HKH include urban and rural places within the HKH and the nearby IGP; smaller amounts of pollution arrive from further away.

To address air pollution in the $\mathrm{HKH}$, it is essential to understand not only which harmful pollutants exist at what concentrations, but also where they come from and how they reach the region. An increasing number of national and regional emissions inventories have been set up that help us assess the magnitude and the source of air pollutant emissions in the HKH countries. In addition, studies using transport and receptor models have provided estimates of where these emissions come from. While more research is essential, they provide us with the basis for two general observations:

- Certain sources - such as cooking and heating, agricultural residue burning, forest fires, brick kilns and diesel pumps - are particularly important for the HKH and the IGP.

- We find a large seasonality in emissions for some of these sources. Agricultural residue burning and brick kilns are especially important seasonal emissions sources, with both taking place in the dry season. 


\subsubsection{The Major Air Pollutant Emissions Source Sectors in the HKH}

Different pollutants may be emitted by the same source, while many pollutants are chemically transformed in the atmosphere, forming secondary pollutants, such as secondary aerosols (both organic and inorganic, such as nitrates and sulphates) and tropospheric $\mathrm{O}_{3}$ (Fig. 10.15). Emission sources also vary in different countries, as well as the magnitude, depending on factors such as the source of power, industrial activities, and domestic heating/cooking needs. Part of the reason for this is the increase in population density in the $\mathrm{HKH}$, particularly in the lower altitude regions. We illustrate the magnitude and the contribution of the five emission sources (power, industry, transport, domestic, and other) for the five primary pollutants $\left(\mathrm{CO}, \mathrm{NO}_{x}, \mathrm{SO}_{2}, \mathrm{BC}\right.$, and $\left.\mathrm{PM}_{2.5}\right)$ estimated in Regional Emissions inventory in ASia (REAS) v2 for each of the HKH countries in Fig. 10.16.

\subsubsection{Cooking and Heating}

Domestic cooking and heating, mainly using biofuels (e.g., wood and dung) is the largest source of CO and PM in the HKH (Venkataraman et al. 2005). Cookstove emissions are also the largest source of BC in South Asia (Gustafsson et al. 2009). This is due to low access to clean fuels and high usage of solid biofuel such as dung, charcoal, and fuelwood in the region, as illustrated in Table 6.1. There are few studies measuring emissions in the field (e.g., Roden et al. 2009; Stockwell et al. 2016) and some studies have attempted to estimate the contributions of indoor air pollution on outdoor air pollution in India (Rehman et al. 2011) and China (Liu et al. 2016). However, more research is essential to not only understand the magnitude of various emissions coming from the residential sector, but also assess the fraction remaining indoors versus the amount leaving the homes to contribute to ambient air pollution.

\subsubsection{Agricultural Residue Burning}

Agricultural residue burning takes place in two distinct forms, as illustrated in Fig. 10.17. The first is the burning of small piles of collected agricultural residue. This may take place on the field, or near the homes, and the purpose might be to get rid of waste material or to generate smoke to chase away mosquitoes and flies from farm animals. Such fires are lit millions of times a day across the IGP and the hilly and mountainous parts of the $\mathrm{HKH}$, in both rural and peri-urban areas. The second is the open-field burning of rice and wheat stubbles in the IGP after mechanical harvest using combine harvesters. The purpose is to clear the fields quickly for the planting of the next crop.

Agricultural residue burning emits $\mathrm{OC}$ and $\mathrm{BC}$ aerosols, as well as a variety of gaseous air pollutants, including $\mathrm{CO}$,
Fig. 10.15 Multiple pollutants and their multiple adverse effects (Cao et al. 2013 adapted by Clean Air Asia 2016)

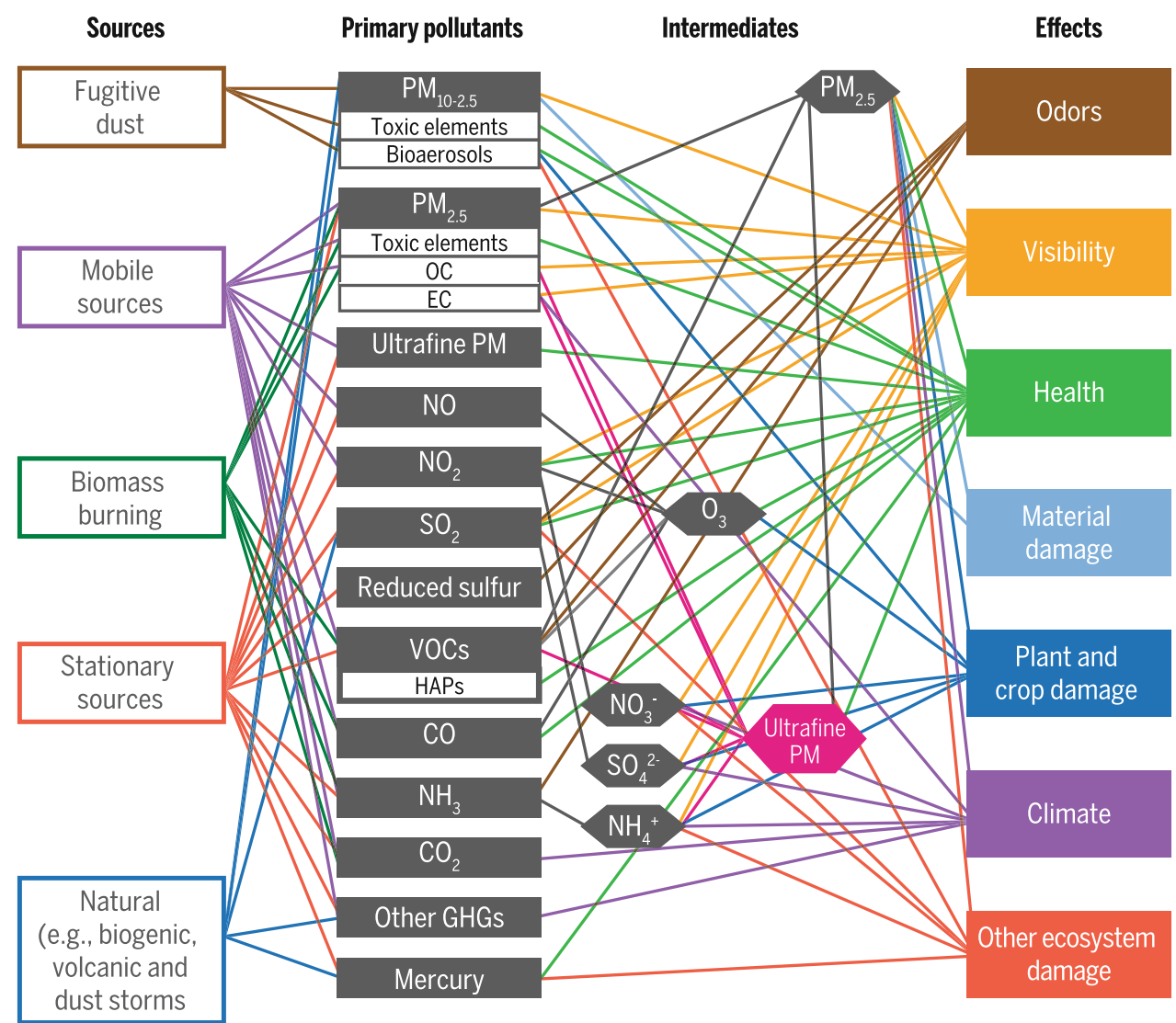


Fig. 10.16 Magnitudes and contribution of five sources (power, industry, transport, domestic, and other) for five pollutants $\left(\mathrm{CO}, \mathrm{NO}_{x}, \mathrm{SO}_{2}, \mathrm{PM}_{2.5}\right.$, and $\mathrm{BC}$ ) for each of the $\mathrm{HKH}$ countries estimated in the REAS v2 emissions inventory (Created based on data from Kurokawa et al. 2013)

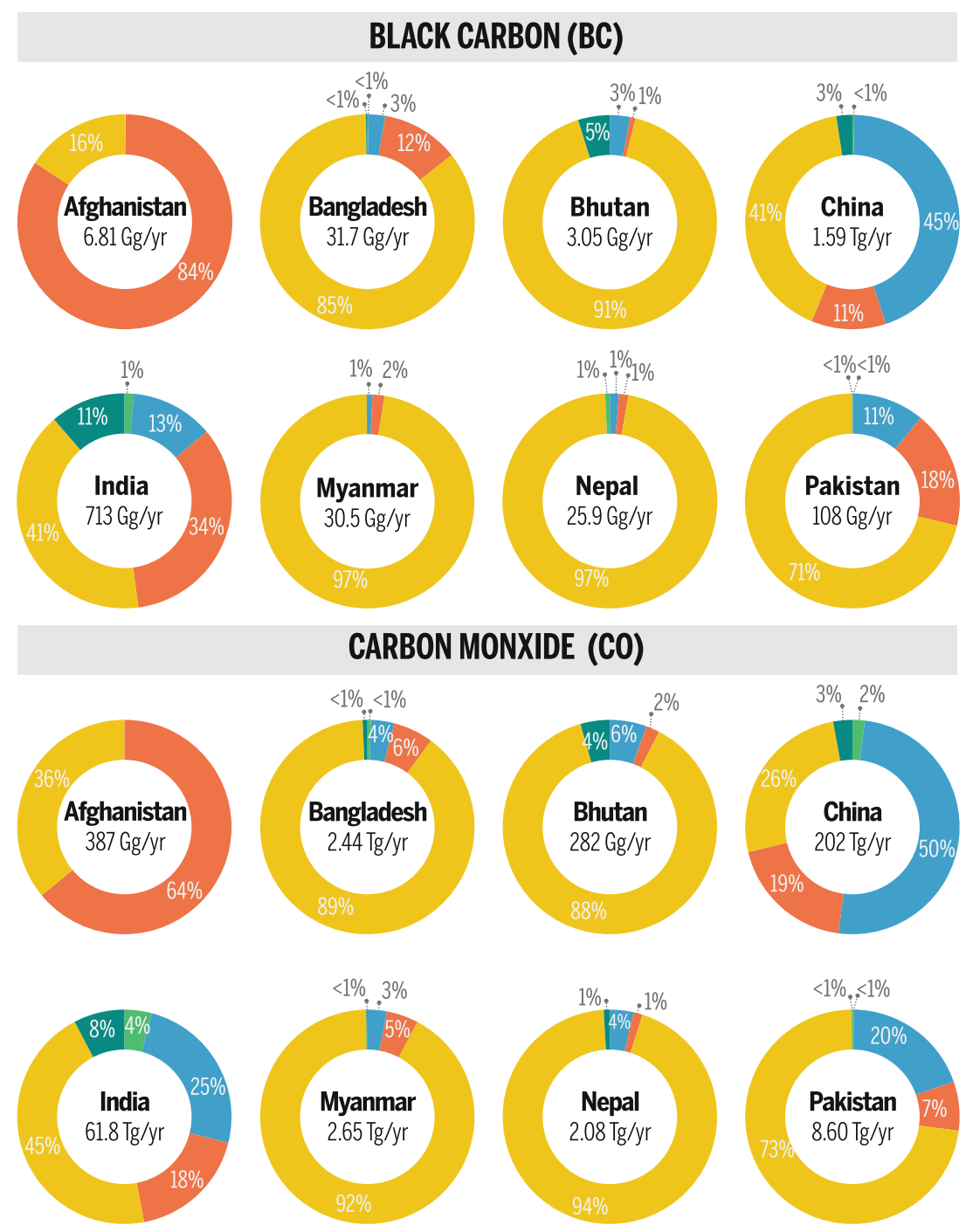

\section{NITROGEN OXIDES (NO $\left.{ }_{x}\right)$}
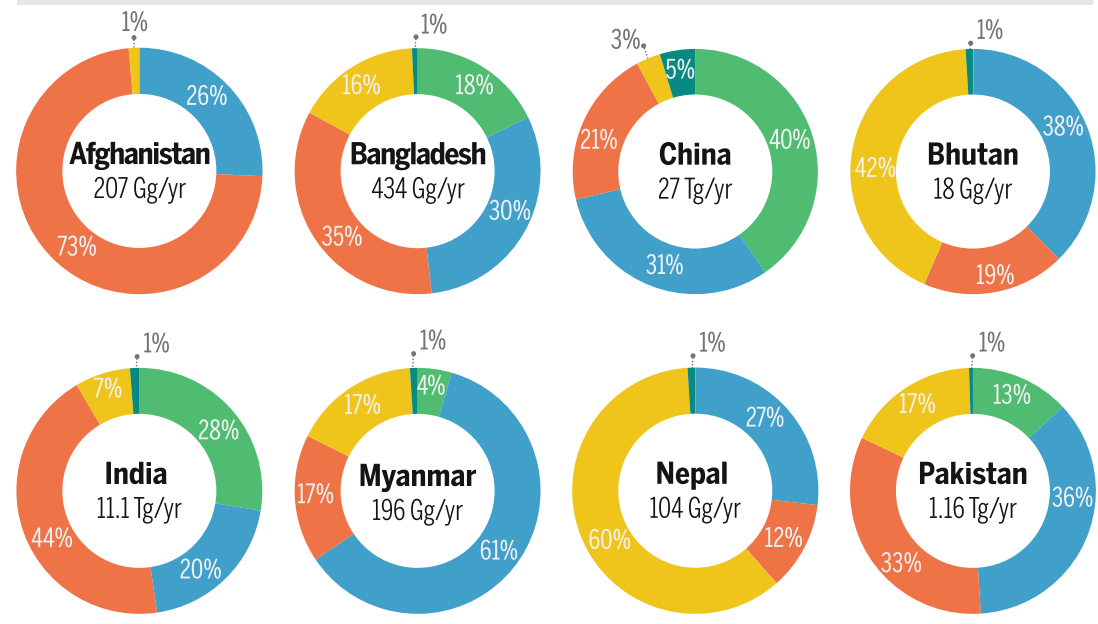
Fig. 10.16 (continued)

\section{PARTICULATE MATTER $\left(\mathrm{PM}_{2.5}\right)$}
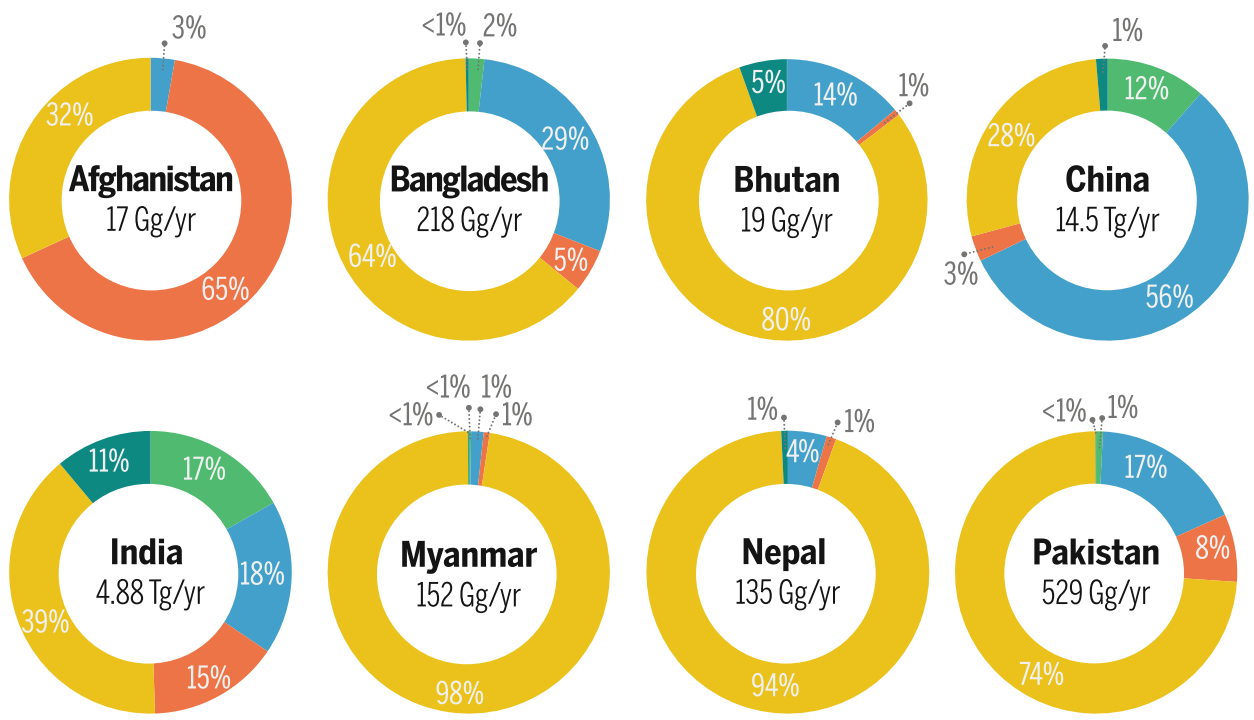

\section{SULFUR DIOXIDE $\left(\mathrm{SO}_{2}\right)$}
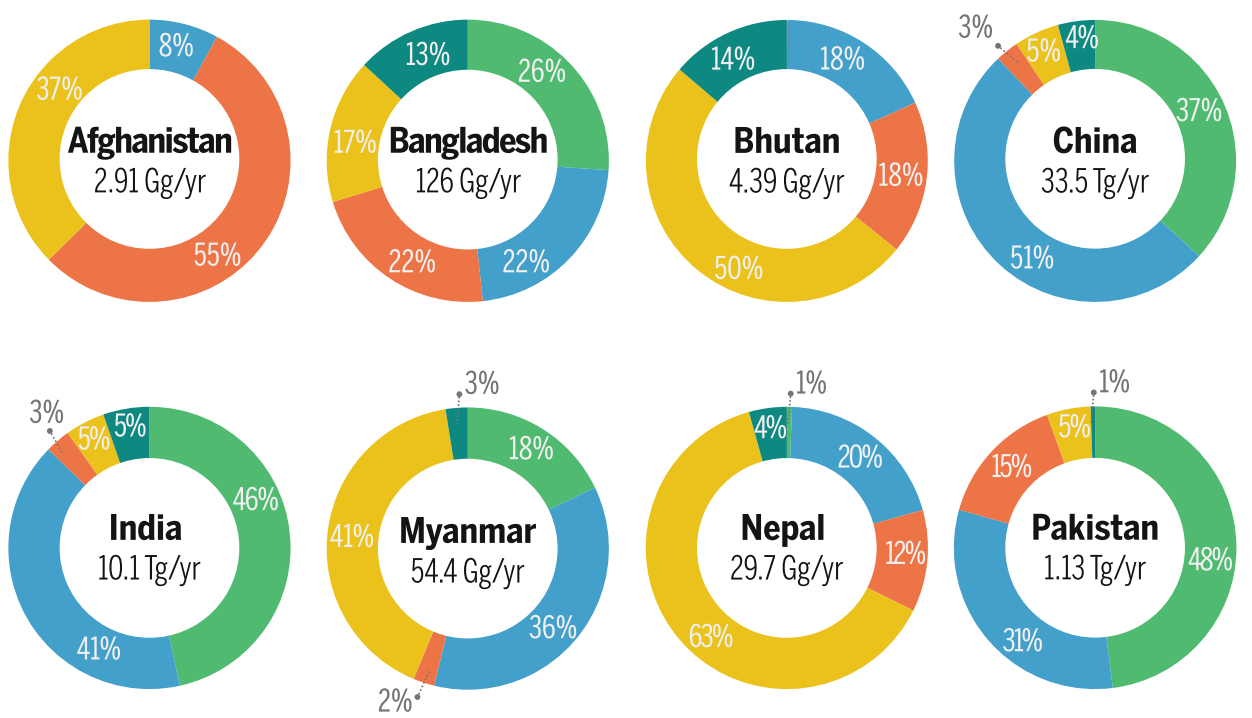

Power

Industry

Transport

Domestic

Other

$\mathrm{CO}_{2}, \mathrm{CH}_{4}, \mathrm{NO}_{x}$, and non-methane VOCs (NMVOCs) (Andreae and Merlet 2001; Guyon et al. 2005; Sharma et al. 2010). Jain et al. (2014) estimated that $21.32 \mathrm{Mt} / \mathrm{year}$ of residue is burned in Punjab alone, leading to $1961 \mathrm{Gg} / \mathrm{year}$ of $\mathrm{CO}, 53 \mathrm{Gg} /$ year of $\mathrm{NO}_{x}, 335 \mathrm{Gg} /$ year of NMVOCs, 83 $\mathrm{Gg} /$ year of $\mathrm{PM}_{2.5}$, and $15 \mathrm{Gg} /$ year of BC in the year 200809. The Nepal Ambient Monitoring and Source Testing Experiment (NAMaSTE) campaign (see Box 10.4) also found that agricultural residue burning is a large contributor to brown carbon (BrC) and $\mathrm{SO}_{2}$ (Stockwell et al. 2016). These emissions contribute to the haze $(\mathrm{ABC})$ and to the worsening of winter fog in the HKH. The large agricultural fires detected by MODIS satellite sensors illustrate that burning is most prevalent in Bangladesh, Bhutan, China, India, Nepal, and Pakistan. MODIS is unable to capture the small and short-lived fires outside the passing times, although they are also important sources of air pollution.

Two distinct periods of post-harvest agricultural residue burning are prevalent in the IGP - the burning of paddies between October and November and the burning of wheat residue between April and May. $\mathrm{PM}_{2.5}$ mass concentrations of $60-390 \mu \mathrm{g} / \mathrm{m}^{3}$ have been observed during paddy residue 

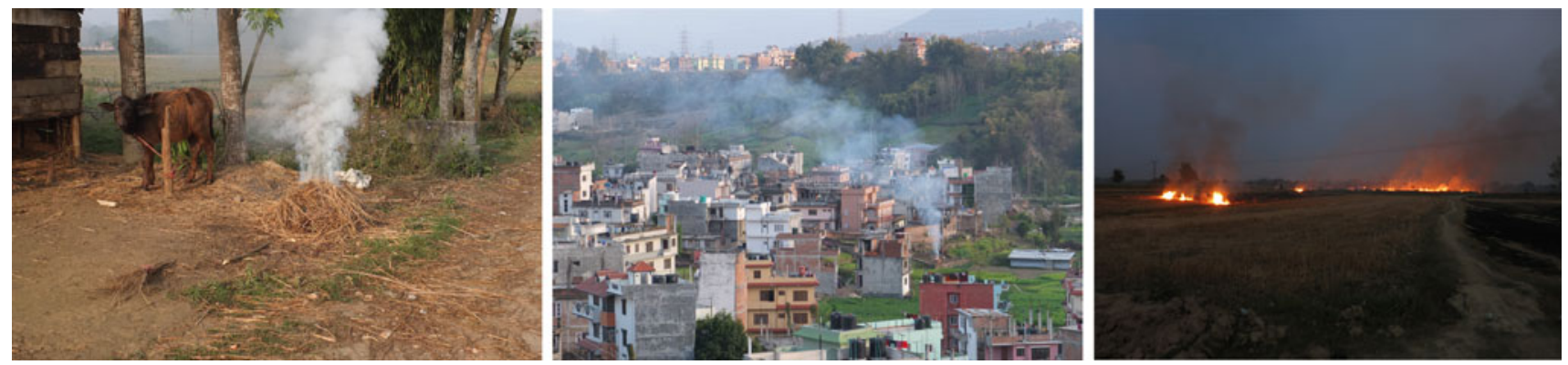

Fig. 10.17 Burning of small piles of agricultural residue (left and centre) versus open-field burning (right). Photos by Arnico Panday

burning, with high OC contribution of more than $30 \%$, in Patiala, Punjab, India. Approximately $250 \mathrm{Gg} / \mathrm{year}$ of $\mathrm{OC}$ and $60 \mathrm{Gg} /$ year of BC emissions are estimated to be due to agricultural residue burning in the IGP (Rajput et al. 2014). Based on the ratio of the tracers levoglucosan and $\mathrm{OC}$, it was found that in the post-monsoon season, the OC derived from biomass burning contributed a large fraction of the total aerosol OC $(\sim 40 \%)$ in Lumbini, Nepal, reconfirming the regional influence of agricultural residue burning (Wan et al. 2017).

\subsubsection{Garbage Burning}

The open burning of waste contributes substantially to local and regional air pollution, and it is a common way to dispose of garbage in South Asia (Asian Productivity Organization 2007). Waste management is considered one of the most important issues in urban areas in the HKH. Indeed, public opinion shows that $59 \%$ of urban residents consider solid waste to be the most important problem in Nepal. In the same survey, only $7 \%$ listed air pollution as the most important problem; garbage burning is also one of the most poorly characterized emissions sources even in developed countries (USEPA 2006; Stockwell et al. 2016). Garbage burning in the $\mathrm{HKH}$ is ubiquitous on a range of scales, and mixed garbage items, including paper products, plastics, and rubber tyres, are often burned together.

Garbage burning is a large contributor to $\mathrm{BC}, \mathrm{OC}, \mathrm{PM}$, and CO emissions. Wiedinmyer et al. (2014) estimated emissions of various trace gases and PM from the open burning of waste globally and they show a large hotspot of $\mathrm{CO}$ emissions within and south of the HKH. Uncertainty is still large in these emissions estimates and more effort to validate and improve these emissions is essential. For example, the NAMaSTE campaign results estimated benzene emissions due to Nepal trash burning to be $1.68 \mathrm{Gg} /$ year (Stockwell et al. 2016), compared to $0.580 \mathrm{Gg} /$ year estimated by Wiedinmyer et al. (2014) using a different methodology.

\subsubsection{Forest and Scrub Fires}

During the dry season, especially from March to May, many forest and scrub fires occur in the southern HKH foothills of India, Nepal, and Bhutan (Rupakheti et al. 2017). Some of these can take place at high altitudes, close to the cryosphere. According to the MODIS fire spot product, an average of 3,908 fire counts per year (2005-10) were recorded in this region. The average burnt areas were estimated to be $1,129 \mathrm{~km}^{2}$, with BC emissions of $431 \mathrm{t} /$ year (Vadrevu et al. 2012). A vertical profile of aerosols revealed by CALIPSO, as well as the example shown in Fig. 10.18a, suggests smoke plumes can reach altitudes of 4,000-5,000 m, which is much beyond the typical planetary boundary layer height in the region; this gives them a higher chance to undergo long-range transport for dispersion, but also brings them into contact with the lower reaches of the Himalaya cryosphere.

The MODIS fire spot product may still underestimate fires in the HKH due to several reasons. First, it cannot see fires taking place under clouds or heavy haze. Second, MODIS only takes instantaneous snapshots four times a day. Often, the fires take place in the early evenings when there is no MODIS overpass. Fires on steep slopes travel rapidly upwards until they reach the ridgeline or some other barrier, and extinguish themselves when they run out of fuel in their path. The fire photographed in the early evening in Fig. 10.18b did not appear in MODIS, nor did 22 large fires observed by an author at 19:00 on 14 April 2016 from a mountaintop in Gorkha, Nepal.

\subsubsection{Brick Kilns and Industries}

The fired clay brick is one of the most widely used construction materials in the HKH and the IGP, and most of the brick kilns operate only during the dry season. While data on emissions from brick kilns is still lacking, there are estimates of almost 100,000 brick kilns across the IGP. In the Indian states of Uttar Pradesh and Bihar, almost 23,000 brick kilns are known to be in operation. There are no brick kilns in Bhutan and just over 100 and 1,000 brick kilns within the Kathmandu Valley and in Nepal, respectively. Indeed, 75\% of global brick production is considered to be concentrated in four countries - China (54\%), India (11\%), Pakistan (8\%), and Bangladesh (4\%) - all part of the HKH.

The recent NAMaSTE campaign indicated that brick kilns are a significant source of $\mathrm{SO}_{2}, \mathrm{NO}_{x}, \mathrm{BC}, \mathrm{OC}$, and $\mathrm{PM}$, and that the type of kilns, as well as the primary fuels 

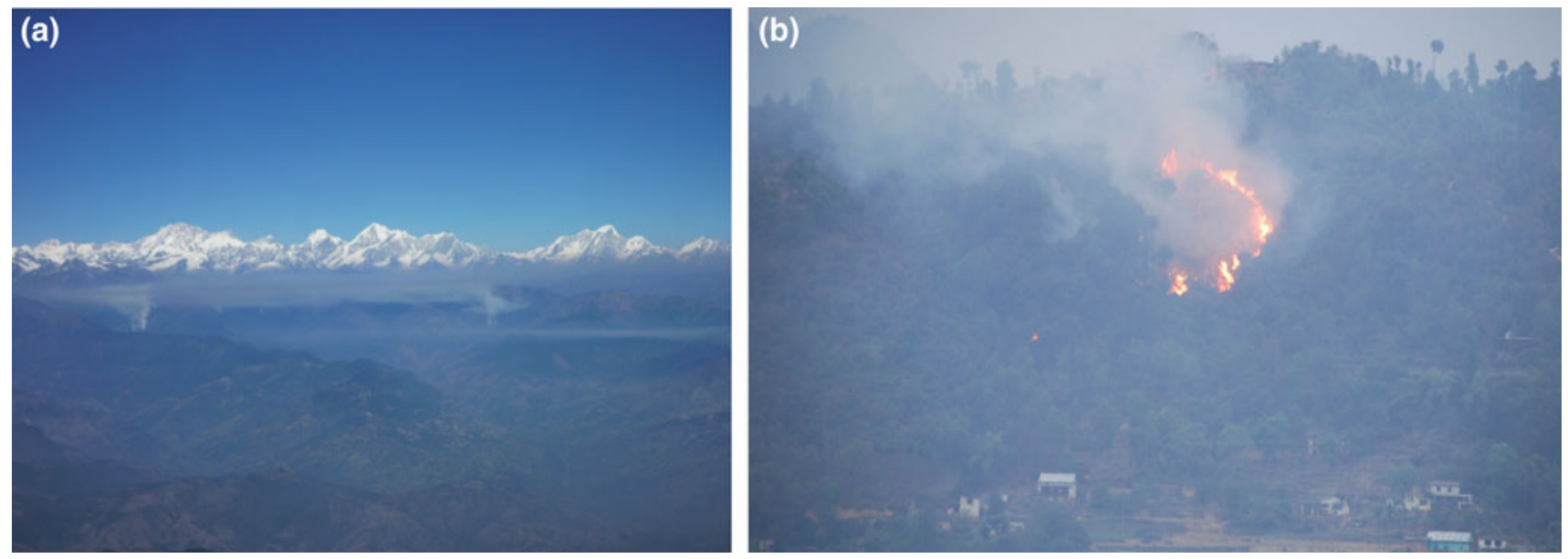

Fig. 10.18 Forest fires in the HKH at high altitude (a) and on the outskirts of Kathmandu (b). Photos by Arnico Panday

burned, matters in the resulting emissions (Stockwell et al. 2016). Brick production levels are not well understood and more data need to be collected. What seems to be the case is that the number of brick kilns is growing rapidly in many places within the $\mathrm{HKH}$ with increasing urban populations (Bisht and Neupane 2015), other than Bhutan, which has no domestic production but imports its bricks.

\subsubsection{Diesel Generators and Irrigation Pumps}

Fossil fuel combustion in the power sector contributes a large portion of $\mathrm{SO}_{2}$ emissions in the $\mathrm{HKH}$, excluding brick kilns. Diesel generators are an important source of emissions that are often neglected; they are used to meet power demand during frequent power shortages in the region (Laghari 2013). Over ten million diesel pumps are estimated to be in operation in the IGP consumed by these pumps. Distributed generator sets are a significant pollution source and contribute to local and regional air pollution, especially during the winter and pre-monsoon seasons due to the prolonged power shortages (World Bank 2014). BC emissions estimated from diesel generators in the Kathmandu Valley are $75 \%$ of diesel emissions estimated in the REAS V2 (Kurokawa et al. 2013), which excludes these emissions. In other words, when power cuts were common in the Kathmandu Valley between 2009 and 2015, emissions from diesel generators were responsible for more than half of the total BC emissions. Although the Kathmandu Valley in recent years reduced power cuts significantly, frequent power cuts are still prevalent in the other parts of HKH and illustrate the importance of these emissions from diesel generator sets in the region.

\subsubsection{Transport (Road, Rail)}

The transport sector contributes to emissions of all pollutants in all of the HKH countries, as shown in Fig. 10.16. It is an especially important source of $\mathrm{NO}_{x}$ emissions. For each of the eight $\mathrm{HKH}$ countries, the transport sector contributes from at least $12 \%$ up to $73 \%$ of total $\mathrm{NO}_{x}$ emissions in a country. For countries with a substantial number of gasoline vehicles, $\mathrm{CO}$ emissions from the transport sector are also important. $\mathrm{SO}_{2}$ emissions from the transport sector illustrate the low fuel quality with high sulphur content used in the engines. Afghanistan, China, India, and Pakistan have substantial contributions by the transport sector to BC emissions, illustrating the existence of polluting diesel vehicles in these countries.

\subsubsection{Source Regions and Transport Pathways for Pollution Reaching and Crossing the High Mountains}

The HKH receives pollution from sources within the region, both rural and urban, as well as from a number of regions outside. In spring, dust from the Thar Desert reaches the western and central Himalaya (Hegde et al. 2007; Ram et al. 2010). South-eastern Tibet receives biomass-burning emissions from Myanmar, Bangladesh, and eastern India (Zhao et al. 2013), while the northern parts of the Tibetan Plateau receive dust from the Taklimakan Desert (Huang et al. 2007; Cao et al. 2009; Xiao et al. 2010; Chen et al. 2013; Zhao et al. 2013; Wang et al. 2015). Pollution episodes at Mount Waliguang at the north-eastern corner of the HKH, as well as at Mount Muztagh Ata, in the Pamir range and in the Pakistani Karakoram, have been traced to Central Asia and the Middle East (Wang et al. 2006; Che et al. 2011; Gul et al. 2018). Manora Peak in India receives pollution from the IGP, but also from the Middle East (Dumka et al. 2010, 2015).

Pollution episodes at the Nam Co observatory in south central Tibet have been traced to emissions in the IGP (Cong et al. 2007; Xiao et al. 2010; Xia et al. 2011; Wang et al. 
2015). The high-altitude areas of HKH were once thought to be relatively pristine, and it was assumed that the Himalaya acted as a barrier to block the transport of pollutants from South Asia to the Tibetan Plateau. However, the in situ observations have pointed out that the high Himalaya are particularly vulnerable to the haze accumulated in the foothills (Li et al. 2016). In addition, high altitude areas have a second vulnerability: incomplete fuel combustion due to decreased oxygen levels, which contributes to pollution in the city of Lhasa (Ran et al. 2014).

The observational data from high altitude sites reveal regional scale pollution processes. For example, the high altitude sites from both sides of the Himalaya (i.e., NCO-P and QOMS) exhibit similar OC and EC abundances. Particularly, $\mathrm{OC}, \mathrm{EC}$, and other ionic species $\left(\mathrm{NH}_{4}{ }^{+}, \mathrm{K}^{+}, \mathrm{NO}_{3}{ }^{-}\right.$, and $\mathrm{SO}_{4}{ }^{2-}$ ) at QOMS exhibited a pronounced peak in the pre-monsoon period and a minimum in the monsoon season, similar to the seasonal trends of aerosol composition reported previously from Langtang and NCO-P (Cong et al. 2015). Pollutants from regional haze episodes over the IGP have been found to be transported across the Himalaya to trans-Himalayan valleys (Babu et al. 2011b) and to the Tibetan Plateau (Kusaka et al. 2001; Lüthi et al. 2015).

Li et al. (2016) reported, based on observation at multiple sites on both the north and south sides of the Himalaya and the Tibetan Plateau (TP), equal contributions from fossil fuel $(46 \pm 11 \%)$ and biomass $(54 \pm 11 \%)$ combustion to $\mathrm{BC}$ in the Himalaya, consistent with $\mathrm{BC}$ source fingerprints from the IGP, whereas BC in the remote northern TP predominantly derives from fossil fuel combustion (66 $\pm 16 \%)$, consistent with Chinese sources. This study and three other studies by Dhungel et al. (2016), Rupakheti et al. (2017), and Lüthi et al. (2015), which reported transport of air pollutants from the IGP to Nepal and then ultimately to the TP crossing the Himalaya under favourable meteorological conditions, indicate the importance of long-range and trans-border transport of air pollution in the region.

A case study combining ground-based and satellite remote sensing data identified a severe aerosol pollution episode over the Tibetan Plateau during 13-19 March 2009 (pre-monsoon) (Lüthi et al. 2015). Trajectory calculations based on the high-resolution numerical weather prediction model, Consortium for Small-scale Modeling (COSMO), were used to locate the source regions and investigate the mechanisms of pollution transport in the complex topography of the Himalaya and Tibet. Lifting and advection of polluted air masses over the great mountain range is enabled by a combination of synoptic-scale and local meteorological processes. During the days prior to the event, winds over the IGP were generally weak at lower levels, allowing for accumulation of pollutants and thus the formation of ABCs. The subsequent passing of synoptic-scale troughs led to south-westerly flow in the middle troposphere over northern and central India, which carried the polluted air mass across the Himalaya. Based on the results of the field observation of aerosols at the north slope of the Himalaya (QOMS), strong positive correlations were observed for dicarboxylic acids with biomass-burning tracers, levoglucosan, and $\mathrm{K}^{+}$, demonstrating that this area was clearly affected by biomass burning (Cong et al. 2015). The seasonal pattern of dicarboxylic acids is consistent with OC and EC, characterized by a pronounced maximum in the pre-monsoon season. It has been proposed that the local valley breezes and regional atmospheric flow process could facilitate the penetration of the carbonaceous aerosols from South Asia across the high Himalaya.

The mountain/valley wind systems in the southern Himalaya are characterized by up-valley winds in the daytime with a maximum in the afternoon, which delivers substantial pollutants (e.g., $\mathrm{BC}$ and $\mathrm{O}_{3}$ ) from lowland to higher altitude. This has been studied in situ both in the Kali Gandaki Valley which crosses the high Himalaya at relatively low altitude (Dhungel et al. 2016), as well as at NCO-P, near Everest Base Camp (Bonasoni et al. 2008, 2010; Gobbi et al. 2010; Marcq et al. 2010; Marinoni et al. 2010; Sellegri et al. 2010). Meanwhile, satellite-based tools were used to map the northward slanting haze layers that penetrate into Himalayan valleys from the IGP (Brun et al. 2011). The Karakoram also receives pollution from lower valleys (Putero et al. 2014), while Manora Peak observatory in Nainital, overlooking the IGP, receives substantial afternoon arrival of pollutants from the IGP (Pant et al. 2006b; Ram et al. 2010; Ojha et al. 2012; Dumka et al. 2015).

Chemical transport models, despite their inherent uncertainties in simulating atmospheric processes, are a useful tool to link emission source regions with in situ observations in areas with no local pollution sources. One study used the global chemical transport model GEOS-Chem to trace the origin of $\mathrm{BC}$ reaching four different high altitude sites in the $\mathrm{HKH}$, finding sources as far away as Siberia, tropical Africa, and Europe (Kopacz et al. 2011). One of the techniques used by the atmospheric modeling community is to release region-tagged chemical tracers such as $\mathrm{CO}$ into the atmosphere and assess their concentration in the area of interest. Another widely used technique is to simply calculate wind back trajectories from the observation site and estimate the contributing region(s) (Jaffee et al. 1999). Numerical simulations have limitations and especially over the extreme topography of the HKH face a trade-off between doing computationally very expensive runs at high spatial and temporal resolution, versus going to lower resolutions that are able to capture key features elsewhere in the world but would miss key features in the HKH. Many atmospheric processes in the HKH are tied closely to the shape of the topography, and if a model does not accurately capture the height of peaks, the depth of valleys, or the cross-section of 
passes then it might not accurately capture the direction and speed of up- or down-valley flows, the location of cloud formation, or the extent of trans-Himalayan flows.

Satellite-based remote sensing products also provide a good spatial and semi-continuous temporal coverage. However, these products also have severe limitations during cloud cover, over bright reflecting surfaces especially over complex topography, and with regards to the number of tropospheric air pollutants they can observe directly.

The Sulfur Transport and dEposition Model (STEM), an offline regional chemical transport model (Adhikary et al. 2007; Kulkarni et al. 2015) driven by the Weather Research and Forecasting (WRF) model (Skamarock et al. 2008), was used to assess the relative strength of emissions from different geographical regions affecting the high mountain glaciers of the HKH. Anthropogenic CO emissions inventory provided by the Task Force on Hemispheric Transport of Air Pollutants was used to simulate the region-tagged tracers for 2013. For this assessment, region-tagged CO tracers were run on inert mode, thus providing an estimate of the maximum concentration reaching the observation site from the source region. In addition, it is important to note that the emissions are tagged at the time of release and not the actual path that the pollutant follows. Figure 10.19 shows the contribution as a percentage of total for $\mathrm{CO}$ pollutant reaching Yala Glacier in the central Himalaya. Although CO is used for this particular analysis, the technique allows for interpolating to other relatively inert species, which have similar spatial emission patterns. Thus, we interpret the results as air pollutants reaching high mountain glacier as opposed to strictly $\mathrm{CO}$ tracer.

Analyses of the simulation results show that Yala Glacier is affected mostly by pollutants from Nepal and India (nearby source regions), while occasional contributions come from regions as far away as Africa and the Middle East. Observations of pollutants thought to have originated from the Middle East and Africa over the Langtang region

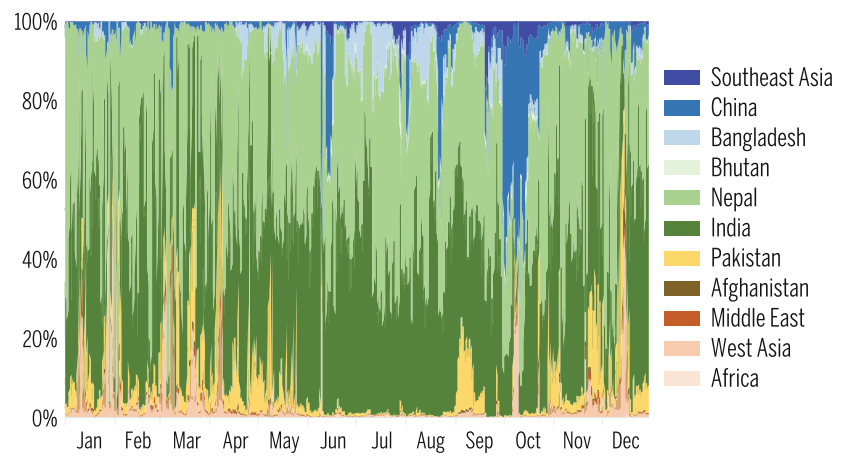

Fig. 10.19 Percent contribution to $\mathrm{CO}$ concentration over Yala Glacier, estimated with emissions from various geographic regions. Figure prepared for HIMAP by Bhuphesh Adhikary, ICIMOD. Model configuration and simulations described in Rupakheti et al. (2017) have been published earlier (Carrico et al. 2003). Since the model is simulated at $25 \times 25 \mathrm{~km}$ horizontal grid resolution, it is too coarse to capture up-valley winds and other thermally driven microclimates. However, the model does give an overall synoptic picture, consistent with the expected behaviour of pollution transport reaching the high glaciers of the HKH. Several research papers using wind back trajectories analysis report that the source of the observed air pollutants reaching the HKH are primarily from the IGP and as far away as Africa (Carrico et al. 2003; Bonasoni et al. 2012; Ming et al. 2009; Babu et al. 2011b; Lu et al. 2012; Gul et al. 2018).

\subsubsection{Assessment of Our Knowledge About Emissions and Processes in the HKH}

While some progress has been made in increasing our understanding of the contributions from some sources, much work remains before we can reliably link specific sources to their exact impacts. One of the challenges in the overall quantification of emission transport and climate effects over the IGP is in the general underestimation of aerosol loading in climate and chemical transport model simulations (both global and regional scale models), due to various emissionand meteorology-related factors (Ganguly et al. 2009; Henriksson et al. 2011; Nair et al. 2012; Cherian et al. 2013; Sanap et al. 2014; Pan et al. 2015).

\subsubsection{Based on Source Apportionment Studies}

Source apportionment studies by receptor modeling can assess how much various source categories contribute to ambient pollution levels at a specific site. Figure 10.20 shows the contribution of different sources, including household garbage and municipal solid waste burning to $\mathrm{PM}_{10}$ concentrations in the Kathmandu Valley, using a multivariate receptor model (Kim et al. 2015). It is clear that both garbage burning and brick kilns impact the Kathmandu air quality significantly. Kim et al. (2015) conducted measurements for two periods: the first between 21 December 2012 and 3 January 2013 and the second between 13 and 21 February 2013. They analysed BC, OC, ions, and trace metals in the $\mathrm{PM}_{10}$ data to assess the quantitative source contribution. They found that brick kilns and biomass/garbage burning contribute to $40 \%$ and $22 \%$ of BC in the Kathmandu Valley in winter, respectively, while biomass/garbage burning contributes to $32 \%$ of OC. Unfortunately, this work was carried out only at a single site, in a single season. Wiedinmyer et al. (2014) estimate that $644 \mathrm{Gg} /$ year of municipal solid waste is burned in Nepal, leading to $6.3 \mathrm{Gg} /$ year $(7.7 \mathrm{Gg} /$ year $)$ of $\mathrm{PM}_{2.5}\left(\mathrm{PM}_{10}\right)$. As for $\mathrm{BC}(\mathrm{OC})$, they estimate $0.42 \mathrm{Gg} /$ year $(3.4 \mathrm{Gg} /$ year) due to garbage burning in Nepal. Recalculating the estimated 


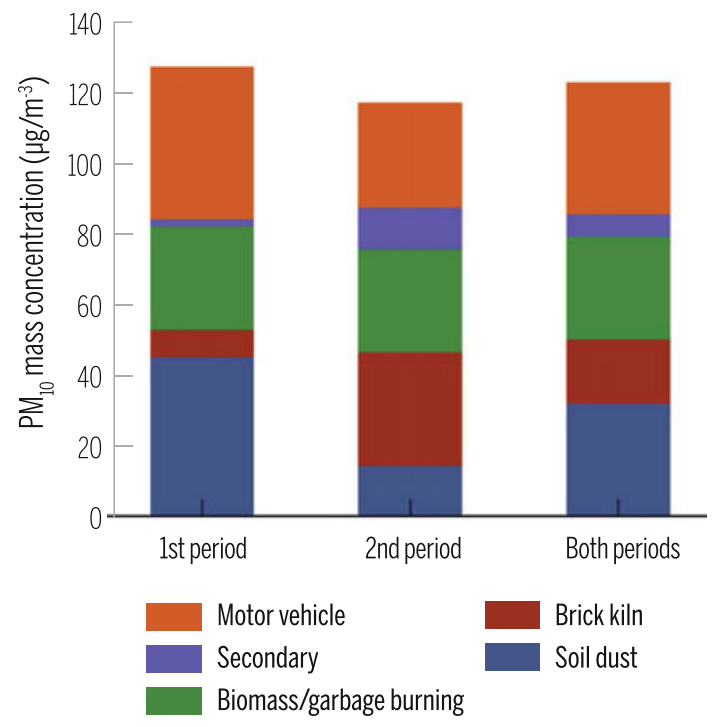

Fig. 10.20 Contribution of motor vehicles, secondary, biomass/garbage burning, brick kilns, and soil dust to $\mathrm{PM}_{10}$ concentrations in Nepal (Source Kim et al. 2015)

emissions using the emission factors measured in the NAMaSTE campaign, but keeping the same solid waste estimate, garbage burning emits seven, five, and 15 times more $\mathrm{PM}_{2.5}, \mathrm{BC}$, and $\mathrm{OC}$, respectively, (Stockwell et al. 2016; Jayarathne et al. in press). This translates into revised $\mathrm{PM}_{2.5}, \mathrm{BC}$, and $\mathrm{OC}$ emissions estimates from garbage burning in Nepal being 7.3, 5.1, and $15 \mathrm{Gg}$ /year.

\subsubsection{Based on Chemical Transport Modeling}

The HKH is influenced by both monsoons and westerlies. During the winter and pre-monsoon months of OctoberApril, large-scale circulation patterns (mainly westerlies from central Asia) are the main source of air masses to the region. During the monsoon season of June-September, low pressure systems over the region bring air masses from the Indian Ocean. These result in pollution transport from South Asia (Meitiv 2010). Based on adjoint model results, Kopacz et al. (2011) estimated emissions from northern India and central China to be the major contributor of $\mathrm{BC}$ emissions to the Himalaya. For the Tibetan Plateau, they found western and central China, as well as India, Nepal, the Middle East, and Pakistan, to be source origins.

\subsubsection{Assessment of Existing Emission Inventories}

Understanding the spatial and temporal distribution of air pollutant emissions is vital to the implementation of appropriate climate and air quality mitigation measures. Increases in anthropogenic aerosol emissions and loading in South Asia in recent decades have also been well documented (Ohara et al. 2007; Hsu et al. 2012; Babu et al. 2013; Kaskoutis et al. 2013), in contrast to the decreasing emission trends over Europe and
North America (Granier et al. 2011). However, large uncertainties exist in emissions inventories, and quantification of these uncertainties is essential for better understanding of the linkages among emissions and air quality, climate, and health. For India, for example, Saikawa et al. (2017a) find large differences among the inventory estimates in the domestic sector for $\mathrm{CO}_{2}(82 \%)$, transport for $\mathrm{NO}_{x}(57 \%)$ and $\mathrm{PM}(108 \%)$, and industry for $\mathrm{CO}(63 \%)$ and $\mathrm{SO}_{2}(44 \%)$.

In Nepal, residential sector emissions dominate for many species, and there are significant differences in the inventory estimates for all pollutants. The two emissions inventories, Emissions Database for Global Atmospheric Research (EDGAR) and REAS estimate following percentages due to the residential sector in Nepal: $73 \%$ and $90 \%$ for $\mathrm{PM}_{10}, 27 \%$ and $83 \%$ for $\mathrm{NO}_{x}, 67 \%$ and $79 \%$ for $\mathrm{SO}_{2}$; and $67 \%$ and $98 \%$ for CO, respectively. Similarly, estimates for road transport sector emissions vary significantly, depending on the source. Large uncertainties exist in emissions estimates in China and India and more efforts are needed to constrain emissions better in the IGP (Saikawa et al. 2017a, b), as well as in each country of the HKH. There is a need for more ground-based measurements and modeling studies, such as source apportionment, in this region.

Box 10.4 Nepal Ambient Monitoring and Source Testing Experiment (NAMaSTE) campaign

A major input needed by emissions inventories is the "emission factor" for each pollution source-the amount of each pollutant emitted when a certain amount of fuel is burned. For many important pollution sources in the $\mathrm{HKH}$, emission factors either do not exist in global databases or are very different in real life. The Nepal Ambient Monitoring and Source Testing Experiment (NAMaSTE) campaign was implemented in and near Kathmandu and the plains of southern Nepal by ICIMOD and U.S. universities during April 2015. NAMaSTE produced the first, or rare, measurements of aerosol optical properties, aerosol mass, and detailed trace gas speciation for the emissions. The sources of these emissions included many important, under-sampled combustion sources that are widespread in the HKH. Emissions from generators, irrigation pumps, brick kilns, cooking with various stoves and solid fuels, open burning of garbage and crop residue, and motorcycles were measured.

Light absorption by both brown carbon $(\mathrm{BrC})$ and $\mathrm{BC}$ was important for many sources. Dung-fuel cooking fires produced higher $\mathrm{BrC} / \mathrm{BC}$ than fuelwood cooking fires. BTEX compounds (benzene, toluene, ethylbenzene, xylenes) are air toxins and carcinogens and were major emissions from both types of cooking fires. Biogas was the cleanest cooking fuel 
of $\sim 12$ stove/fuel combinations measured. Crop-residue burning produced high emissions of $\mathrm{BrC}$ and $\mathrm{SO}_{2}$. A clamp kiln (with more biomass fuel) produced large emissions quantities of organic gases, organic aerosol precursors, and $\mathrm{BrC}$, while a zig-zag brick kiln burning mostly coal still emitted large amounts of $\mathrm{BC}$, hydrogen fluoride $(\mathrm{HF})$, hydrogen chloride $(\mathrm{HCl})$, and $\mathrm{NO}_{\mathrm{x}}$, with the halogenated emissions coming from the clay. Both kilns emitted very high $\mathrm{SO}_{2}$. Garbage burning produced high $\mathrm{BC}$ and BTEX emissions. Diesel burned more efficiently than gasoline, but produced larger $\mathrm{NO}_{x}$ and aerosol emission factors. The most polluting common source sampled was gasoline-fueled motorcycles during startup and idling, for which the CO emission factor was $\sim 10$ times that of a typical biomass fire (Stockwell et al. 2016). We find that underestimation of the transport sector emissions is possible in the HKH due to the high start-up and idling, combined with increasing number of motorbikes and bad traffic in the region. On the other hand, cooking with biomass is gradually decreasing due to the increasing availability of LPG, particularly in India. Total CO emissions from the rapidly growing transport sector may soon be larger than those from biomass burning.

\section{Box 10.5 Atmospheric Composition and the Asian Monsoon (ACAM)}

Understanding the broader impacts of air pollutants in the Himalaya and their interaction with the monsoon system is of great importance. An international group of scientists have been meeting as a part of Atmospheric Composition and the Asian Monsoon (ACAM, https://www2.acom.ucar.edu/acam). Jointly sponsored by the International Global Atmospheric Chemistry project and SPARC (Stratosphere-troposphere Processes and their Role in Climate), ACAM seeks to understand how this rapidly changing part of the world is influencing the atmosphere on regional-to-global scales.

The Himalaya are a data-sparse region in terms of atmospheric composition measurements, and interactions between the monsoon circulation and human emissions have impacts from the surface to the upper atmosphere that are relevant to both air quality and climate. ACAM focuses on four themes: (1) emissions and air quality in the Asian monsoon region; (2) aerosols, clouds, and their interactions with the Asian monsoon; (3) impact of monsoon convection on chemistry; and (4) Upper Troposphere and Lower Stratosphere Response to the Asian Monsoon.

Since 2013, biennial workshops have attracted atmospheric scientists from the international community to share research related to these themes. Participation from Himalayan countries has included scientists from Nepal, China, India, and Pakistan. ACAM offers a venue for community building that emphasizes research cooperation through data sharing, coordinated field observations, and training schools. ACAM representatives also interact with the international chemistry and climate modeling community to understand what observations are most needed to enable better representation of the Himalaya in global models.

\subsection{Adverse Impacts of Air Pollution in the HKH}

Due to the growing emissions described in the preceding sections, along with rapid urbanisation, industrialization, and motorization, the level of PM (e.g., soot and dust) is very high in many $\mathrm{HKH}$ cities. A large population is thus exposed to pollution levels much higher than those recommended by the WHO. But air pollution not only harms the health of people and ecosystems, it also affects the climate, the cryosphere, monsoon patterns, water availability, agriculture, and incomes.

\subsubsection{Temperature}

Air pollution is responsible for changing the temperature. Absorbing aerosols such as BC and dark dust warm the layers of air where they are located (Ramanathan and Carmichael 2008). In addition, they contribute to cryospheric melting by darkening surfaces onto which they are deposited. Kaspari et al. (2014) estimated (using in situ-observed dust and $\mathrm{BC}$ properties and concentrations) the radiative forcing due to $\mathrm{BC}$ deposition to be within $75-120 \mathrm{Wm}^{-2}$, whereas significantly larger forcing (as high as $\sim 500 \mathrm{Wm}^{-2}$ ) resulted due to dust deposition. Ménégoz et al. (2014) applied a climate-chemistry global model to evaluate the impact of $\mathrm{BC}$ deposition on the snow cover. They estimated that in $\mathrm{HKH}$ ranges, $\mathrm{BC}$ in snow causes an increase of the net shortwave radiation with an annual mean of $1-3 \mathrm{Wm}^{-2}$, reducing the snow cover annual duration by one to eight days. 


\section{Box 10.6 SusKat-ABC international air pollution measurement campaign 2012-13}

Air pollution is a major environmental and societal problem in Nepal that can exert substantial impacts on public health, socioeconomic systems, and national development goals. As the first step towards comprehensive understanding of various aspects of air pollution in Nepal, the SusKat-ABC (Sustainable Atmosphere for the Kathmandu Valley-Atmospheric Brown Cloud) measurement campaign was conducted from December 2012 to June 2013 in Nepal, with a two-month-long intensive measurement phase from December 2012 to February 2013.

SusKat-ABC was jointly coordinated by the Institute for Advanced Sustainability Studies, Germany, and ICIMOD. More than 40 senior scientists and students from 18 research groups in nine countries in Asia, Europe, and the United States deployed state-of-the-art scientific instruments at a network of 23 measurement sites located inside the Kathmandu Valley (with a supersite at Bode), on the valley rim, and in other regions in Nepal, spanning from Lumbini on the northern edge of the IGP, across the Himalaya foothills, to the base of Mount Everest to the north.

The SusKat-ABC campaign was the second-largest international air pollution measurement campaign ever undertaken in South Asia, after the Indian Ocean Experiment (INDOEX) in 1999 (Ramanathan et al. 2001). High-quality ground-based data on air quality and meteorology were collected with unprecedented detail. Measurements of some important species were extended beyond the campaign to provide an opportunity to investigate, for the first time, their seasonal and inter-annual variations at multiple sites. The main objectives of the campaign were to document quantitatively the magnitudes of various air pollutants and to estimate the percentage contributions of major sources and sectors to air quality degradation in the Kathmandu Valley and other regions in Nepal.

In the Kathmandu Valley, wintertime $\mathrm{PM}_{10}$ is contributed mainly by local primary sources (motor vehicles: $31 \%$, soil dust including road dust: $26 \%$, biomass/garbage burning: 23\%, brick factories: $15 \%$ ) and about $5 \%$ by secondary sources (Kim et al. 2015). PM also contained high levels of toxic compounds such as polycyclic aromatic hydrocarbons (PAHs) (Chen et al. 2016) and mercury (Guo et al. 2017) at levels comparable to those observed in megacities like Delhi and Beijing. The campaign also revealed that gaseous air pollutants such as $\mathrm{O}_{3}, \mathrm{SO}_{2}, \mathrm{NO}_{\mathrm{x}}$, and a variety of volatile organic compounds (VOCs), some toxic to humans, are an important aspect of air pollution problems in the Kathmandu Valley and surrounding regions (Putero et al. 2015; Kiros et al. 2016; Sarkar et al. 2016). Speciated measurements of VOCs with a proton-transfer-reaction-time-of-flightmass-spectrometry (PTR-ToF-MS), the first PTR-ToFMS deployment in South Asia, made it possible to identify their sources and estimate their $\mathrm{O}_{3}$ production potential and contributions to secondary organic aerosol formation (Sarkar et al. 2016).

As a follow-up to the SusKat-ABC campaign, Shakya et al. (2016) conducted a study in spring and summer of 2014 involving traffic police officers in the Kathmandu Valley. They found that lung functions degraded significantly with exposure to increasing levels of $\mathrm{PM}_{2.5}$ and BC. Outside the Kathmandu Valley, they found that Lumbini, Pokhara, and Jomsom also suffer from high levels of PM, including BC and PAHs, CO, and $\mathrm{O}_{3}$ (Chen et al. 2016; Dhungel et al. 2016; Tripathee et al. 2016; Rupakheti et al. 2017).

In summary, the SusKat-ABC results suggest that local action is necessary, but that it alone will not be sufficient to achieve clean air in the region. These key measurements and results provide the strong scientific basis needed for air quality management programmes or pathways to improve air quality and reduce adverse impacts in the region.

Regarding the Tibetan Plateau, Qian et al. (2011) suggested $\mathrm{BC}$ in snow increased the surface air temperature by around $1{ }^{\circ} \mathrm{C}$ and reduced the spring snowpack, resulting in increased runoff during the late winter and early spring, while the runoff decreased during late spring and early summer. The long-term regional mean radiative forcing via dust deposition on snow showed a rising trend during 1990-2009, which suggested the contribution of aerosols surface radiative effects induced by snow darkening has increased since 1990 (Ji et al. 2016). Furthermore, based on a model simulation, carbonaceous aerosols (BC and $\mathrm{OC}$ ) increased surface air temperatures by $0.1-0.5^{\circ} \mathrm{C}$ over the Tibetan Plateau and decreased temperatures in South Asia during the monsoon season. In the non-monsoon period, temperatures decreased by $0.1-0.5{ }^{\circ} \mathrm{C}$ over the southern Tibetan Plateau (Ji et al. 2015).

\subsubsection{Precipitation and Monsoon (Cloud Microphysics to Regional Scale)}

Air pollution also alters precipitation patterns. Major sources of absorbing aerosols (e.g., dust and BC) are located within Asia, which include both anthropogenic emissions (fossil fuel and biofuel sources) as well as naturally emitted mineral 
dust aerosols from desert/arid regions. Several climate modeling studies have suggested the importance of aerosol solar absorption in modulating the monsoon circulation and rainfall distribution over Asia (Menon et al. 2002; Ramanathan and Ramana 2005; Chung and Ramanathan 2006; Lau et al. 2006; Meehl et al. 2008; Randles and Ramaswamy 2008; Collier and Zhang 2009; Sud et al. 2009; Wang et al. 2009; Bollasina et al. 2011; Ganguly et al. 2012; Vinoj et al. 2014). The summer monsoon rainfall, particularly over southern Asia, constitutes over $70 \%$ of the annual rainfall and is a major freshwater resource to the region. Along with the summer monsoon, the seasonal snow melt from the Himalaya glaciers and snowpack also contributes to the regional socioeconomic livelihood. Therefore, perturbations to the monsoon circulation and Himalayan cryosphere via aerosol radiative effects in terms of regional warming, and subsequent impact on rainfall dynamics, are of critical scientific and societal significance.

One of the physical mechanisms of aerosol-induced radiative impact on the monsoon circulation and long-term effects on monsoon rainfall variability and trends is the "surface dimming effect" proposed by Ramanathan and Ramana (2005). This mechanism focuses on the northern Indian Ocean region, where thick haze, consisting of dust, $\mathrm{BC}$, sulphate, and fly ash aerosols, is transported from southern Asia towards the Indian Ocean. The aerosol transport occurs annually during the dry season, primarily during the winter and early spring months. It has earlier been shown by Satheesh et al. (1999) that the widespread anthropogenic haze results in significant perturbations to the radiation budget, with large reductions in the solar insolation at the ocean surface. The reduction of sunlight reduces the evaporation rates, which further suppresses convection from the Indian Ocean, leading to reduced moisture transport towards the South Asian landmass during the peak monsoon season. This mechanism suggests the weakening of monsoon circulation and reduction of monsoon rainfall.

On an intra-seasonal scale, other mechanisms have been suggested which rest on the heavy and vertically extended aerosol loading over northern parts of south Asia, primarily over the IGP and the foothills of the Himalaya. The so-called elevated heat pump (EHP) hypothesis, proposed by Lau and Kim (2006), focuses on the absorbing aerosol build-up over the IGP prior to the onset of the summer monsoon. The enhanced dust loading, mixed with carbonaceous soot aerosols, is vertically advected to elevated altitudes against the southern slopes of the Himalaya and causes significant warming in the mid-upper troposphere. In their climate model simulations, Lau et al. (2006) demonstrated that the resulting warming creates a temperature anomaly that can amplify the overturning of the meridional circulation, thus causing enhanced moisture influx from the Indian Ocean. This mechanism has been hypothesized in the advancement and intensification of the early summer monsoon. From an observational perspective, few studies have also investigated the various feedback mechanisms of aerosol absorption effects on monsoon circulation and rainfall variability and trends (Lau et al. 2006; Gautam et al. 2009b; Manoj et al. 2010; Bollasina et al. 2011). In addition to the aforementioned direct radiative impacts of aerosols on the monsoon, aerosol particles can also affect cloud microphysics via indirect effects of aerosols by modifying cloud properties; however, the impact of aerosol indirect effects on the system-wide monsoon rainfall are still largely unknown (Rosenfeld 2000).

\subsubsection{Cryosphere and Hydrosphere}

Glaciers on the HKH hold the largest ice mass outside the polar region, resulting in the name the Third Pole. Ten major Asian rivers originate in this region, including the Yangtze, Yellow, Yarlung Tsangpo (Brahmaputra), Ganges, and Indus. Like a water storage tower, glaciers and snow cover in this region provide fresh water to billions of people downstream. The proximity of the HKH to some of the largest sources of $\mathrm{BC}$ makes this area particularly vulnerable. The increasing air pollution in the HKH could impact the cryosphere through a complicated mechanism. First, the light-absorbing particles (e.g., BC, BrC, and iron oxides in dust) could warm the atmosphere through absorbing solar radiation. Ramanathan and Carmichael (2008) suggested that the BC in the high Himalaya may contribute as much as carbon dioxide to the radiative forcing. Such atmospheric warming could subsequently lead to further melting of the snow through thermal transfer. More importantly, the impurities absorb the incoming solar radiation, thereby accelerating snow aging and melting processes and triggering snow-albedo feedback (Flanner et al. 2009; Lau et al. 2010; Yasunari et al. 2010; Qian et al. 2015).

Using MODIS snow albedo data, Ming et al. (2015) investigated the changes of snow and glacier albedo in $\mathrm{HKH}$ for the period 2000-11. A general darkening trend of glacier surface was revealed, with the most rapid albedo decrease in the glacial area above $6,000 \mathrm{~m}$. The mass-loss equivalent (MLE) of the HKH glacial area caused by surface shortwave radiation absorption was estimated to be $10.4 \mathrm{Gt} / \mathrm{yr}$, which may contribute to $1.2 \%$ of the global sea level rise on annual average (2003-09) (Ming et al. 2015).

Major sources of light-absorbing atmospheric aerosols are located around the HKH snowpack and glaciers, which include mineral dust and carbonaceous aerosols source regions. Mineral dust transport originates over the Thar Desert in India and several southwest Asian desert regions as far away as the Arabian Peninsula regions. The mineral dust aerosol loading peaks during the pre-monsoon and early summer monsoon months (April to July) on an annual basis 
(Gautam et al. 2010). Major sources of carbonaceous aerosols are located widely over the IGP. Although the absorption strength of BC aerosols is several orders of magnitude larger than that of dust, the absolute concentrations of dust found in the HKH cryosphere are substantially larger than BC deposition (Ginot et al. 2014; Kaspari et al. 2014). Therefore, in addition to $\mathrm{BC}$, dust aerosol deposition is considered a major agent causing snow albedo reduction in the HKH.

For example, a recently conducted ice core study in the Mera Peak Glacier shows that annual mass fluxes of dust are a few orders of magnitude higher than of BC (Ginot et al. 2014). Longer-term ice core records (on the scale of centuries) have also indicated peak annual dust concentrations in the Tibetan Plateau prior to the summer monsoon season, with enhanced dust deposition during periods of dry/drought conditions over southern Asia (Kang et al. 2000; Thompson et al. 2000). Satellite observations have also found widespread areas with desert dust deposited onto snow cover, and a reduction in snow reflectance in the western Himalaya and Hindu Kush cryosphere (Gautam et al. 2013). The concentrations of both BC and dust are typically found to peak during the pre-monsoon season (Kaspari et al. 2011), although in situ-based measurements of snow impurities are still sparse and limited. The BC deposition over the $\mathrm{HKH}$ primarily comes from residential, industrial, and transport sectors, with the largest deposition occurring in summer months (Jenkins et al. 2013).

Modeling results suggested that mineral dust caused a decrease of 5-25 $\mathrm{mm}$ in the snow water equivalent over the western Tibetan Plateau, Himalaya, and Pamir Mountains in winter and spring ( $\mathrm{Ji}$ et al. 2016). Also in the Himalayan region, a 2.0-5.2\% albedo reduction from $\mathrm{BC}$ deposition could result in an 11.6-33.9\% increase in annual discharge if the reduced albedo snow layer remained at the glacier surface (Yasunari et al. 2010; Gertler et al. 2016). It should be noted that, currently, the modeling works for the transport, deposition, and radiative forcing of snow impurities indicate remarkable uncertainties (Qian et al. 2015). Biases may be partly due to the mismatch in the timescale between the modeling and observation. The lack of accurate data on optical and physical properties of impurities (e.g., BC, dust, and organic matters) in the atmosphere and snow is also an important reason. More field observations with higher time resolution (e.g., daily) at representative locations are urgently needed to validate the modeling results.

\subsubsection{Ecosystems and Agriculture}

Air pollution also has significant impacts on the ecosystem. Acid rain causes damage to forests and acidifies soils, and highly acidic precipitation has been observed in the eastern Himalaya, with $\mathrm{pH}$ value as low as 4.2 in Darjeeling, India
(Roy et al. 2016). Acid deposition also affects yields for many crops and accelerates the erosion of buildings, statues, and sculptures (Singh and Agrawal 2008). Similarly, leaching of nutrients such as nitrates and phosphates in the rivers has resulted in harmful algal blooms, turning the coastal areas into "dead zones" (Rabalais et al. 2010). Increased nitrogen transport in rivers can also lead to enhanced microbial production of nitrogenous trace gases, including the greenhouse gas $(\mathrm{GHG})$ nitrous oxide $\left(\mathrm{N}_{2} \mathrm{O}\right)$, both in streams and in receiving coastal areas (Beaulieu et al. 2011; Naqvi et al. 2000).

Exposure to increased ground-level $\mathrm{O}_{3}$ harms forest, plants, and agricultural crops by penetrating leaves through stomata and by oxidizing plant tissues. Adverse impacts result in impaired photosynthesis, protein and chlorophyll degradation, and reduction in metabolic activity (Booker et al. 2009; Fuhrer 2009). As a result, surface $\mathrm{O}_{3}$ exposure leads to crop yield losses, increased susceptibility to diseases, and increased senescence (Mauzerall and Wang 2001). Losses of USD 1.2-3.8 billion per year are estimated due to wheat, maize, cotton, and soybean crop damage in India (Avnery et al. 2011; Ghude et al. 2014).

\subsubsection{Health}

Ambient and indoor air pollution are both large contributors to poor health, especially in developing countries. A recent report by the WHO (2014) estimated the global premature mortality rate linked to these two forms of air pollution at 2.7 million and 4.3 million, respectively. The most recent Global Burden of Disease Study estimates approximately 5.8 million premature deaths due to PM pollution, half due to ambient pollution and half to household air pollution, as well as 217,000 deaths due to ambient ozone $\left(\mathrm{O}_{3}\right)$ pollution (Forouzanfar et al. 2016). The largest number of premature mortalities from both ambient and indoor air pollution is considered to be from Asia. For example, in South Asia, household air pollution (HAP) from solid fuel burning is the dominant cause of death (Lim et al. 2012). In East Asia, ambient PM pollution is the fourth largest cause of death, while HAP is ranked fifth (Lim et al. 2012). The HKH is therefore no exception, and there is a large estimated number of premature deaths due to air pollution in each of the countries within the HKH as shown in Table 10.1. The estimates vary, however, depending on the emissions used in the study, as well as the choice of the chemical transport model and the chosen concentration-response functions. For example, the premature mortality from outdoor air pollution in China can range from 300,000 to over a million, depending on the studies (Saikawa et al. 2009; Health Effects Institute 2017). What is important, however, is that these numbers are not negligible and more studies are essential for a better 
Table 10.1 Air pollution and impacts of $\mathrm{PM}_{2.5}$ exposure in 1990 and 2013 for each of the HKH countries

\begin{tabular}{|c|c|c|c|c|c|c|c|c|}
\hline & \multirow{2}{*}{\multicolumn{2}{|c|}{\begin{tabular}{|l}
$\begin{array}{l}\text { Mean annual } \\
\text { ambient } \mathrm{PM}_{2.5}\end{array}$ \\
$\mu \mathrm{g} / \mathrm{m}^{3}$
\end{tabular}}} & \multirow{2}{*}{\multicolumn{2}{|c|}{$\begin{array}{l}\text { Total deaths from air } \\
\text { pollution }\end{array}$}} & \multirow{2}{*}{\multicolumn{2}{|c|}{$\begin{array}{l}\text { Total welfare losses } \\
\begin{array}{l}\text { Million } 2011 \text { USD, } \text { PPP }^{1} \text {-adjusted } \\
\text { (\% GDP equivalent) }\end{array}\end{array}$}} & \multirow{2}{*}{\multicolumn{2}{|c|}{$\begin{array}{l}\text { Total forgone labour output } \\
\begin{array}{l}\text { Million } 2011 \text { USD, } \text { PPP }^{1} \text {-adjusted } \\
\text { (\% GDP equivalent) }\end{array} \\
\end{array}$}} \\
\hline & & & & & & & & \\
\hline & 1990 & 2013 & 1990 & 2013 & 1990 & 2013 & 1990 & 2013 \\
\hline Afghanistan & N/A & N/A & N/A & N/A & N/A & N/A & N/A & N/A \\
\hline Bangladesh & 29.92 & 48.36 & 92880 & 154,898 & $6379(4.66 \%)$ & $27,452(6.14 \%)$ & $1195(0.87 \%)$ & $2579(0.58 \%)$ \\
\hline Bhutan & N/A & N/A & N/A & N/A & N/A & N/A & N/A & N/A \\
\hline China & 39.3 & 54.36 & $1,518,942$ & $1,625,164$ & $\begin{array}{l}126,592 \\
(7.35 \%)\end{array}$ & $\begin{array}{l}1,589,767 \\
(9.92 \%)\end{array}$ & $\begin{array}{l}12,558 \\
(0.73 \%)\end{array}$ & $\begin{array}{l}44,567 \\
(0.28 \%)\end{array}$ \\
\hline India & 30.25 & 46.68 & $1,043,182$ & $1,403,136$ & $104,906(6.8 \%)$ & $505,103(7.69 \%)$ & $\begin{array}{l}28,742 \\
(1.86 \%)\end{array}$ & $\begin{array}{l}55,390 \\
(0.84 \%)\end{array}$ \\
\hline Myanmar & N/A & N/A & N/A & N/A & N/A & N/A & N/A & N/A \\
\hline Nepal & 29.68 & 46.09 & 16,436 & 22,038 & $1033(4.60 \%)$ & $2833(4.68 \%)$ & $195(0.87 \%)$ & $287(0.47 \%)$ \\
\hline Pakistan & 36.55 & 46.18 & 103,111 & 156,191 & $19,935(6.06 \%)$ & $47,713(5.88 \%)$ & $4713(1.43 \%)$ & $6582(0.81 \%)$ \\
\hline
\end{tabular}

Source World Bank and Institute for Health Metrics and Evaluation (2016)

Note 1. PPP stands for purchasing power parity

assessment. Available studies on health impacts have focused on exposure to $\mathrm{PM}$, tropospheric $\mathrm{O}_{3}, \mathrm{NO}_{x}$, and $\mathrm{SO}_{2}$, as well as polycyclic aromatic hydrocarbons (PAHs) and heavy metals.

\subsubsection{Particulate Matter and Health}

Studies have found that the surface concentration of $\mathrm{PM}_{2.5}$ is linearly associated with increased risk of various adverse health impacts, including premature mortality and morbidity (Hogg et al. 2004; Pope et al. 2002, 2004; Brook et al. 2010; Schwartz et al. 2008). Fine particles $\left(\mathrm{PM}_{2.5}\right)$ penetrate deep into the lung and damage cells in the airways, as well as causing lung and cardiovascular diseases. Ambient air pollution and $\mathrm{PM}_{2.5}$, in particular, have been classified as carcinogenic to humans (Loomis et al. 2013). There have been 21 studies identified since 1984, which have assessed the health burden of outdoor air pollution in the Kathmandu Valley and Nepal. Despite the limited data and resources, all of these studies have suggested adverse outcomes linked to air pollution exposure.

Key findings from these research projects are threefold. First, the hospital records between 2007 and 2013 show an increase in cases and proportion of respiratory diseases, as well as their contribution to mortality among children under five years old over this period, which corresponded to the deterioration in air quality. Second, survey and observation analyses among people with different occupations, active locations, and age groups show that people who work or live near the main roads in urban areas are exposed to much higher levels of PM concentrations and therefore suffer more from health problems such as respiratory diseases, headache, and chest pain than those who do not. Third, estimated health effects from the dose-response functions show a heavy health burden due to the excessive PM concentrations. Reducing such health burdens can also relieve the country from the economic burden of mitigating those negative health effects.

\subsubsection{Other Air Pollutants and Health}

Tropospheric $\mathrm{O}_{3}$ also causes adverse health impacts, and studies have linked the exposure to it to higher rates of respiratory and cardiovascular diseases, as well as chronic obstructive pulmonary disease (COPD) (Balakrishnan et al. 2011; Chhabra et al. 2001; Gupta et al. 2007; Jerrett et al. 2009; Pande et al. 2002; Schwartz et al. 1994; Siddique et al. 2010). Asthma mortality and morbidity is also linked to $\mathrm{O}_{3}$ exposure, and even short-term exposure is known to aggravate existing lung diseases. $\mathrm{NO}_{x}$ is known to have harmful effects on human and ecosystem health and is also linked to the formation of other harmful atmospheric pollutants, such as $\mathrm{O}_{3}$ and nitrate aerosols (Costa et al. 2014). $\mathrm{SO}_{2}$ is also harmful to humans (Rall 1974) and ecosystem health and welfare, and it is a precursor to acid rain and sulphate particles (Horton 2012; Loomis et al. 2013; Murray et al. 2012; Pope et al. 2007; Schwartz et al. 1994). Exposure to ambient CO is also harmful to human health (Allred et al. 1989; Haldane 1912; Morris et al. 1995; Stern et al. 1988), and CO emissions are also important precursors to the formation of $\mathrm{O}_{3}$. Polycyclic aromatic hydrocarbons (PAHs) have also been investigated for possible links to an increased risk of cancers and cardiopulmonary diseases (Armstrong and Gibbs 2009; Burstyn et al. 2003; Mastrangelo et al. 1996). PAHs are produced by incomplete combustion of fuel containing carbon, and there are several hundred compounds in this group. There have so far been only limited studies that have measured indoor PAH 
concentrations in the HKH ( $\mathrm{Li}$ et al. 2012; Rantalainen et al. 1999). For the ambient air, during a two-week study period in autumn 2009, Kabul and Mazar-e Sharif in Afghanistan both showed high levels of PAHs from traffic, as well as coal and biomass combustion (Wingfors et al. 2011).

\subsubsection{Household Air Pollution}

HAP contributes to poor health and disproportionately affects those living in developing countries. HAP contains all the pollutants mentioned above and is considered as an additional exposure to ambient air pollution due to the burning within the household. Households that use biomass fuels usually have much higher household exposure than those using cleaner fuels (Shrestha and Shrestha 2005; Xiao et al. 2015). Several acute and chronic health conditions are associated with HAP, including acute respiratory infections (ARI), pneumonia, tuberculosis, chronic lung disease, cardiovascular disease, cataracts, and cancers (Smith et al. 2000; Balakrishnan et al. 2004; Bruce et al. 2007; Dherani et al. 2008; Pope et al. 2010; Epstein et al. 2013). Prolonged exposure to high levels of HAP has been found to increase the frequency of ARI (Ezzati and Kammen 2001). Upadhyay et al. (2015) found that there was a higher probability of life-threatening respiratory illnesses $(O R=1.71-1.78)$ with the use of solid fuels. It is also important to note that the disease burden is borne predominantly by women and young children, who spend more time indoors (Boy et al. 2002; Smith and Mehta 2003; Bruce et al. 2006).

Approximately 400,000 deaths from acute lower respiratory infection in children under five and 34,000 deaths from COPD in women are attributed annually to HAP in India (Smith et al. 2000; Balakrishnan et al. 2011). India contributes to $24 \%$ of the global annual child mortality due to ARI, $50 \%$ of which is due to HAP (Upadhyay et al. 2015). In addition, the use of solid fuels is considered to have been responsible for $20 \%$ of the total deaths among children between one and four years old (IIPS \& ORC Macro 2007).

This high number of premature deaths from HAP in the $\mathrm{HKH}$ is due to the high rate of solid fuel use, as shown in Table 6.1. For example, in India, $71 \%$ of total households are assumed to use solid fuel, and the rate is $90 \%$ in rural areas (Agrawal 2012). Similarly, 50-60\% and 98-99\% of the population still cooks with biomass fuels in urban and rural Bangladesh, respectively (Bangladesh DHS 2011). In urban and rural Pakistan, respectively, $58 \%$ and $94 \%$ of the population uses biomass fuel (Qasim et al. 2014). One exception is the urban population in Afghanistan, where $50 \%$ use LPG and $10 \%$ use electricity. In the rural areas, however, $62 \%$ rely on wood and $31 \%$ on dung, comprising more than $95 \%$ nationally dependent on wood.
Although most research has been focused on health outcomes in adulthood, some recent studies also demonstrate HAP to be associated with low birth weight and infant mortality (Farmer et al. 2014; Pope et al. 2010). There are also some studies that support the hypothesis that exposure to HAP increases the risk of tuberculosis infection and disease, although the data is still too limited to draw firm conclusions (Lin et al. 2007). There is conflicting evidence between HAP and asthma (Bruce et al. 2000), but there is a need for further research, as there has been a recent surge in the childhood asthma prevalence rate in many developing countries, including in the $\mathrm{HKH}$.

Through the $\mathrm{PM}_{2.5}$ and $\mathrm{BC}$ field campaign conducted in households in Nam Co, Tibet, in 2013, the highest and the third highest 6-h average $\mathrm{BC}\left(24.5 \mu \mathrm{g} / \mathrm{m}^{3}\right)$ and $\mathrm{PM}_{2.5}$ $\left(873 \mu \mathrm{g} / \mathrm{m}^{3}\right)$ concentrations were observed from a stone house that had a chimney stove, due most likely to limited ventilation in the household (Xiao et al. 2015). Despite the fact that $75 \%$ of the residents using a stove with a chimney indicated that they were not worried about indoor air quality, as opposed to only $29 \%$ of those using stoves without chimneys, they find that chimney installation did not by itself ensure adequate indoor air quality. Not simply the implementation but also chimney infrastructure is essential for mitigating HAP.

\subsubsection{Cost of Air Pollution in the HKH}

In addition to adverse health issues, air pollution also results in the loss of labour forces and reduces human welfare. Table 10.1 summarizes the mean annual $\mathrm{PM}_{2.5}$, total deaths from air pollution, total welfare losses, and total forgone labour output for years 1990 and 2013 (World Bank and Institute for Health Metrics and Evaluation 2016).

According to the annual report of Nepal's Department of Health Services (DoHS), ARI ranked No. 1 among the top 10 diseases accounting for morbidity in Nepal. The historical data on ARI incidence in Nepal show a significant increase since fiscal year 2007-08. The incidence of ARI per 1,000 children under five years old among new patient visits is as high as 951 during fiscal year 2013-14 (DoHS 2014).

Nepal's annual health cost attributed to urban air pollution is estimated at USD 21 million, equivalent to $0.29 \%$ of the nation's GDP (World Bank 2008). The impact of the high air pollution is witnessed and experienced by millions in their daily lives, in terms of worsening air quality (degrading visibility), respiratory health issues, and regionally changing weather/climate patterns. 


\subsection{Mitigation Efforts for Improving Air Quality in the HKH}

For many of the pollution sources detailed earlier, technologies exist that can reduce emissions at the source or that allow carrying out the same activity with lower emissions. The challenge lies with barriers to their uptake: affordability and financing, behavioural inertia, design and durability of technological solutions, and institutional mechanisms to promote them. Infrastructure and energy planning at regional, national, and urban levels has a large impact on reducing emissions in the long term. Many of the countries lack coherent and dedicated institutions that could form and adopt evidence-based policies. Where such institutions exist, implementation and enforcement are weak. The transboundary nature of the problem calls for regional coordination, but this remains an even bigger challenge. This section discusses current and potential mitigating efforts in $\mathrm{HKH}$.

\subsubsection{Mitigation Options in the HKH to Reduce Emissions}

What technologies can reduce emissions? And what motivates behavioural changes that lead to reduced emissions? This section looks at mitigation efforts and potential future approaches. There are existing technological solutions in various source sectors and we list the main sectors below, including cleaner cookstoves, cleaner brick kilns, diesel particulate filters, the Happy Seeder, solar powered irrigation pumps (SPIP) and others that will most likely be effective in mitigating air pollution in the HKH.

\subsubsection{Cookstoves}

In order to mitigate the prevalent HAP problem in developing countries, a large research effort has centred on intervention studies and the development of so-called "improved cookstoves". These stoves are optimized for fuel efficiency or to minimize HAP (Rehfuess et al. 2014). Installing a stovepipe to vent pollution out of the household is one example. Such stoves can improve health (Ezzati et al. 2004), reduce climate change impact, and be cost effective (Baillis et al. 2009). However, many of these intervention programmes, including those using the Kyoto Protocol's Clean Development Mechanism, have failed (Clark and Peel 2014; Rehfuess et al. 2014). The local residents often do not adopt these improved cookstoves and even if they do, the traditional cookstoves are in many cases used simultaneously, leading to no health benefits or any significant reduction of HAP (Edwards et al. 2007). On the other hand, in some parts of Tibet, there are households that have installed improved cookstoves for comfort or convenience, although awareness of HAP is non-existent and no intervention programmes have taken place. Here again, however, we find that the installation of an improved cookstove by itself does not necessarily lead to adequate indoor air quality. In short, the installation of improved cookstoves has not contributed to HAP reduction as intended. While improved solid-fuel stoves can reduce air pollution, the existing generation of stoves does not do so by enough to provide significant health benefits (Edwards et al. 2007).

There are numerous potential reasons as to why cookstove interventions have failed, including stove design, cultural obstacles, and inappropriateness for local cooking needs. Another major reason is that the prioritization of other basic needs by the local residents (Martin et al. 2011; Mobarak et al. 2012) and the complex interactions between technology, human behaviour, economics, and infrastructure (Jin et al. 2006) have not been sufficiently considered.

Switching to LPG, biogas, or electricity is more promising in some countries where it will be more readily available. Subsidies, credit, and marketing can help in moving households to clean fuels. Subsidies to biogas can be expanded by using a voluntary climate change mitigation approach developed by parties to the United Nations Framework Convention on Climate Change called REDD+ schemes (Somanathan and Bluffstone 2015). The expansion of rural electricity access in Bhutan resulted in the percentage of rural households having electric rice cookers increasing from about $20 \%$ in 2003 to about $80 \%$ in 2012 (Bhutan Living Standards Survey 2013), presumably substituting some solid fuel with electricity and thus reducing emissions.

\subsubsection{Brick Kilns}

Seven main brick kiln types exist in and surrounding the HKH: clamp kiln, moveable chimney Bull's trench kiln (MCBTK), fixed chimney Bull's trench kiln (FCBTK), zig-zag kiln, vertical shaft brick kiln (VSBK), Hoffman kiln, and tunnel kiln. MCBTK used to be most popular technology in the region but since it was banned across Nepal in 2012, following the ban in the Kathmandu Valley and in India in 2003, FCBTK is now the most widely used technology in the HKH. Bangladesh, however, has not banned MCBTK, which is therefore still ubiquitous in some parts of the country. MCBTK and FCBTK are both continuous, moving fire kiln types, where the fire always stays on and different parts of the kiln are used to warm, fire, and cool bricks simultaneously. Seventy-nine percent of bricks (260 billion) are considered to be produced by this method in India, Pakistan, Bangladesh, and Nepal (Greentech 2014). 
This is the most polluting of all the brick kiln types and commonly used fuels include coal, biomass, agricultural residue, and industrial waste.

A zig-zag kiln is very similar to FCBTK with a continuous, moving fire, with the main difference being that the air flow within the kiln follows a zig-zag pattern around the bricks being baked, rather than the oval shape of the kiln. It also uses coal, biomass, and industrial waste as fuel. In VSBK, the ware moves, rather than the fire, creating counter-current heat exchange between air moving upward and bricks moving downward, and it uses coal as major fuel. The Hoffman kiln is a continuous, moving fire kiln that is semi-mechanized. It uses wood and coal as fuel. Like VSBK, the tunnel kiln is a continuous moving ware kiln. Clay products are passed on cars through a horizontal tunnel to be fired in a production process. This is a completely mechanized system and is considered to be the most advanced technology. It uses coal and petcoke as fuel. There are only a limited number of these in the HKH.

Emissions can be reduced significantly by upgrading kiln technology (Schmidt 2013). For example, shifting from the intermittent kilns such as clamp kilns or continuous kilns, including Hoffman or Bull's trench, to a more efficient type, such as vertical shaft (VSBK), would lead to reduced fuel consumption and lower emissions of air pollutants as well as $\mathrm{CO}_{2}$. Use of alternative building materials, like hollow and perforated bricks or compressed unbaked bricks, should also be encouraged, since they require less raw material and energy to fire. Implementation of the new technologies and building materials, however, is not easy because of the cost associated with such changes. Increased availability of financial incentives for new technologies and stricter policies on emissions from brick kilns is essential for effective mitigation.

\subsubsection{Mitigating Transport Emissions}

There are several approaches to reducing transport emissions in the HKH. One approach is to implement emission standards along with fuel quality standards. For this, catalytic converters in gasoline and diesel vehicles will be particularly useful in mitigating air pollutant emissions. Studies have found that complying with the Euro 3 standards in the $\mathrm{HKH}$ would lead to significantly reduced transport emissions (Saikawa et al. 2011; Shrestha et al. 2013).

Another way to mitigate PM emissions effectively from the transport sector is using a diesel particulate filter (DPF). A DPF is a device mounted in the diesel vehicle's exhaust system as an after-treatment device to remove PM from the exhaust. It is usually installed with a catalyst that is programmed to burn off the accumulated PM, when the filter becomes full. A DPF can reduce the amount of particulate emissions from diesel to levels comparable with compressed natural gas $(\mathrm{CNG})$ vehicles. However, DPF is only effective with diesel fuel that has a sulphur content less than $50 \mathrm{ppm}$. For many countries in the HKH, this fuel quality is currently not available.

To reduce vehicle emissions, a move to electric vehicles, as well as to CNG or LPG vehicles, is a potential option for some countries in the HKH. A decade and a half ago the Kathmandu Valley initiated the installation of 600+ electric three-wheeler vehicles called Safa Tempos to reduce emissions; in recent years, several hundred electric private vehicles have joined. For countries such as Bhutan and Nepal, where its electricity is mostly from renewable sources, this option is extremely beneficial and effective in mitigating air pollution from the transport sector. Pakistan has been leading the installation of $\mathrm{CNG}$ vehicles in the world until the 2000s, and several countries in the region have followed suit to convert taxis and some diesel buses in various cities. For countries such as Bangladesh, retrofitting conventional vehicles with $\mathrm{CNG}$ will be a better option.

For mitigating emissions from the transport sector, three ingredients are essential: stringent policies to reduce emissions, governmental mechanisms to incentivize the change through tax reduction on cleaner vehicles or subsidies for cleaner fuel, and inspection and maintenance.

\subsubsection{Other Sources-Agricultural Burning, Burning of Garbage and Emissions for Diesel Powered Irrigation Pumps}

Emissions from crop residue burning in the IGP could be reduced via subsidization and expansion of the Happy Seeder, a machine that allows wheat to be planted without removing the residue from the previous rice crop (Gupta 2014). Other alternatives are distinctly more costly for farmers (Pant 2015).

People burn garbage because of the absence or inadequacy of garbage collection services in most less-developed countries (Hoornweg and Bhada-Tata 2012). Public awareness of the health hazards of emissions from garbage burning could lead to alternative disposal via composting, especially in less dense areas. In most urban areas, however, the solution lies in better municipal solid waste collection. Increasing awareness of the problem could help build public support and pressure for financing such services.

Emissions from diesel powered irrigation pumps can be reduced by replacing these with solar powered irrigation pumps. 


\subsubsection{Incentives and Behaviour Change for Improving Air Quality in the HKH}

Emissions from industry and transport require regulations to reduce emissions. Nevertheless, public awareness can also play a vital role. It seems very likely that the deluge of media reports that Delhi had the worst air quality in the world influenced the January 2016 advancement of the time schedule for introducing Euro 6-equivalent standards for fuel and new vehicles in India from 2024 to 2020 (Dallman and Bandivadekar 2016), despite opposition from the automobile industry (Mukherjee 2015). While obvious events like winter smog evoke media coverage and regulation (Wang 2015), without publicly available air quality monitoring data, news reports on Delhi's air quality would not have been possible. Monitoring can, therefore, be important for public and media awareness, which in turn influences regulatory action.

The same is potentially true for HAP reduction. For example, China has pursued improved cookstove programs in the past and the National Improved Stove Program (NISP) of the 1980s and 1990s was successful in distributing 180 million stoves across the country. However, research has indicated that NISP was not successful in adequately mitigating HAP (Edwards et al. 2007). In 2007, the Chinese government launched the One Solar Cooker and One Biomass Stove Program specifically in Tibetan regions and distributed 79,833 biomass stoves and 244,474 solar cookers over four years. In 2012, another China Clean Stove Initiative was launched (World Bank 2013). Yet the literature on interventions that seek to reduce HAP by raising knowledge and awareness is scant (Barnes 2014). It appears essential that cookstove interventions become more community based and community driven so that there is increased awareness and induced behaviour change in order to effectively mitigate HAP in the HKH. Financial incentives and policies that exploit potential co-benefits are also appropriate to nudge individuals to switch to cleaner fuel options.

\subsubsection{Planning, Policies, and Institutions for Air Quality Management in the HKH}

What infrastructure investments would reduce emissions? What are the existing institutions and policies in $\mathrm{HKH}$ countries? What broader frameworks exist today? Many of the technical options surveyed in the previous section focused on abating air pollution at the source level. But there are also upstream structural changes to the energy and transport systems that could lead to significant reductions in air pollution, some of which are SLCPs, as well as GHGs.

\subsubsection{Clean Energy}

Among the most significant changes in recent years has been the sharp increase in renewable energy. As mentioned earlier, clean energy is abundant in Bhutan and Nepal, with most electricity originating from hydropower. Both India and China have been at the forefront of efforts to scale up solar, wind, and hydropower. For instance, China's 11th and 12th Five-Year Plans contain percentage targets for renewable energy (Lin et al. 2007; Guo et al. 2014). These targets are often accompanied by policies that support investments in renewables. These include, for instance, feed-in tariffs (FIT) that pay back consumers for transferring renewable energy into the grid during off-peak times. Other sets of reforms place the onus on local governments to identify context-appropriate solutions. Cities such as Rizhao (Shandong Province) - which has become a pioneer in the use and manufacture of solar technologies — offer good examples of how local governments have innovated even before the central government's energy-saving targets (Starke 2007). There have also been similar efforts to improve energy efficiency in China's five-year plans. Among the more notable is the Top-1,000 Energy-Consuming Enterprises that pushed China's most energy-intensive firms to embrace a series of reforms to firm-level planning and management systems (Price 2008). In India, tariff from solar powered plants is at its historical low and even lower than tariff from thermal plants - thereby making solar energy quite lucrative in the long run.

\subsubsection{Urban and Transport Planning}

Rapid urbanisation and motorization in the $\mathrm{HKH}$ have contributed greatly to deteriorating air quality. The transport community divides solutions to these kinds of problems into options that (1) avoid unnecessary travel through land use planning, (2) shift travelers to more efficient modes (often through providing and upgrading public transport), and (3) improve vehicle technologies or fuels (Leather 2009). Many parts of the HKH are developing programs that draw upon the avoid-shift-improve scheme. For instance, India began implementing the Jawaharlal Nehru Urban Renewal Mission, which offered fast-growing cities fiscal transfers to improve the quality of the public transport system and surrounding roads and infrastructure (Agarwal and Zimmerman 2008). The infrastructure improvements are important, as significant levels of pollution can come from the resuspended dust on unpaved or poorly paved roads (Guttikunda and Koppaka 2012).

Some of the transport solutions will need to focus on emissions from diesel vehicles. A well-designed diesel control strategy will require not only tightening emissions standards that enable the installation of control technologies (particulate filters), but also improving fuel quality to ensure that sulphur does not degrade the operation of those 
technologies (Minjares and Rutherford 2010). In recent years, some countries in the $\mathrm{HKH}$ have adopted tighter emissions and fuel quality standards - often with large cities such as Beijing and Delhi leading the way. These reforms will help mitigate emissions from new vehicles; a more challenging issue is the inspection and maintenance (I\&M) of existing vehicles. A small percentage of so-called super-emitting vehicles can be responsible for more than $50 \%$ of emissions. Unfortunately, I\&M programs for diesel have proven notoriously difficult to design and operate effectively in developing country contexts (Hausker 2004).

In Nepal, the ban on the import of new three-wheelers and two-stroke engine vehicles in 1991 and 1992, respectively, marked the initial government efforts to combat air pollution from the road transport sector. The first in-use vehicle emission standard was introduced in 1995 and the vehicle emission testing and control system was implemented in the same year. In 1999, Nepal started importing unleaded fuel, removed highly polluting diesel three-wheelers, and enforced the Green Sticker system to enhance vehicle emission testing and control. In 2004, two-stroke three-wheelers and 20-year-old taxis were removed from Kathmandu, and the ban on the plying of 20-year-old public transport vehicles inside Kathmandu Valley was implemented as well. For emission standards, Government of Nepal (GoN) introduced the Euro 1 equivalent norms for new vehicles in 2000, and started supplying Euro 3 standard fuel in 2010. In addition, since 2007, GoN started collecting a pollution tax of NPR 0.5 from each litre of petrol and diesel sold in Kathmandu Valley. While the necessary policies are in place, compliance remains a challenge.

As growing motorized vehicle fleets have made many streets more dangerous, the fraction of people walking or using bicycles has decreased. Urban transport planning that not only focuses on motorized vehicles, but also provides sufficient safe space and cross-city pathways for non-motorized transport is important both to keep air pollution down and to promote the health benefits of physical exercise.

\subsubsection{National Ambient Air Quality Standards and Air Quality Management in the HKH}

Table 10.2 illustrates the national ambient air quality standards implemented in each of the countries in the HKH, as well as the three WHO interim targets and the WHO air quality guideline.

\subsubsection{Air Quality Management Institutions}

Institutional arrangements that enable interagency coordination and actively engage multiple stakeholders are critical to managing air pollution problems. One of the main constraints in the HKH (and elsewhere) has been the lack of clear division of roles and responsibilities and the absence of a coordinating mechanism that could break down agency silos (ICIMOD 2007). Many of the HKH countries lack a coherent air pollution institutional framework and clear responsibilities for air quality management of each stakeholder. The institutional framework for air quality management in Nepal (Box 10.7) illustrates why better coordination is needed.

Box 10.7 Nepal's air quality management institutional framework

The institutional framework for air quality management in Nepal involves four ministries and seven departments and centres, as well as four local agencies and institutions such as municipalities and traffic police. The framework is divided into two parts corresponding with respective managing functions-policy making and implementation. Policymaking responsibilities are handled chiefly by the four ministries: the Ministry of Industry (MoI), Ministry of Forest and Environment (MoFE), Ministry of Physical Infrastructure \& Transport (MoPIT), and Ministry of Urban Development (MoUD). MoFE is mainly responsible for the environmental protection-related policy making and supervision. MoI and MoPIT are charged with the policy making and supervision related to the industry and transportation sectors, respectively. Since road transport and industries such as brick kilns and cement factories are significant air pollution sources in Nepal, industrial and transportation policies have considerable impacts on air quality. MoUD plays a critical role in the framework, managing urban planning and developing road standards.

Within the ministries, there are several departments and institutions, such as the Department of Environment, which is responsible for the development of vehicle emission standards, and the Department of Transport Management, which is responsible for vehicle inspection and registration. Further, Nepal's Bureau of Standards and Metrology is in charge of fuel quality. Besides ministries and departments, local governments and institutions also contribute to the Kathmandu Valley's air quality control. For example, on-street vehicle emission inspections are often undertaken by the traffic police. Furthermore, although the Environment Protection Council, formed under the chairmanship of the Prime Minister, was intended to be a high-level body that could help with interagency coordination, it did not meet from the early 2000s until 2017. 


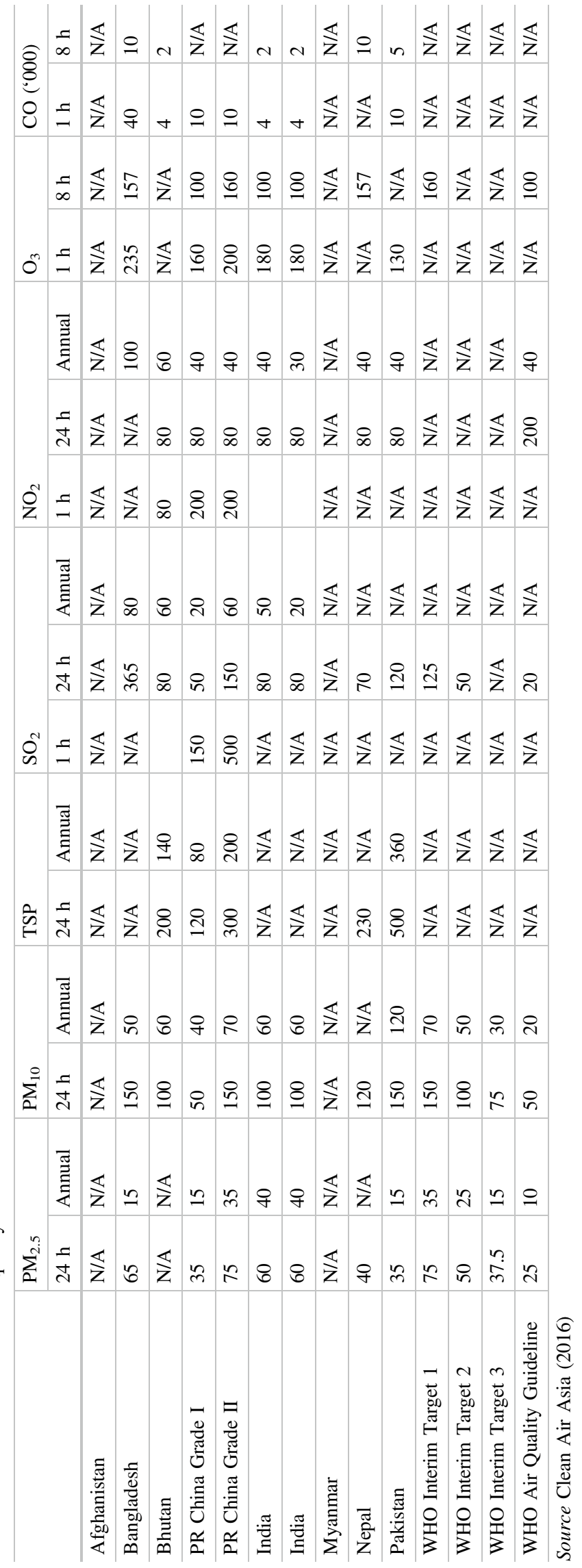


There is some evidence of reforms in the region that have helped overcome some of these institutional challenges. In China, the performance of local officials on many of the air pollution targets is being used to determine whether and where officials will be promoted (Guo et al. 2014; Young et al. 2015). Meanwhile, in Delhi, India, the judicial system played an instrumental role in public transport introducing less polluting CNG (Goyal 2003).

\subsubsection{Air Quality Management Programs and Initiatives in the HKH}

China has instituted a series of increasingly stringent regulations to curb emissions of $\mathrm{PM}_{2.5}$. These followed a set of serious smog episodes that beset Beijing and other cities in 2013. In response to the growing public concerns over the smog, the Ministry of Environmental Protection (MEP) published Guidelines for Preparing Emergency Response Plans for Heavy Air Pollution in Cities in May 2013 (General Office of the Ministry of Environmental Protection 2013). Air pollution was also deemed important by the top leaders of the Chinese government, and in September 2013, the State Council issued the Action Plan for Air Pollution Prevention and Control (State Council 2013). One week later, the MEP, together with five other ministries, jointly issued the Detailed Implementation Guidelines for Carrying Out the Plan for Air Pollution Prevention and Control in Beijing-Tianjin-Hebei and Surrounding Areas (Ministry of Environmental Protection 2013).

In addition to the aforementioned initiatives by China, there are also other intergovernmental agreements and frameworks in the HKH to reduce air pollution. We list some of the major ones below to illustrate the current efforts and emphasize the need for more collaboration within the region.

Malé Declaration on Transboundary Air Pollution (19982016)

The Malé Declaration on Control and Prevention of Air Pollution and Its Likely Transboundary Effects for South Asia was created in 1998 to bring together Bangladesh, Bhutan, India, Iran, Maldives, Nepal, Pakistan, and Sri Lanka in addressing transboundary air pollution and consequential impacts in South Asia. The agreement was signed by the Governing Council of South Asia Cooperative Environment Program (SACEP) and implemented by the United Nations Environment Programme (UNEP) and SACEP with funding from the Swedish International Development Cooperation Agency. The agreement has made progress on science and gained financial support from the Indian government that could increase ownership and influence. Bangladesh, Bhutan, Nepal, and Sri Lanka have submitted their national emissions inventory as a part of the agreement to prevent transboundary air pollution. There were five phases in total until 2016 and the main activities also included air pollution monitoring and modeling; health, crop, ecosystem, and corrosion impact assessment; integrated assessment modeling; development of policy responses; and awareness raising activities. More information can be found at http://www.sacep.org/?page_id=2725.

\section{The Acid Deposition Monitoring Network in East Asia} (EANET) (1993-Current)

EANET covers 13 countries and receives technical support from the Asia Centre for Air Pollution Research as the network centre in Niigata, Japan. The UNEP Regional Resource Centre for Asia and the Pacific serves as the EANET Secretariat. EANET has concentrated on compiling, evaluating, exchanging, and disseminating data. The network has made progress in standardizing and strengthening monitoring and building capacity, but most of this progress has been on science, not policy. Some have concluded that EANET is at the same point as Europe's Convention on Long-Range Transboundary Air Pollution (CLRTAP) in the late 1970s (see discussion of other networks) and that strengthening the implementation of national actions may be more productive than aspiring to emission targets and compliance mechanisms characteristic of a hard-law agreement (Schreurs 2011). More information can be found at http://www.eanet.asia.

\section{Asia Pacific Clean Air Partnership (2014-Current)}

The Asia Pacific Clean Air Partnership (APCAP) was launched in 2014 as a mechanism that has as one of its main goals bringing together many regional air pollution agreements in Asia. To help achieve that goal, a Joint Forum was first convened that same year. The Joint Forum aims enable countries and officials associated with different air pollution agreements to discuss pragmatic approaches to improving air quality. A second goal of the APCAP is to equip the region's policy makers with the most recent atmospheric science. To help achieve this goal, an APCAP science panel was created with eminent scientists in the region. Many of the panel members are contributing to a high-profile assessment report on air pollution in the Asia Pacific region. The assessment report will be the shared output of APCAP and the Climate and Clean Air Coalition.

\section{Climate and Clean Air Coalition (2012-Current)}

The Climate and Clean Air Coalition (CCAC) was launched in 2012 with seven initial partners (the governments of Bangladesh, Canada, Ghana, Mexico, Sweden, and the United States, along with the UNEP) to improve air quality and climate by reducing SLCPs, especially focusing on BC, 
methane, and hydrofluorocarbons (HFCs). It has now expanded to more than 50 country partners and even more non-state partners, although to date Bangladesh and Pakistan are the only $\mathrm{HKH}$ countries. The CCAC does not intend to promote actions on SLCPs (BC, HFCs, methane and tropospheric $\mathrm{O}_{3}$ ) as a substitute to mitigating $\mathrm{GHG}$; rather it recognizes the importance of complementing and supplementing GHG emissions under the United Nations Framework Convention on Climate Change. The CCAC aims to achieve its objectives through a set of seven sector-specific (diesel, waste management, brick kilns) and four cross-cutting (national action planning, urban health) initiatives. Each of these initiatives functions by raising awareness of impacts and mitigation strategies, improving scientific understanding of their impacts, and enhancing and developing national as well as regional actions. More information can be found at http://www.ccacoalition.org/en.

\section{Other Sector-Specific Mechanisms}

One of the mechanisms aiming to reduce emissions from residential cookstoves is the Global Alliance for Clean Cookstoves. The Global Alliance was established in 2010 as a private-public partnership with the explicit goal of increasing the number of clean cookstoves to 100 million by 2020 . The Global Alliance works with national governments, non-governmental organizations, and the private sector to raise awareness, strengthen scientific evidence, develop standards and labels, and explore innovative financing for clean cookstoves programmes. The alliance shares a close relationship with the Partnership for Clean Indoor Air, which has focused on capacity building, technical assistance, project implementation, and knowledge management on indoor air pollution, household energy, and health. For several years, UNEP has worked with partners on Project Surya on a people-centred approach to support clean cookstoves in India. More information can be found at http://cleancookstoves.org.

There are also several mechanisms with the potential to provide support on clean diesel. The Partnership for Clean Fuels and Vehicles (PCFV) was launched at the World Summit on Sustainable Development in 2002 to assist developing countries in reducing mobile source air pollution. Having achieved success with the removal of lead, the PFCV is now working on lowering sulphur levels in diesel to below $50 \mathrm{ppm}$. Lowering sulphur levels would be a necessary precondition for installing diesel after-treatment devices. The PCFV has also gathered valuable insights into the aforementioned I\&M programmes.

\section{Relevant Experiences from Elsewhere}

CLRTAP is one of the best known regional frameworks for reducing transboundary air pollution. It includes the first treaty in 1979 and eight associated protocols between 1984 and 1999 to reduce emissions of selected air pollutants in Europe and North America. CLRTAP offers an example of a science-based, legally binding convention that has been successfully implemented over the years. Each contracting party is responsible for developing the best policies and strategies, and CLRTAP emphasizes the control measures that are both economically feasible and the best available technology. It is also important to recognize the exchange of information that was essential among the countries.

Within Asia itself, another initiative is the ASEAN Haze Agreement. The agreement recognizes the problem of forest fires on air pollution, as well as the economic loss associated with it. Prevention, operational mechanisms, and enforcement are all included in the agreement.

\subsection{Key Challenges in Reducing Air Pollution in the HKH}

It is clear that rapid urbanisation and other changes in the $\mathrm{HKH}$ and surrounding areas have brought increased emissions from industry and transport that require regulation to reduce emissions. There are several key challenges to effectively mitigating the air pollution issues in the $\mathrm{HKH}$, and in this section we list several major challenges in the region.

\subsubsection{Recognition of Air Pollution as a Problem and Co-benefits of Mitigation}

It is essential for the $\mathrm{HKH}$ country governments to recognize air pollution as a problem and to implement effective measures to mitigate it. Health benefits from mitigating air pollution are undeniably the most important and strategies that aim to achieve such benefits from reducing PM emissions from the transport sector and solid fuel use in cookstoves have significant potential in the region (UNEP 2011). Another important source of PM emissions, as illustrated earlier, is brick kilns. Cost-effective measures need to be scaled up to reduce these emissions.

In some cases, measures targeting SLCPs, especially BC, tropospheric $\mathrm{O}_{3}$, and methane, will lead to co-benefits, including improved public health, reduced crop-yield losses, and reduced climate change impacts (UNEP 2011). There is sufficient evidence of BC concentrations increasing adverse health impacts, including all-cause and cardiovascular mortality, and cohort studies also provide similar evidence of long-term average BC exposure with these mortalities (Janssen et al. 2012). From such measures targeting SLCPs, the greatest benefit for regional climate is expected in the HKH (UNEP/WMO 2011). 


\subsubsection{Transboundary Pollution Flows, Collaborations, and Cooperation}

The regional air pollution problems, including winter haze and fog, have strong implications for the region. As detailed in the previous sections, air pollution is a transboundary issue and has impacts on the region-wide weather, climate, and agriculture, as well as socioeconomic sectors. A coordinated South Asian effort is thus necessary to better understand the processes governing the severity of the regional air pollution in the HKH. Regional coordination and collaboration is essential to enhance the mitigation at the local and national levels (UNEP 2011).

Legally binding regional agreements, similar to the CLRTAP and the ASEAN Haze Agreement, could be used to provide a platform for policy action on controlling air pollution. Intergovernmental initiatives like the Malé Declaration could be an important basis for developing necessary scientific knowledge, in addition to raising awareness and enhancing capacity building for improving air quality in the region. In the $\mathrm{HKH}$, where the impact of $\mathrm{BC}$ on climate change is clearly visible, coordinated regional action as seen in the Arctic is particularly important (UNEP 2011).

\subsubsection{Implementation Gaps and Challenges}

As highlighted in the previous section, there is no shortage of solutions to help manage air pollution in the HKH. Furthermore, in many cases the recommended policy options have already been promulgated in the region. There are, however, several persistent implementation gaps that separate what is written on paper from what is achieved on the ground. This section discusses some of the barriers behind these implementation gaps.

The vast majority of technical solutions require supportive technologies infrastructure to be implemented effectively. This is particularly true for transportation. Improvements in the quality and coverage of public transport, for instance, will fail to generate significant reductions unless there are well-paved and thoughtfully designed roads and hubs. Similarly, the penetration and diffusion of large-scale renewable installations depends heavily on the quality and quantity of the electricity grid. Supportive technologies also play a role in enabling the introduction and diffusion of smaller scale technologies. To illustrate, switching from biomass-based cookstoves to those powered by cleaner fuels requires infrastructure that can deliver a dependable supply of those fuels. In many cases, it is the combined absence of multiple supportive technologies that leads to a condition known as "lock-in," referring to the frequently observed resistance to change that permeates energy systems (Unruh 2000, 2002).
Another set of policy and institutional barriers can also lock in the current technologies and place a drag on reform. Arguably, the most prominent set of policy barriers involve energy subsidies. In many parts of the world, governments provide resources to bring down the costs of fossil fuels. However, in many cases these price supports have had the unintended consequence of placing cleaner fuels and energy sources at a price disadvantage. For example, excessively high subsidies (up to $90 \%$ some cases) on solar powered irrigation pumps in some states in India has reduced incentives for technical innovations on the one hand and limited the adoption to only the richest and politically connected farmers (Kishore et al. 2014). More troubling still is that efforts to rein in subsidies are often met with political backlash and reprisals that can force governments to reverse decisions to curb price supports. Further, while subsidies are intended to benefit chiefly the poor, they often bring disproportionate benefits to companies that extract and refine fuels and wealthier segments of the population (Coady et al. 2015).

A related set of barriers involves the institutions that are chiefly responsible for designing and implementing air pollution regulations. As mentioned in the discussion of air quality institutions, interagency coordination can be a major constraint on needed policy reforms. The majority of air pollution problems require more than one agency working together; absent institutional arrangements to facilitate that coordination, policy formulations are likely to be flawed from their inception. More commonly, a lack of institutional coordination surfaces as a barrier during policy implementation. This is particularly true because government agencies in some cases have missions that are closely aligned with those of the polluting entities. The end result can be that while one branch of the government works to enforce regulations, another works at cross-purposes to flout those regulations (Rock 2002; Bhatt et al. 2008).

A third set of institutional barriers relates to administrative capacities. There are multiple ways that a lack of capacity can impinge on regulatory enforcement. Arguably, the most obvious is that an insufficient workforce makes it difficult to enforce regulations. There is, however, also the need not just for sufficient numbers of people, but for people who possess needed skills and knowledge. Well-trained staff are particularly important for a policy area such as air pollution, as the topic is inherently complex and thus requires a clear understanding of the links between source, emissions, and impacts. Finally, it is worth noting that capacity is not simply necessary for effective enforcement; it can also prove useful in conceiving of innovative incentives for behavioural and lifestyle changes that may prevent emissions in the first place (Li and Zusman 2006; World Bank 2007).

A final set of challenges involves some of the regional and global air pollution initiatives discussed previously. 
Many scholars of international relations suggest that these institutions would not struggle to regulate the behaviour of governments. The fact that these institutions focus on different countries and pollutants and tend to focus more on information sharing and raising awareness suggests there may be some merit to these claims. At the same time, there is also a body of literature that argues that information sharing and raising awareness play an important though less obvious role in shaping the interests of governments when it comes to transboundary environmental problems (Mitchell 2003, 2006). It is clear that for reducing air pollution in the HKH, policies for mitigation need to be implemented together with enhanced education and awareness-raising campaigns within and surrounding the HKH.

\section{References}

Adhikary, B., Carmichael, G. R., Tang, Y., Leung, L. R., Qian, Y., Schauer, J. J., et al. (2007). Characterization of the seasonal cycle of south Asian aerosols: A regional-scale modeling analysis. Journal of Geophysical Research, 112(D22), D22S22. http://doi.org/10. 1029/2006JD008143.

Agarwal, O. P., \& Zimmerman, S. L. (2008). Toward sustainable mobility in urban India. Transportation Research Record: Journal of the Transportation Research Board, 2048, 1-7.

Agrawal, S. (2012). Effect of indoor air pollution from biomass and solid fuel combustion on prevalence of self-reported asthma among adult men and women in India: Findings from a nationwide large-scale cross-sectional survey. Journal of Asthma, 494(4), 355365. https://doi.org/10.3109/20770903.2012.663030.

Ali, K., Momin, G. A., Tiwari, S., Safai, P. D., Chate, D. M., \& Rao, P. S. P. (2004). Fog and precipitation chemistry at Delhi, North India. Atmospheric Environment, 38(25), 4215-4222. https://doi org/10.1016/j.atmosenv.2004.02.055.

Allred, E. N., Bleecker, E. R., Chaitman, B. R., Dahms, T. E., Gottlieb, S. O., Hackney, J. D., et al. (1989). Short-term effects of carbon monoxide exposure on the exercise performance of subjects with coronary artery disease. The New England Journal of Medicine, 321 (21), 1426-1432. http://doi.org/10.1056/NEJM198911233212102.

Andreae, M. O., \& Merlet, P. (2001). Emission of trace gases and aerosols from biomass burning. Global Biogeochemical Cycles, 15(4), 955-966.

Armstrong, B. G., \& Gibbs, G. (2009). Exposure-response relationship between lung cancer and polycyclic aromatic hydrocarbons (PAHs). Occupational and Environmental Medicine, 66(11), 740-746. https://doi.org/10.1136/oem.2008.043711.

Aryal, R. K., Lee, B. K., Karki, R., Gurung, A., Kandasamy, J., Pathak, B. K., et al. (2008). Seasonal PM10 dynamics in Kathmandu Valley. Atmospheric Environment, 42(37), 8623-8633. http://doi. org/10.1016/j.atmosenv.2008.08.016.

Aryal, R. K., Lee, B. K., Karki, R., Gurung, A., Baral, B., \& Byeon, S. H. (2009). Dynamics of PM2.5 concentrations in Kathmandu Valley, Nepal. Journal of Hazardous Materials, 168(2-3), 732738. http://doi.org/10.1016/j.jhazmat.2009.02.086.

Asian Productivity Organization. (2007). Solid-waste management issues and challenges in Asia. Report of the APO Survey on Solid-Waste Management 2004-05. Published by the Asian Productivity Organization. ISBN: 92-833-7058-9.

Avnery, S., Mauzerall, D. L., Liu, J., \& Horowitz, L. W. (2011). Global crop yield reductions due to surface ozone exposure: 1 . Year 2000 crop production losses and economic damage. Atmospheric Environment, 45(13), 2284-2296. http://doi.org/10.1016/j.atmosenv. 2010.11.045.

Babu, S. S., Moorthy, K. K., Manchanda, R. K., Sinha, P. R., Satheesh, S. K., Vajja, D. P., et al. (2011a). Free tropospheric black carbon aerosol measurements using high altitude balloon: Do BC layers build "their own homes" up in the atmosphere? Geophysical Research Letters, 38(8). http://doi.org/10.1029/2011GL046654.

Babu, S. S., Chaubey, J. P., Krishna Moorthy, K., Gogoi, M. M., Kompalli, S. K., Sreekanth, V., et al. (2011b). High altitude ( $\sim 4520 \mathrm{~m} \mathrm{amsl})$ measurements of black carbon aerosols over western trans-Himalayas: Seasonal heterogeneity and source apportionment. Journal of Geophysical Research: Atmospheres, 116 (D24). http://doi.org/10.1029/2011JD016722.

Babu, S. S., Manoj, M. R., Moorthy, K. K., Gogoi, M. M., Nair, V. S., Kompalli, S. K., et al. (2013). Trends in aerosol optical depth over Indian region: Potential causes and impact indicators. Journal of Geophysical Research Atmospheres, 118(20), 11794-11806. http:// doi.org/10.1002/2013JD020507.

Balakrishnan, K., Sambandam, S., et al. (2004). Exposure assessment for respirable particulates associated with household fuel use in rural districts of Andhra Pradesh, India. Journal of Exposure Analysis and Environmental Epidemiology, $1(14$ Suppl), S14-S25.

Balakrishnan, K., Ramaswamy, P., Sambandam, S., Thangavel, G., Ghosh, S., Johnson, P., et al. (2011). Air pollution from household solid fuel combustion in India: An overview of exposure and health related information to inform health research priorities. Global Health Action, 4, 1-9. http://doi.org/10.3402/gha.v4i0.5638.

Baillis, et al. (2009). Arresting the killer in the kitchen: The promises and pitfalls of commercializing improved cookstoves. World Development, 37(10), 1694-1705.

Bangladesh DHS (Demographic and Health Survey). (2011). Retrieved January, 2013, from http://dhsprogram.com/publications/ publication-FR265-DHS-Final-Reports.cfm.

Barnes, B. R. (2014). Behavioural change, indoor air pollution and child respiratory health in developing countries: A review. International Journal of Environmental Research and Public Health, 11 (5), 4607-4618. https://doi.org/10.3390/ijerph110504607.

Beaulieu, J. J., Tank, J. L., Hamilton, S. K., Wollheim, W. M., Hall, R. O., Mulholland, P. J., et al. (2011). Nitrous oxide emission from denitrification in stream and river networks. Proceedings of the National Academy of Sciences of the United States of America, 108 (1), 214-219. http://doi.org/10.1073/pnas.1011464108.

Beegum, S. N., Moorthy, K. K., Babu, S. S., Satheesh, S. K., Vinoj, V., Badarinath, K. V. S., et al. (2009). Spatial distribution of aerosol black carbon over India during pre-monsoon season. Atmospheric Environment, 43(5), 1071-1078. http://doi.org/10.1016/j.atmosenv. 2008.11.042.

Bell, M. L., \& Davis, D. L. (2001). Reassessment of the lethal London fog of 1952: Novel indicators of acute and chronic consequences of acute exposure to air pollution. Environmental Health Perspectives, 109(3), 389-394.

Bhatt, M. S., Ashraf, S., \& Illiyan, A. (2008). Problems and prospects of environment policy: Indian perspective. New Delhi: Aakar Books.

Bhutan Living Standards Survey. (2013). Government of Bhutan and Asian Development Bank.

Bisht, G., \& Neupane, S. (2015). Impact of Brick Kilns' emission on soil quality of agriculture fields in the vicinity of selected Bhaktapur Area of Nepal. Applied and Environmental Soil Science. http://doi. org/10.1155/2015/409401.

Biswas, K. F., Ghauri, B. M., \& Husain, L. (2008). Gaseous and aerosol pollutants during fog and clear episodes on South Asian urban atmosphere. Atmospheric Environment, 42, 7775-7785. 
Bollasina, M., Ramaswamy, V., \& Ming, Y. (2011). Anthropogenic aerosols and the weakening of the South Asian summer monsoon. Science, 334(6055), 502-505. https://doi.org/10.1126/science. 1204994.

Bollasina, M. A., Bertolani, L., \& Tartari, G. (2002). Meteorological observations in the Khumbu Valley, Nepal Himalayas, 1994-1999. Bulletin of Glaciological Research, 19, 1-11.

Bonasoni, P., Laj, P., Angelini, F., Arduini, J., Bonafè, U., Calzolari, F., et al. (2008). The ABC-Pyramid Atmospheric Research Observatory in Himalaya for aerosol, ozone and halocarbon measurements. Science of the Total Environment, 391, 252-261.

Bonasoni, P., Laj, P., Marinoni, A., Sprenger, M., Angelini, F., Arduini, J., et al. (2010). Atmospheric brown clouds in the Himalayas: First two years of continuous observations at the Nepal Climate Observatory-Pyramid (5079 m). Atmospheric Chemistry and Physics, 10(15), 7515-7531. https://doi.org/10.5194/acp-107515-2010.

Bonasoni, P., Cristofanelli, P., Marinoni, A., Vuillermoz, E., \& Adhikary, B. (2012). Atmospheric pollution in the Hindu Kush-Himalaya Region. Mountain Research and Development, 32 (4), 468-479. https://doi.org/10.1659/MRD-JOURNAL-D-1200066.1.

Booker, F., Muntifering, R., McGrath, M., Burkey, K., Decoteau, D., Fiscus, E., et al. (2009). The ozone component of global change: Potential effects on agricultural and horticultural plant yield, product quality and interactions with invasive species. Journal of Integrative Plant Biology, 51(4), 337-351.

Boy, E., Bruce, N., et al. (2002). Birth weight and exposure to kitchen wood smoke during pregnancy in rural Guatemala. Environmental Health Perspectives, 110(1), 109-114.

Brook, R. D., Rajagopalan, S., Pope III, C. A., Brook, J. R., Bhatnagar, A., Diez-Roux, A. V., et al. (2010). Particulate matter air pollution and cardiovascular disease. An update to the Scientific Statement from the American Heart Association. Circulation, 121(21), 2331-2378.

Bruce, N., Perez-Padilla, R., \& Albalak, R. (2000). Indoor air pollution in developing countries: A major environmental and public health challenge. Bulletin of the World Health Organization, 78, 1078-1092.

Bruce, N., Weber, M., et al. (2007). Pneumonia case-finding in the RESPIRE Guatemala indoor air pollution trial: Standardizing methods for resource-poor settings. Bulletin of the World Health Organization, 85(7), 535-544.

Bruce, N., Rehfuess, E., et al. (2006). Indoor air pollution. In D. T. Jamison, J. G. Breman, A. R. Measham, et al. (Eds.), Disease control priorities in developing countries, Chapter 42 (2nd ed.). World Bank, Washington, DC. Retrieved from: http://www.ncbi. nlm.nih.gov/books/NBK11760/.

Brun, J., Shrestha, P., \& Barros, A. P. (2011). Mapping aerosol intrusion in Himalayan valleys using the Moderate Resolution Imaging Spectroradiometer (MODIS) and Cloud-Aerosol Lidar and Infrared Pathfinder Satellite Observation (CALIPSO). Atmospheric Environment, 45, 6382-6392.

Burstyn, I., Boffetta, P., Heederik, D., Partanen, T., Kromhout, H., Svane, O., et al. (2003). Mortality from obstructive lung diseases and exposure to polycyclic aromatic hydrocarbons among asphalt workers. American Journal of Epidemiology, 158(5), 468-478. http://doi.org/10.1093/aje/kwg180.

Cao, J.-J., Xu, B.-Q., He, J.-Q., Liu, X.-Q., Han, Yo.-M., Wang, G., et al. (2009). Concentrations, seasonal variations, and transport of carbonaceous aerosols at a remote Mountainous region in western China. Atmospheric Environment, 43, 4444-4452.

Cao, J., Chow, J. C., Lee, F. S. C., \& Watson, J. G. (2013). Evolution of $\mathrm{PM}_{2.5}$ measurements and standards in the U.S. and future perspectives for China. Aerosol and Air Quality Research, 13(4), 1197-1211. http://doi.org/10.4209/aaqr.2012.11.0302.

Carrico, C. M., Bergin, M. H., Shrestha, A. B., Dibb, J. E., Gomes, L., \& Harris, J. M. (2003). The importance of carbon and mineral dust to seasonal aerosol properties in the Nepal Himalaya. Atmospheric Environment, 37, 2811-2824.

Chakraborty, A., Bhattu, D., Gupta, T., Tripathi, S. N., \& Canagaratna, M. R. (2015). Real-time measurements of ambient aerosols in a polluted Indian city: Sources, characteristics and processing of organic aerosols during foggy and non-foggy periods. Journal of Geophysical Research, 120, 9006-9019. https://doi.org/10.1002/ $2015 \mathrm{jd} 023419$.

Che, H., Wang, Y., \& Sun, J. (2011). Aerosol optical properties at Mt. Waliguan Observatory. China Atmospheric Environment, 45, 60046009.

Chen, S., Huang, J., Zhao, C., Qian, Y., Leung, L. R., \& Yang, B. (2013). Modeling the transport and radiative forcing of Taklimakan dust over the Tibetan Plateau: A case study in the summer of 2006. Journal of Geophysical Research: Atmospheres, 118(2), 797-812. https://doi.org/10.1002/jgrd.50122.

Chen, P. F., Li, C. L., Kang, S. C., Yan, P., Zhang, Q. G., Ji, Z. M., et al. (2016). Source apportionment of particle-bound polycyclic aromatic hydrocarbons in Lumbini, Nepal by using the positive matrix factorization receptor model. Atmospheric Research, 182, 46-53.

Cherian, R., Venkataraman, C., Quaas, J., \& Ramachandran, S. (2013). GCM simulations of anthropogenic aerosol-induced changes in aerosol extinction, atmospheric heating and precipitation over India. Journal of Geophysical Research Atmospheres, 118(7), 2938-2955.

Chhabra, S. K., Chhabra, P., Rajpal, S., \& Gupta, R. K. (2001). Ambient air pollution and chronic respiratory morbidity in Delhi. Archives of Environmental Health, 56(1), 58-64. https://doi.org/10. 1080/00039890109604055.

Chung, C., \& Ramanathan, V. (2006). Weakening of the North Indian SST gradients and the monsoon rainfall in India and the Sahel. Journal of Climate, 19, 2036-2045.

Clark, M. L., \& Peel, J. L. (2014). Perspectives in household air pollution research: Who will benefit from interventions? Current Environmental Health Reports, 1, 250-257.

Clean Air Asia. (2016). Guidance framework for better air quality in Asian cities. Retrieved from http://cleanairasia.org/ibaq-programme/.

Coady, D., Flamini, V., \& Sears, L. (2015). The unequal benefits of fuel subsidies revisited: Evidence for developing countries. Washington D.C.

Collier, J. C., \& Zhang, G. J. (2009). Aerosol direct forcing of the summer Indian monsoon as simulated by the NCAR CAM3. Climate Dynamics, 32(2-3), 313-332. https://doi.org/10.1007/ s00382-008-0464-9.

Cong, Z., Kang, S., Liu, X., \& Wang, G. (2007). Elemental composition of aerosol in the Nam Co region, Tibetan Plateau, during summer monsoon season. Atmospheric Environment, 41, $1180-1187$.

Cong, Z., Kang, S., Gao, S., Zhang, Y., Li, Q., \& Kawamura, K. (2013). Historical trends of atmospheric black carbon on Tibetan Plateau as reconstructed from a 150-year lake sediment record. Environmental Science and Technology, 47, 2579-2586.

Cong, Z., Kawamura, K., Kang, S., \& Fu, P. (2015). Penetration of biomass-burning emissions from South Asia through the Himalayas: New insights from atmospheric organic acids. Scientific Report., 5, 9580. https://doi.org/10.1038/srep09580.

Costa, S., Ferreira, J., Silveira, C., Costa, C., Lopes, D., Relvas, H., et al. (2014). Integrating health on air quality assessment-Review report on health risks of two major European outdoor air pollutants: PM and NOx. Journal of Toxicology and Environmental Health. 
Part B, Critical Reviews, 17(6), 307-340. http://doi.org/10.1080/ 10937404.2014.946164.

Cristofanelli, P., Bracci, A., Sprenger, M., Marinoni, A., Bonafè, U., Calzolari, F., et al. (2010). Tropospheric ozone variations at the Nepal Climate Observatory-Pyramid (Himalayas, $5079 \mathrm{~m}$ a.s.1.) and influence of deep stratospheric intrusion events. Atmospheric Chemistry and Physics, 10(14), 6537-6549. https://doi.org/10. 5194/acp-10-6537-2010.

Dallmann, T., \& Bandivadekar, A. (2016). India Bharat Stage Vi Emission Standards. Retrieved from http://www.theicct.org/sites/ default/files/publications/IndiaBS\%20VI\%20Policy\%20Update\% 20vF.pdf.

De, U. S., \& Dandekar, M. M. (2001). Natural disasters in urban areas. Deccan Geogr, 39(2), 1-12.

Dey, S., \& Di Girolamo, L. (2010). A climatology of aerosol optical and microphysical properties over the Indian subcontinent from 9 years (2000-2008) of Multiangle Imaging Spectroradiometer (MSIR) data. Journal of Geophysical Research, 115(D15204). http://doi.org/10.1029/2009JD013395.

Dherani, M., Pope, D., et al. (2008). Indoor air pollution from unprocessed solid fuel use and pneumonia risk in children aged under five years: A systematic review and meta-analysis. Bulletin of the World Health Organization, 86(5), 390-398.

Dhungel, S., Kathayat, B., Mahata, K., \& Panday, A. (2016). Transport of regional pollutants through a remote trans-Himalayan valley in Nepal. Atmospheric Chemistry and Physics Discussions, 1-23. https://doi.org/10.5194/acp-2016-824.

Di Girolamo, L., Bond, T. C., Bramer, D., Diner, D. J., Fettinger, F., Kahn, R. A., et al. (2004). Analysis of multi-angle Imaging SpectroRadiometer (MISR) aerosol optical depths over greater India during winter 2001-2004. Geophysical Research Letters, 31(23), 15. http://doi.org/10.1029/2004GL021273.

DoHS. (2014). Department of Health Services 2070/71 (2013/14) Annual Report. Teku, Kathmandu.

Dumka, U. C., Krishna Moorthy, K., Kumar, R., Hegde, P., Sagar, R., Pant, P., et al. (2010). Characteristics of aerosol black carbon mass concentration over a high altitude location in the Central Himalayas from multi-year measurements. Atmospheric Research, 96, 510 521.

Dumka, U. C., Kaskaoutis, D. G., Srivastava, M. K., \& Devara, P. C. S. (2015). Scattering and absorption properties of near-surface aerosol over Gangetic-Himalayan region: The role of boundary-layer dynamics and long-range transport. Atmospheric Chemistry and Physics, 15(3), 1555-1572. http://doi.org/10.5194/acp-15-15552015.

Edwards, R. D., Liu, Y., He, G., Yin, Z., Sinton, J., Peabody, J., et al. (2007). Household CO and PM measured as part of a review of China's National Improved Stove Program. Indoor Air, 17(3), 189_ 203.

Epstein, M. B., Bates, M. N., Arora, N. K., Balakrishnan, K., Jack, D. W., \& Smith, K. R. (2013). Household fuels, low birth weight, and neonatal death in India: The separate impacts of biomass, kerosene, and coal. International Journal of Hygiene and Environmental Health, 216(5), 523-532. https://doi.org/10.1016/j.ijheh.2012.12. 006.

Ezzati, M., \& Kammen, D. (2001). Indoor air pollution from biomass contribution and acute respiratory infections in Kenya: An exposure-response study. Lancet, 358, 619-624.

Ezzati, et al. (2004). Energy management and global health. Annual Review of Environmental Resources, 29.

Farmer, S. A., Nelin, T. D., Falvo, M. J., \& Wold, L. E. (2014). Ambient and household air pollution: Complex triggers of disease. American Journal of Physiology Heart and Circulatory Physiology, 307(4), H467-H476. https://doi.org/10.1152/ajpheart.00235.2014.
Firdaus, G., \& Ahmad, A. (2011). Changing air quality in Delhi, India: Determinants, trends, and policy implications. Regional Environmental Change, 11(4), 743-752. https://doi.org/10.1007/s10113011-0207-z.

Flanner, M. G., Zender, C. S., Hess, P. G., Mahowald, N. M., Painter, T. H., Ramanathan, V., et al. (2009). Springtime warming and reduced snow cover from carbonaceous particles. Atmospheric Chemistry and Physics, 9, 2481-2497. https://doi.org/10.5194/acp9-2481-2009.

Forouzanfar, M. H., \& Collaborators, G. 2013 R. F. (2016). Global, regional, and national comparative risk assessment of 79 behavioural, environmental and occupational, and metabolic risks or clusters of risks in 188 countries, 1990-2013: A systematic analysis for the Global Burden of Disease Study 2013. The Lancet, 386 (10010), 2287-2323. http://doi.org/10.1016/S0140-6736(15)001282.Global.

Foster, A., \& Kumar, N. (2011). Health effects of air quality regulations in Delhi, India. Atmospheric Environment, 45(9), 1675-1683. https://doi.org/10.1016/j.atmosenv.2011.01.005.

Fuhrer, J. (2009). Ozone risk for crops and pastures in present and future climates. Naturwissenschaften, 96, 173-194.

Gadi, R., Singh, N., Sarkar, A. K., \& Parashar, D. C. (2000). Mass size distribution and chemical composition of aerosols at New Delhi. In K. Siddappa, S. Sadasvian, V. N. Sastri, K. P. Eappen, R. K. Somashekar, \& N. Manamoha Rao (Eds.), Pollution urban environment (Vol. 488, pp. 30-32). Banglore: Banglore University.

Ganguly, D., Jayaraman, A., \& Gadhavi, H. (2006). Physical and optical properties of aerosols over an urban location in western India: Seasonal variabilities. Journal of Geophysical Research, 111 (D24206). https://doi.org/10.1029/2006jd007392.

Ganguly, D., Ginoux, P., Ramaswamy, V., Winker, D. M., Holben, B. N., \& Tripathi, S. N. (2009). Retrieving the composition and concentration of aerosols over the Indo-Gangetic basin using CALIOP and AERONET data. Geophysical Research Letters, 36 (13), 1-5. https://doi.org/10.1029/2009GL038315.

Ganguly, D., Rasch, P. J., Wang, H., \& Yoon, J. H. (2012). Climate response of the South Asian monsoon system to anthropogenic aerosols. Journal of Geophysical Research Atmospheres, 117(13), 1-20. https://doi.org/10.1029/2012JD017508.

Gautam, R., Hsu, N. C., Kafatos, M., \& Tsay, S. C. (2007). Influences of winter haze on fog/low cloud over the Indo-Gangetic plains. Journal of Geophysical Research Atmospheres, 112(5), 1-11. https://doi.org/10.1029/2005JD007036.

Gautam, R., Liu, Z., Singh, R. P., \& Hsu, N. C. (2009a). Two contrasting dust dominant periods over India observed from MODIS and CALIPSO data. Geophysical Research Letters, 36, L06813. https://doi.org/10.1029/2008g1036967.

Gautam, R., Hsu, N. C., Lau, K.-M., \& Kafatos, M. (2009b). Aerosol and rainfall variability over the Indian monsoon region: Distribution, trends, and coupling. Annales Geophysicae, 27, 3691-3703.

Gautam, R., Hsu, N. C., \& Lau, K.-M. (2010). Premonsoon aerosol characterization and radiative effects over the Indo-Gangetic Plains: Implications for regional climate warming. Journal of Geophysical Research, 115(D17), D17208. https://doi.org/10. 1029/2010JD013819.

Gautam, R., Hsu, N. C., Lau, W. K. M., \& Yasunari, T. J. (2013). Satellite observations of desert dust-induced Himalayan snow darkening. Geophysical Research Letters, 40(5), 988-993. https:// doi.org/10.1002/grl.50226.

Gautam, R. (2014). Challenges in early warning of the persistent and widespread winter fog over the indo-gangetic plains: A satellite perspective in early warning systems for climate change. In Reducing disaster: Early warning systems for climate change (pp. 51-61). 
General Office of the Ministry of Environmental Protection. (2013). Letter on issuing the guidelines for preparing emergency response plan for heavy air pollution in cities (edited).

Gertler, C. G., Puppala, S. P., Panday, A., Stumm, D., \& Shea, J. (2016). Black carbon and the Himalayan cryosphere: A review. Atmospheric Environment, 125, 404-417. https://doi.org/10.1016/j. atmosenv.2015.08.078.

Ghude, S. D., Jena, C., Chate, D. M., Beig, G., Pfister, G. G., Kumar, R., et al. (2014). Reductions in India's crop yield due to ozone. Geophysical Research Letters, 41(15), 5685-5691. https://doi.org/ 10.1002/2014GL060930.

Ghude, S. D., Bhat, G. S., Prabhakaran, T., Jenamani, R. K., Chate, D. M., Safai, P. D., et al. (2017). Winter fog experiment over the Indo-Gangetic plains of India. Current Science, 112(4). http://doi. org/10.18520/cs/v112/i04/767-784.

Giles, D. M., Holben, B. N., Tripathi, S. N., Eck, T. F., Newcomb, W. W., Slutsker, I., et al. (2011). Aerosol properties over the Indo-Gangetic Plain: A mesoscale perspective from the TIGERZ experiment. Journal of Geophysical Research, 116(D18), D18203. http://doi.org/10.1029/2011JD015809.

Ginot, P., Dumont, M., Lim, S., Patris, N., Taupin, J., Wagnon, P., et al. (2014). A 10 year record of black carbon and dust from a Mera Peak ice core (Nepal): Variability and potential impact on melting of Himalayan glaciers. The Cryosphere, 1479-1496. https://doi.org/ 10.5194/tc-8-1479-2014.

Gobbi, G. P., Angelini, F., Bonasoni, P., Verza, G. P., Marinoni, A., \& Barnaba, F. (2010). Sunphotometry of the 2006-2007 aerosol optical/ radiative properties at the Himalayan Nepal Climate ObservatoryPyramid (5079 m a.s.1.). Atmospheric Chemistry and Physics, 10(22), 11209-11221. https://doi.org/10.5194/acp-10-11209-2010.

Goyal, P. (2003). Present scenario of air quality in Delhi: A case study of CNG implementation. Atmospheric Environment, 37(38), 54235431.

Granier, C., Bessagnet, B., Bond, T., Angiola, A. D., Gon, H. D., Van Der Frost, G. J., et al. (2011). Evolution of anthropogenic and biomass burning emissions of air pollutants at global and regional scales during the 1980-2010 period. Climatic Change, 109-163. http://doi.org/10.1007/s10584-011-0154-1.

Greentech. (2014). Factsheets about brick kilns in South Asia and Southeast Asia. Retrieved October 18, 2016, from http://www. ccacoalition.org/sites/default/files/resources/Bricks-SEA.pdf.

Gul, C., Praveen, P. S., Kang, S., Adhikary, B., Zhang, Y., Ali, S., et al. (2018). Concentrations and source regions of light-absorbing particles in snow/ice in northern Pakistan and their impact on snow albedo. Atmospheric Chemistry and Physics, 18(4981-5000), 2018.

Gultepe, I., Tardif, R., Michaelides, S. C., Cermak, J., Bott, A., Bendix, J., et al. (2007). Fog research: A review of past achievements and future perspectives. Pure and Applied Geophysics, 164, 1127-1159.

Guo, J., Zusman, E., \& Moe, E. (2014). Enabling China's low-carbon transition: The 12th Five-Year Plan and the future climate regime. The political economy of renewable energy and energy security (pp. 241-257). London: Palgrave Macmillan.

Guo, J., Kang, S., Huang, J., Zhang, Q., Rupakheti, M., Sun, S., et al. (2017). Characterizations of atmospheric particulate-bound mercury in the Kathmandu Valley of Nepal, South Asia. Science of the Total Environment, 579. http://doi.org/10.1016/j.scitotenv.2016.11.110.

Gupta, R. (2014). Low-hanging fruit in black carbon mitigation: Crop residue burning in South Asia. Climate Change Economics, 5(4), 1450012

Gupta, S. K., Gupta, S. C., Agarwal, R., Sushma, S., Agrawal, S. S., \& Saxena, R. (2007). A multicentric case-control study on the impact of air pollution on eyes in a metropolitan city of India. Indian Journal of Occupational and Environmental Medicine, 11(1), 3740. https://doi.org/10.4103/0019-5278.32463.
Gurjar, B. R., Ravindra, K., \& Singh, A. (2016). Air pollution trends over Indian megacities and their local-to-global implications. Atmospheric Environment, 142, 475-495.

Gustafsson, Ö., Kruså, M., Zencak, Z., Sheesley, R. J., Granat, L., Engström, E., et al. (2009). Brown clouds over South Asia: Biomass or fossil fuel combustion. Science, 323, 495-498.

Guttikunda, S. K., \& Koppaka, R. (2012). Co-benefits of an air quality management action plan for transport sector in Hyderabad, India. In Low carbon transport in Asia: Capturing climate and development co-benefits.

Guyon, P., Frank, G. P., Welling, M., Chand, D., Artaxo, P., Rizzo, L., et al. (2005). Airborne measurements of trace gas and aerosol particle emissions from biomass burning in Amazonia. Atmospheric Chemistry and Physics, 5(11), 2989-3002. http://doi.org/10.5194/ acp-5-2989-2005.

Habib, G., Venkataraman, C., Chiapello, I., Ramachandran, S., Boucher, O., \& Shekar Reddy, M. (2006). Seasonal and interannual variability in absorbing aerosols over India derived from TOMS: Relationship to regional meteorology and emissions. Atmospheric Environment, 40(11), 1909-1921. https://doi.org/10.1016/j. atmosenv.2005.07.077.

Haldane, J. (1912). The dissociation of oxyhaemoglobin in human blood during partial CO poisoning. Journal of Physiology, 45, 22-24.

Hameed, S., Ishaq Mirza, M., Ghauri, B. M., Siddiqui, Z. R., Javed, R., Khan, A. R., et al. (2000). On the widespread winter fog in Northeastern Pakistan and India. Geophysical Research Letters, 27 (13), 1891-1894. http://doi.org/10.1029/1999GL011020.

Hausker, K. (2004). Vehicle inspection and maintenance programs: International experience and best practices. Washington D.C.

Health Effects Institute. (2017). State of global air 2017. Special Report. Boston, MA: Health Effects Institute.

Hegde, P., Pant, P., Naja, M., Dumka, U. C., \& Sagar, R. (2007). South Asian dust episode in June 2006: Aerosol observations in the central Himalayas. Geophysical Research Letters, 34, L23802. https://doi. org/10.1029/2007gl030692.

Helfand, W. H., Lazarus, J., \& Theerman, P. (2001). Donora, Pennsylvania: An environmental disaster of the 20th century. American Journal of Public Health, 91(4), 553.

Henriksson, S. V., Laaksonen, A., Kerminen, V. M., Räisänen, P., Järvinen, H., Sundstrom, A. M., et al. (2011). Spatial distributions and seasonal cycles of aerosols in India and China seen in global climate-aerosol model. Atmospheric Chemistry and Physics, 11(15), 7975-7990. http://doi.org/10.5194/acp-11-7975-2011.

Hogg, J. C., Chu, F., Utokaparch, S., Woods, R., Elliott, W. M., Buzatu, L., et al. (2004). The nature of small-airway obstruction in chronic obstructive pulmonary disease. The New England Journal of Medicine, 350(26), 2645-2653.

Hoornweg, D., \& Bhada-Tata, P. (2012). What a waste: A global review of solid waste management. Washington, D.C.: World Bank.

Horton, R. (2012). GBD 2010: Understanding disease, injury, and risk. The Lancet. http://doi.org/10.1016/S0140-6736(12)62133-3.

Hsu, N. C., Gautam, R., Sayer, A. M., Bettenhausen, C., Li, C., Jeong, M. J., et al. (2012). Global and regional trends of aerosol optical depth over land and ocean using SeaWiFS measurements from 1997 to 2010. Atmospheric Chemistry and Physics, 12(17), 8037-8053. http://doi.org/10.5194/acp-12-8037-2012.

Huang, J., Minnis, P., Yi, Y., Tang, Q., Wang, X., Hu, Y., et al. (2007). Summer dust aerosols detected from CALIPSO over the Tibetan Plateau. Geophysical Research Letters, 34, L18805. https://doi.org/ 10.1029/2007g1029938.

Hyvärinen, A.-P., Raatikainen, T., Brus, D., Komppula, M., Panwar, T. S., Hooda, R. K., et al. (2011a). Effect of the summer monsoon on aerosols at two measurement stations in Northern India-Part 1: PM 
and BC concentrations. Atmospheric Chemistry and Physics, 11 (16), 8271-8282. http://doi.org/10.5194/acp-11-8271-2011.

Hyvärinen, A.-P., Raatikainen, T., Komppula, M., Mielonen, T., Sundström, A.-M., Brus, D., et al. (2011b). Effect of the summer monsoon on aerosols at two measurement stations in Northern India -Part 2: Physical and optical properties. Atmospheric Chemistry and Physics, 11(16), 8283-8294. http://doi.org/10.5194/acp-118283-2011.

ICIMOD. (2007). Kathmandu valley environment outlook. Kathmandu: International Centre for Integrated Mountain Development (ICIMOD).

IIPS \& ORC Macro. (2007). National Family Halth Survey 3 (NFHS3) 2005-06. Mumbai: International Institute for Population Sciences and Macro International.

Imhoff, R. E., Valente, R., Meagher, J. F., \& Luria, M. (1995). The production of $\mathrm{O} 3$ in an urban plume: Airborne sampling of the Atlanta urban plume. Atmospheric Environment, 29(17), $2349-2358$.

Jaffee, D., et al. (1999). Transport of Asian air pollution to North America. Geophysical Research Letters, 26(6), 711-714.

Jain, N., Bhatia, A., \& Pathak, H. (2014). Emission of air pollutants from crop residue burning in India. Aerosol and Air Quality Research, 14, 422-430.

Janssen, N. A., Gerlofs-Nijland, M. E., Lanki, T., Salonen, R. O., Cassee, F., Hoek, G., et al. (2012). Health effects of black carbon.

Jayarathne, T., Stockwell, C. E., Christian, T. J., Bhave, P. V., Rathnayake, C., Robiul Islam, Md., et al. (2017). Nepal Ambient Monitoring and Source Testing Experiment (NAMaSTE): Emissions of particulate matter from wood and dung cooking fires, brick kilns, generators, trash and crop residue burning. Atmospheric Chemistry and Physics (in press).

Jenamani, R. K. (2007). Alarming rise in fog and pollution causing a fall in maximum temperature over Delhi. Current Science, 93(3), 314-322.

Jenamani, R. K., \& Tyagi, A. (2011). Monitoring fog at IGI Airport and analysis of its runway-wise spatio-temporal variations using Meso-RVR network. Current Science, 100(4), 491-501.

Jenkins, M., Kaspari, S., Kang, S., Grigholm, B., \& Mayewski, P. a. (2013). Black carbon concentrations from a Tibetan Plateau ice core spanning 1843-1982: Recent increases due to emissions and glacier melt. The Cryosphere Discussions, 7(5), 4855-4880. http://doi.org/ 10.5194/tcd-7-4855-2013.

Jerrett, M., Burnett, R. T., Pope, C. A., Ito, K., Thurston, G., Krewski, D., et al. (2009). Long-term ozone exposure and mortality. New England Journal of Medicine, 360(11), 1085-1095. http://doi.org/ 10.1056/NEJMoa0803894.

Jethva, H., Satheesh, S. K., \& Srinivasan, J. (2005). Seasonal variability of aerosols over the Indo-Gangetic basin. Journal of Geophysical Research Atmospheres, 110(21), 1-15. https://doi.org/10.1029/ 2005JD005938.

Ji, Z., Kang, S., Cong, Z., Zhang, Q., \& Yao, T. (2015). Simulation of carbonaceous aerosols over the Third Pole and adjacent regions: Distribution, transportation, deposition, and climatic effects. Climate Dynamics, 45(9-10), 2831-2846. https://doi.org/10.1007/ s00382-015-2509-1.

Ji, Z., S. Kang, Q. Zhang, Z. Cong, P. Chen, M. Sillanpää. (2016). Investigation of mineral aerosols radiative effects over High Mountain Asia in 1990-2009 using a regional climate model. Atmospheric Research, 178-179, 484-496. https://doi.org/10.1016/ j.atmosres.2016.05.003.

Jin, et al. (2006). Exposure to indoor air pollution from household energy use in rural China: The interactions of technology, behavior, and knowledge in health risk management. Social Science and Medicine, 62, 3161-3176.
Joshi, H., Naja, M., Singh, K. P., Kumar, R., Bhardwaj, P., Babu, S. S., et al. (2016). Investigations of aerosol black carbon from a semi-urban site in the Indo-Gangetic Plain region. Atmospheric Environment, 125, 346-359.

Kang, S., Wake, C. P., Qin, D., Mayewski, P. A., \& Yao, T. (2000). Monsoon and dust signals recorded in Dasuopu Glacier, Tibetan Plateau. Journal of Glaciology, 46(153), 222-226.

Kang, S., Chen, P., Li, C., Liu, B., \& Cong, Z. (2016). Atmospheric aerosol elements over the inland Tibetan Plateau: Concentration, seasonality, and transport. Aerosol and Air Quality Research, 16, 789-800. https://doi.org/10.4209/aaqr.2015.05.0307.

Kaskoutis, D. G., Sinha, P. R., Vinoj, V., Kosmopoulos, P. G., Tripathi, S. N., Misra, A., et al. (2013). Aerosol properties and radiative forcing over Kanpur during severe aerosol loading conditions. Atmospheric Environment, 79, 7-19.

Kaspari, S. D., Schwikowski, M., Gysel, M., Flanner, M. G., Kang, S., Hou, S., et al. (2011). Recent increase in black carbon concentrations from a Mt. Everest ice core spanning 1860-2000 AD. Geophysical Research Letters, 38(4), 11-16. http://doi.org/10.1029/ 2010 GL046096.

Kaspari, S., Painter, T. H., Gysel, M., Skiles, S. M., \& Schwikowski, M. (2014). Seasonal and elevational variations of black carbon and dust in snow and ice in the Solu-Khumbu, Nepal and estimated radiative forcings. Atmospheric Chemistry and Physics, 14(15), 8089-8103. http://doi.org/10.5194/acp-14-8089-2014.

Kim, B. M., Park, J.-S., Kim, S.-W., Kim, H., Jeon, H., Cho, C., et al. (2015). Source apportionment of $\mathrm{PM}_{10}$ mass and particulate carbon in the Kathmandu Valley, Nepal. Atmospheric Environment, 123. http://doi.org/10.1016/j.atmosenv.2015.10.082.

Kiros, F., Shakya, K. M., Maharjan, R., Byanju, R. M., Regmi, R. P., Naja, M., et al. (2016). Variability of trace gases: Nitrogen oxides, sulfur dioxide, ozone and ammonia in Kathmandu Valley, Nepal. Aerosol and Air Quality Research, 16, 3088-3101.

Kopacz, M., Mauzerall, D. L., Wang, J., Leibensperger, E. M., Henze, D. K., \& Singh, K. (2011). Origin and radiative forcing of black carbon transported to the Himalayas and Tibetan Plateau. Atmospheric Chemistry and Physics, 11(6), 2837-2852. http://doi.org/10. 5194/acp-11-2837-2011.

Kulkarni, S., et al. (2015). Source sector and region contributions to BC and $\mathrm{PM}_{2.5}$ in Central Asia. Atmospheric Chemistry and Physics, 15, 1683-1705.

Kumar, R., Naja, M., Venkataramani, S., \& Wild, O. (2010). Variations in surface ozone at Nainital: A high-altitude site in the central Himalayas. Journal of Geophysical Research Atmospheres, 115 (16), 1-12. https://doi.org/10.1029/2009JD013715.

Kumar, M., Tiwari, S., Murari, V., Singh, A. K., \& Banerjee, T. (2015). Wintertime characteristics of aerosols at middle Indo-Gangetic Plain: Impacts of regional meteorology and long range transport. Atmospheric Environment, 104, 162-175.

Kurokawa, J., Ohara, T., Morikawa, T., Hanayama, S., Janssens-Maenhout, G., Fukui, T., et al. (2013). Emissions of air pollutants and greenhouse gases over Asian regions during 20002008: Regional Emission inventory in ASia (REAS) version 2. Atmospheric Chemistry and Physics, 13(21), 11019-11058. http:// doi.org/10.5194/acp-13-11019-2013.

Kusaka, H., Kondo, H., Kikegawa, Y., \& Kimura, F. (2001). A simple single-layer urban canopy model for atmospheric models: Comparison with multi-layer and slab models. Boundary-Layer Meteorology, 101, 329-358.

LaDochy, S. (2013). The disappearance of dense fog in Los Angeles: Another urban impact? Physical Geography, 26(3), 177-191.

Laghari, J. R. (2013). Melting glaciers bring energy uncertainty. Nature, 502, 617-618. https://doi.org/10.1038/502617a. 
Lal, S., Naja, M., \& Subbaraya, B. H. (2000). Seasonal variations in surface ozone and its precursors over an urban site in India. Atmospheric Environment, 34, 2713-2724.

Lau, K.-M., \& Kim, K.-M. (2006). Observational relationships between aerosol and Asian monsoon rainfall, and circulation. Geophysical Research Letters, 33, L21810. https://doi.org/10.1029/ $2006 \mathrm{~g} 1027546$.

Lau, K. M., Kim, M. K., \& Kim, K. M. (2006). Asian summer monsoon anomalies induced by aerosol direct forcing: The role of the Tibetan Plateau. Climate Dynamics, 26(7-8), 855-864. https:// doi.org/10.1007/s00382-006-0114-z.

Lau, W. K. M., Kim, M.-K., Kim, K.-M., Lee, W.-S., \& Lau, W. K. M. (2010). Enhanced surface warming and accelerated snow melt in the Himalayas and Tibetan Plateau induced by absorbing aerosols. Environmental Research Letters, 5(5), 25204. https://doi.org/10. 1088/1748-9326/5/2/025204.

Leather, J. (2009). ADB sustainable development working paper series rethinking transport and climate change. Manila.

Li, C., Chen, P., Kang, S., Yan, F., Hu, Z., Qu, B., et al. (2016a). Concentrations and light absorption characteristics of carbonaceous aerosol in $\mathrm{PM}_{2.5}$ and $\mathrm{PM}_{10}$ of Lhasa city, the Tibetan Plateau. Atmospheric Environment, 127, 340-346.

Li, C. L., Bosch, C., Kang, S. C., Andersson, A., Chen, P. F., Zhang, Q. G., et al. (2016b). Sources of black carbon to the Himalayan-Tibetan Plateau glaciers. Nature Communications, 7, $1-7$.

Li, C., Kang, S., Chen, P., Zhang, Q., \& Fang, G. C. (2012). Characterizations of particle-bound trace metals and polycyclic aromatic hydrocarbons (PAHs) within Tibetan tents of south Tibetan Plateau, China. Environmental Science and Pollution Research, 19(5), 1620-1628. https://doi.org/10.1007/s11356-0110678-y.

Li, W., \& Zusman, E. (2006). Translating regulatory promise into environmental progress: institutional capacity and environmental regulation in China. Environmental Law Reporter, 36(8), 1061610623.

Lim, S. S., Vos, T., Flaxman, A. D., Danaei, G., Shibuya, K., Adair-Rohani, H., et al. (2012). A comparative risk assessment of burden of disease and injury attributable to 67 risk factors and risk factor clusters in 21 regions, 1990-2010: A systematic analysis for the Global Burden of Disease Study 2010. Lancet, 380(9859), 2224-2260. https://doi.org/10.1016/S0140-6736(12)61766-8.

Lin, H.-H., Ezzati, M., \& Murray, M. (2007). Tobacco smoke, indoor air pollution and tuberculosis: A systematic review and meta-analysis. PLoS Med, 4(1), e20. https://doi.org/10.1371/ journal.pmed.0040020.

Liu, B., Kang, S. C., Sun, J. M., Zhang, Y. L., Xu, R., Wang, Y. J., et al. (2013). Wet precipitation chemistry at a high-altitude site (3,326 m a.s.1.) in the southeastern Tibetan Plateau. Environmental Science and Pollution Research, 20, 5013-5027.

Liu, J., Mauzerall, D. L., Chen, Q., Zhang, Q., Song, Y., Peng, W., et al. (2016). Air pollutant emissions from Chinese households: A major and underappreciated ambient pollution source. Proceedings of the National Academy of Sciences, 113(28), 7756-7761. http:// doi.org/10.1073/pnas.1604537113.

Loomis, D., Grosse, Y., Lauby-Secretan, B., Ghissassi, F. El, Bouvard, V., Benbrahim-Tallaa, L., et al. (2013). The carcinogenicity of outdoor air pollution. The Lancet Oncology, 14(13), 1262-1263. http://doi.org/10.1016/S1470-2045(13)70487-X.

Lu, Z., Streets, D. G., Zhang, Q., \& Wang, S. (2012). A novel back-trajectory analysis of the origin of black carbon transported to the Himalayas and Tibetan Plateau during 1996-2010. Geophysical Research Letters, 39, L01809. https://doi.org/10.1029/ 2011 gl049903.
Lüthi, Z. L., Škerlak, B., Kim, S. W., Lauer, A., Mues, A., Rupakheti, M., et al. (2015). Atmospheric brown clouds reach the Tibetan Plateau by crossing the Himalayas. Atmospheric Chemistry and Physics, 15(11), 6007-6021. http://doi.org/10.5194/acp-15-60072015.

Marcq, S., Laj, P., Roger, J. C., Villani, P., Sellegri, K., Bonasoni, P., et al. (2010). Aerosol optical properties and radiative forcing in the high Himalaya based on measurements at the Nepal Climate Observatory-Pyramid site (5079 m a.s.1.). Atmospheric Chemistry and Physics, 10(13), 5859-5872. https://doi.org/10.5194/acp-105859-2010.

Manoj, M. G., Devera, P. C. S., \& Safai, P. D. (2010). Absorbing aerosols facilitate transition of Indian monsoon breaks to active spells. Climate Dynamics, 37, 2181-2198. https://doi.org/10.1007/ s00382-010-0971-3.

Marinoni, A., Cristofanelli, P., Laj, P., Duchi, R., Calzolari, F., Deceseri, S., et al. (2010). Aerosol mass and black carbon concentrations, a two year record at NCO-P (5079 m, Southern Himalayas). Atmospheric Chemistry and Physics, 10, 8551-8562.

Martin, et al. (2011). A major environmental cause of death. Science, 334(6053), 180-181.

Mastrangelo, G., Fadda, E., \& Marzia, V. (1996). Polycyclic aromatic hydrocarbons and cancer in man. Environmental Health Perspectives, 104(11), 1166-1170.

Mauzerall, D. L., \& Wang, X. (2001). Protecting agricultural crops from the effects of tropospheric ozone exposure: Reconciling Science and Standard Setting in the United States, Europe, and Asia. Annual Review of Energy and the Environment, 26(1), 237268. https://doi.org/10.1146/annurev.energy.26.1.237.

Meehl, G. A., Arblaster, J. M., \& Collins, W. D. (2008). Effects of black carbon aerosols on the Indian Monsoon. Journal of Climate, 21, 2869-2882.

Menon, S., Hansen, J., Nazarenko, L., Luo, Y., Husar, R. B., Xu, Q., et al. (2002). Climate effects of black carbon aerosols in China and India. Science (New York, N.Y.), 297(5590), 2250-2253. https://doi. org/10.1126/science.1075159.

Mehta, M. (2015). A study of aerosol optical depth variations over the Indian region using thirteen years (2001-2013) of MODIS and MISR Level 3 data. Atmospheric Environment, 109, 161-170.

Meitiv, D. (2010). SUMMARY: Black carbon and climate change in the Himalayan region prepared for the clean air task force DRAFT: December, 2010. http://www.catf.us/resources/factsheets/files/ 201012-Black_Carbon_and_Climate_Change_at_the_Third_Pole. pdf.

Ménégoz, M., Krinner, G., Balkanski, Y., Boucher, O., Cozic, A., Lim, S., et al. (2014). Snow cover sensitivity to black carbon deposition in the Himalayas: from atmospheric and ice core measurements to regional climate simulations. Atmospheric Chemistry and Physics, 14, 4237-4249. https://doi.org/10.5194/acp-14-4237-2014.

Ming, J., Xiao, C., Cachier, H., Qin, D., Qin, X., Li, Z., et al. (2009). Black carbon (BC) in the snow of glaciers in west China and its potential effects on albedos. Atmospheric Research, 92(1), 114-123. https://doi.org/10.1016/j.atmosres.2008.09.007.

Ming, J., Wang, Y., Du, Z., Zhang, T., Guo, W., Xiao, C., et al. (2015). Widespread Albedo decreasing and induced melting of Himalayan snow and ice in the early 21st century. PLOS ONE, 10(6), e0126235. https://doi.org/10.1371/journal.pone.0126235.

Ministry of Environmental Protection, National Development and Reform Commission, Ministry of Industry and Information, Ministry of Finance, Ministry of Housing and Urban and Rural Construction, and Energy Bureau. (2013). Notice on Issuing the Detailed Implementation Guidelines for Carrying out the Plan for Air Pollution Prevention and Control in Beijing-Tianjin-Hebei and Surrounding Areas (edited). 
Minjares, R. J., \& Rutherford, D. (2010). Maximising the co-benefits of light-duty dieselisation in Asia. In A. Srinivasan, E. Zusman, \& S. Dhakal (Eds.), Low carbon transport in Asia. London: Routledge.

Mitchell, R. B. (2003). International environmental agreements: A survey of their features, formation, and effects. Annual Review of Environment and Resources, 28(3), 429-461.

Mitchell, R. B. (2006). Problem structure, institutional design, and the relative effectiveness of international environmental agreements. Global Environmental Politics, 6(3), https://doi.org/10.1162/glep. 2006.6.3.72.

Mittal, M. L., Hess, P. G., Jain, S. L., Arya, B. C., \& Sharma, C. (2007). Surface ozone in the Indian region. Atmospheric Environment, 41, 6572-6584.

Mobarak, et al. (2012). Low demand for nontraditional cookstove technologies. Proceedings of the National Academy of Sciences, 109(27), 10815-10820.

Mohan, M., \& Payra, S. (2009). Influence of aerosol spectrum. Environmental Monitoring and Assessment, 151, 265-277.

Mohan, M., \& Payra, S. (2014). Aerosol number concentration and visibility during dense fog over a subtropical urban site. Journal of Nanomaterials, 2014, 495457.

Morris, R., Naumova, E. N., \& Munasinghe, R. L. (1995). Ambient air pollution and hospitalization for congestive heart failure among elderly people in seven large U.S. cities. American Journal of Public Health, 85(p 1343), 1361-1365.

Mukherjee, S. (2015). September). Emission Norms: Vrooming to Bharat VI not an option.

Murray, C. J. L., Ezzati, M., Flaxman, A. D., Lim, S., Lozano, R., Michaud, C., et al. (2012). GBD 2010: Design, definitions, and metrics. The Lancet. http://doi.org/10.1016/S0140-6736(12)61899-6.

Nair, V. S., Solmon, F., Giorgi, F., Mariotti, L., Babu, S. S., \& Moorthy, K. K. (2012). Simulation of South Asian aerosols for regional climate studies. Journal Geophysical Research, 117, D04209. https://doi.org/10.1029/2011jd016711.

Naqvi, S. W. A., Jayakumar, D. A., Narvekar, P. V., Naik, H., Sarma, V. V. S. S., D'Souza, W., et al. (2000). Increased marine production of $\mathrm{N}_{2} \mathrm{O}$ due to intensifying anoxia on the Indian continental shelf. Nature, 408(6810), 346-349. Retrieved from http://dx.doi.org/10. $1038 / 35042551$

Niu, F., Li, Z., Li, C., Lee, K.-H., \& Wang, M. (2010). Increase in wintertime fog in China: Potential impacts of weakening of the Eastern Asian monsoon circulation and increasing aerosol loading. Journal of Geophysical Research, 115(D00K20). http://doi.org/10. 1029/2009JD013484.

Ohara, T., Akimoto, H., Kurosawa, J., Horii, N., Yamaji, N., Yamaji, K., et al. (2007). An Asian emission inventory of anthropogenic emission sources for the period 1980-2020. Atmospheric Chemistry and Physics, 7, 4419-4444.

Ojha, N., Naja, M., Singh, K. P., Sarangi, T., Kumar, R., Lal, S., et al. (2012). Variabilities in ozone at a semi-urban site in the Indo-Gangetic Plain region: Association with the meteorology and regional processes. Journal of Geophysical Research Atmospheres, 117(20), 1-19. http://doi.org/10.1029/2012JD017716.

Pan, X., Chin, M., Gautam, R., Bian, H., Kim, D., Colarco, P. R., et al. (2015). A multi-model evaluation of aerosols over South Asia: Common problems and possible causes. Atmospheric Chemistry and Physics, 15 (10), 5903-5928. http://doi.org/10.5194/acp-15-5903-2015.

Panday, A. K. (2006). The diurnal cycle of air pollution in the Kathmandu Valley, Nepal. Cambridge, MA: MIT Center for Global Chance Science.

Panday, A. K., \& Prinn, R. G. (2009). Diurnal cycle of air pollution in the Kathmandu Valley, Nepal: Observations. Journal of Geophysical Research Atmospheres, 114(9). http://doi.org/10.1029/ 2008JD009777.
Panday, A. K., Prinn, R. G., \& Schär, C. (2009). Diurnal cycle of air pollution in the Kathmandu Valley, Nepal: 2. Modeling results. Journal of Geophysical Research Atmospheres, 114(21). http://doi. org/10.1029/2008JD009808.

Pande, J. N., Bhatta, N., Biswas, D., Pandey, R. M., Ahluwalia, G., Siddaramaiah, N. H., et al. (2002). Outdoor air pollution and emergency room visits at a hospital in Delhi. Indian Journal of Chest Diseases and Allied Sciences, 44(1), 13-19.

Pandithurai, G., Dipu, S., Dani, K. K., Tiwari, S., Bisht, D. S., Devara, P. C. S., et al. (2008). Aerosol radiative forcing during dust events over New Delhi, India. Journal of Geophysical Research, 113 (D13), D13209. https://doi.org/10.1029/2008JD009804.

Pant, K. P. (2015). Uniform-price reverse auction for estimating the costs of reducing open-field burning of rice residue in Nepal. Environmental \& Resource Economics, 62(3), 567-581. https://doi. org/10.1007/s10640-014-9830-8.

Pant, P., Hegde, P., Dumka, U. C., Sagar, R., Satheesh, S. K., Moorthy, K. K., et al. (2006a). Aerosol characteristics at a high-altitude location in central Himalayas: Optical properties and radiative forcing. Journal of Geophysical Research, 111(D17), D17206. http://doi.org/10.1029/2005JD006768.

Pant, P., Hegde, P., Dumka, U. C., Saha, A., Srivastava, M. K., \& Sagar, R. (2006b). Aerosol characteristics at a high-altitude location during ISRO-GPB Land Campaign-II. Current Science, 91(8), 1053-1061.

Parekh, P. P., Khwaja, H. A., Khan, A. R., Naqvi, R. R., Malik, A., Shah, S. A., et al. (2001). Ambient air quality of two metropolitan cities of Pakistan and its health implications. Atmospheric Environment, 35(34), 5971-5978. http://doi.org/10.1016/S1352-2310 (00)00569-0.

Pasricha, P. K., Gera, B. S., Shastri, S., Maini, H. K., John, T., Ghosh, A. B., et al. (2003). Role of the water vapour greenhouse effect in the forecasting of fog occurrence. Boundary-Layer Meteorology, 107(2), 469-482. http://doi.org/10.1023/A:1022128800130.

Pope, C. A., Burnett, R. T., Thun, M. J., Calle, E. E., Krewski, D., Ito, K., et al. (2002). Lung cancer, cardiopulmonary mortality, and long-term exposure to fine particulate air pollution. JAMA, the Journal of the American Medical Association, 287(9), 1132-1141. https://doi.org/10.1001/jama.287.9.1132.

Pope, C. A., Burnett, R. T., Thurston, G. D., Thun, M. J., Calle, E. E., Krewski, D., et al. (2004). Cardiovascular mortality and long-term exposure to particulate air pollution: Epidemiological evidence of general pathophysiological pathways of disease. Circulation, 109 (1), 71-77. https://doi.org/10.1161/01.CIR.0000108927.80044.7F.

Pope, C. A., Rodermund, D. L., \& Gee, M. M. (2007). Mortality effects of a copper smelter strike and reduced ambient sulfate particulate matter air pollution. Environmental Health Perspectives, 115(5), 679-683. https://doi.org/10.1289/ehp.9762.

Pope, D. P., Mishra, V., Thompson, L., Siddiqui, A. R., Rehfuess, E. A., Weber, M., et al. (2010). Risk of low birth weight and stillbirth associated with indoor air pollution from solid fuel use in developing countries. Epidemiologic Reviews, 32(1), 70-81. https://doi.org/10.1093/epirev/mxq005.

Porch, W., Chylek, P., Dubey, M., \& Massie, S. (2007). Trends in aerosol optical depth for cities in India. Atmospheric Environment, 41, 7524-7532.

Praveen, P. S., Ahmed, T., Kar, A., Rehman, I. H., \& Ramanathan, V. (2012). Link between local scale BC emissions in the Indo-Gangetic Plains and large scale atmospheric solar absorption. Atmospheric Chemistry and Physics, 12(2), 1173-1187. http://doi.org/10.5194/ acp-12-1173-2012.

Price, L. (2008). China's Top-1000 energy-consuming enterprises program: Reducing energy consumption of the 1000 largest industrial enterprises in China (June). 
Pudasainee, D., Sapkota, B., Bhatnagar, A., Kim, S.-H., \& Seo, Y.-C. (2010). Influence of weekdays, weekends and bandhas on surface ozone in Kathmandu valley. Atmospheric Research, 95, 150-156.

Putero, D., Cristofanelli, P., Laj, P., Marinoni, A., Villani, P., Broquet, A., et al. (2014). New atmospheric composition observations in the Karakorum region: Influence of local emissions and large-scale circulation during a summer field campaign. Atmospheric Environment, 97, 75-82. http://doi.org/10.1016/j.atmosenv.2014.07.063.

Putero, D., Cristofanelli, P., Marinoni, A., Adhikary, B., Duchi, R., Shrestha, S. D., et al. (2015). Seasonal variation of ozone and black carbon observed at Paknajol, an urban site in the Kathmandu Valley, Nepal. Atmospheric Chemistry and Physics, 15(24), 1395713971. http://doi.org/10.5194/acp-15-13957-2015.

Qasim, M., Bashir, A., Anees, M. M., Ghani, M. U., Khalid, M., Malik, J., et al. (2014). Health risk assessment of indoor air quality in developing countries. Asian Journal Management Sciences and Education, 3(2).

Qian, Y., Kaiser, D. P., Leung, L. R., \& Xu, M. (2006). More frequent cloud-free sky and less surface solar radiation in China from 1955 to 2000. Geophysical Research Letters, 33, L01812. https://doi.org/10. $1029 / 2005 \mathrm{~g} 1024586$.

Qian, Y., Wang, W., Leung, L. R., \& Kaiser, D. P. (2007). Variability of solar radiation under cloud-free skies in China: The role of aerosols. Geophysical Research Letters, 34, L12804. https://doi.org/ 10.1029/2006g1028800.

Qian, Y., Flanner, M. G., Leung, L. R., \& Wang, W. (2011). Sensitivity studies on the impacts of Tibetan Plateau snowpack pollution on the Asian hydrological cycle and monsoon climate. Atmospheric Chemistry and Physics, 11, 1929-1948. https://doi.org/10.5194/ acp-11-1929-2011.

Qian, Y., Yasunari, T. J., Doherty, S. J., Flanner, M. G., Lau, W. K. M., Ming, J., et al. (2015). Light-absorbing particles in snow and ice: Measurement and modeling of climatic and hydrological impact. Advances in Atmospheric Sciences, 32(1), 64-91. http://doi.org/10. 1007/s00376-014-0010-0.

Rabalais, N. N., Díaz, R. J., Levin, L. A., Turner, R. E., Gilbert, D., \& Zhang, J. (2010). Dynamics and distribution of natural and human-caused hypoxia. Biogeosciences, 7, 585-619. http://doi. org/10.5194/bg-7-585-2010.

Rajput, P., Sarin, M., Sharma, D., \& Singh, D. (2014). Characteristics and emission budget of carbonaceous species from post-harvest agricultural-waste burning in source region of the Indo-Gangetic Plain. Tellus B, 66, 21026.

Rall, D. P. (1974). Review of the health effects of sulfur oxides. Environmental Health Perspectives. http://doi.org/10.1289/ehp. 74897.

Ram, K., Sarin, M. M., \& Hegde, P. (2010). Long-term record of aerosol optical properties and chemical composition from a high-altitude site (Manora Peak) in Central Himalaya. Atmospheric Chemistry and Physics, 10(23), 11791-11803. http://doi.org/10. 5194/acp-10-11791-2010.

Ram, K., Sarin, M. M., Sudheer, A. K., \& Rengarajan, R. (2012). Carbonaceous and secondary inorganic aerosols during wintertime fog and haze over urban sites in the Indo-Gangetic Plains. Aerosol and Air Quality Research, 12, 359-370.

Ramana, M. V., Ramanathan, V., Feng, Y., Yoon, S.-C., Kim, S.-W., Carmichael, G. R., et al. (2010). Warming influenced by the ratio of black carbon to sulphate and the black-carbon source. Nature Geoscience, 3, 542-545.

Ramanathan, V., \& Carmichael, G. (2008). Global and regional climate changes due to black carbon. Nature Geoscience, 1, 221-227. https://doi.org/10.1038/ngeo156.

Ramanathan, V., Crutzen, P. J., Lelieveld, J., Mitra, A. P., Althausen, D., Anderson, J., et al. (2001). Indian Ocean Experiment: An integrated analysis of the climate forcing and effects of the great
Indo-Asian haze. Journal of Geophysical Research, 106(D22), 28371-28398.

Ramanathan, V., \& Ramana, M. V. (2005). Persistent, widespread, and strongly absorbing haze over the Himalaya. Pure and Applied Geophysics, 162, 1609-1626.

Ran, L., Lin, W. L., Deji, Y. Z., La, B., Tsering, P. M., Xu, X. B., et al. (2014). Surface gas pollutants in Lhasa, a highland city of TibetCurrent levels and pollution implications. Atmospheric Chemistry and Physics, 14(19), 10721-10730. http://doi.org/10.5194/acp-1410721-2014

Randles, C. A., \& Ramaswamy, V. (2008). Absorbing aerosols over Asia: A Geophysical Fluid Dynamics Laboratory general circulation model sensitivity study of model response to aerosol optical depth and aerosol absorption. Journal of Geophysical Research, 113, D21203. https://doi.org/10.1029/2008jd010140.

Rantalainen, A.-L., Hyötyläinen, T., Saramo, M., \& Niskanen, I. (1999). Passive sampling of PAHs in indoor air in Nepal. Toxicological and Environmental Chemistry, 68, 335-348. https:// doi.org/10.1080/02772249909358667.

Rehfuess, et al. (2014). Enablers and barriers to large-scale uptake of improved solid fuel stoves: A systematic review. Environmental Health Perspectives, 122(2), 120-130.

Rehman, I. H., Ahmed, T., Praveen, P. S., Kar, A., \& Ramanathan, V. (2011). Black carbon emissions from biomass and fossil fuels in rural India. Atmospheric Chemistry and Physics, 11(14), 72897299. http://doi.org/10.5194/acp-11-7289-2011.

Rock, M. T. (2002). Pollution control in East Asia: Lessons from newly industrializing economies. Washington D.C.: Resources for the Future.

Roden, C. A., Bond, T. C., Conway, S., Osorto Pinel, A. B., MacCarty, N., \& Still, D. (2009). Laboratory and field investigations of particulate and carbon monoxide emissions from traditional and improved cookstoves. Atmospheric Environment, 43(6), 11701181. https://doi.org/10.1016/j.atmosenv.2008.05.041.

Rosenfeld, D. (2000). Suppression of rain and snow by urban and industrial air pollution. Science, 287, 1793-1796.

Roy, A., Chatterjee, A., Tiwari, S., Sarkar, C., Das, S. K., Ghosh, S. K., et al. (2016). Precipitation chemistry over urban, rural and high altitude Himalayan stations in eastern India. Atmospheric Research, 181, 44-53. https://doi.org/10.1016/j.atmosres.2016.06.005.

Rupakheti, D., Adhikary, B., Praveen, P. S., Rupakheti, M., Kang, S., Mahata, K. S., ... Lawrence, M. G. (2017). Pre-monsoon air quality over Lumbini, a world heritage site along the Himalayan foothills. Atmospheric Chemistry and Physics, 17, 11041-11063. https://doi. org/10.5194/acp-17-11041-2017.

Saikawa, E., et al. (2009). Present and potential future contributions of sulfate, black and organic carbon aerosols from china to global air quality, premature mortality and radiative forcing. Atmospheric Environment, 4343(17), 2814-2822.

Saikawa, E., Kurokawa, J., Takigawa, M., Borken-Kleefeld, J., Mauzerall, D. L., Horowitz, L. W., et al. (2011). The impact of China's vehicle emissions on regional air quality in 2000 and 2020: A scenario analysis. Atmospheric Chemistry and Physics, 11, 9465-9484.

Saikawa, E., Trail, M., Zhong, M., Wu, Q., Young, C. L., \& Janssens-Maenhout, G. (2017a). Uncertainties in emissions estimates of greenhouse gases and air pollutants in India and their impacts on regional air quality. Environmental Research Letters, 65002.

Saikawa, E., Kim, H., Zhong, M., Avramov, A., Zhao, Y., \& Janssens-Maenhout, G. (2017b). Comparison of emissions inventories of anthropogenic air pollutants and greenhouse gases in China. Atmospheric Chemistry and Physics, 6393-6421. https://doi. org/10.5194/acp-17-6393-2017.

Sanap, S. D., Ayantika, D. C., Pandithurai, G., \& Niranjan, K. (2014). Assessment of the aerosol distribution over Indian subcontinent in CMIP5 models. Atmospheric Environment, 87, 123-137. 
Sarangi, T., Naja, M., Ojha, N., Kumar, R., Lal, S., Venkataramani, S., et al. (2013). First simultaneous measurements of ozone, CO, and NOy at a high-altitude regional representative site in the central Himalayas. Journal of Geophysical Research, 119, 1592-1611.

Sarkar, S., Chokngamwong, R., Cervone, G., Singh, R. P., \& Kafatos, M. (2006). Variability of aerosol optical depth and aerosol forcing over India. Advances in Space Research, 37(12), 2153-2159. https://doi.org/10.1016/j.asr.2005.09.043.

Sarkar, C., Kumar, V., \& Sinha, V. (2013). Massive emissions of carcinogenic benzoids from paddy residue burning in North India. Current Science, 104(12), 1703-1709.

Sarkar, C., Sinha, V., Kumar, V., Rupakheti, M., Panday, A., S Mahata, K., et al. (2016). Overview of VOC emissions and chemistry from PTR-TOF-MS measurements during the SusKat-ABC campaign: High acetaldehyde, isoprene and isocyanic acid in wintertime air of the Kathmandu Valley. Atmospheric Chemistry and Physics, 16(6), 3979-4003.

Satheesh, S. K., Krishna Moorthy, K., Babu, S. S., Vinoj, V., \& Dutt, C. B. S. (2008). Climate implications of large warming by elevated aerosols over India. Geophysical Research Letters, 35, L19809. https://doi.org/10.1029/2008gl034944.

Satheesh, S. K., Ramanathan, V., Xu, L.-J., Lober, J. M., Podgorny, I. A., Prospero, J. M., et al. (1999). A model for the natural and anthropogenic aerosols over the tropical Indian Ocean from Indian Ocean Experiment data. Journal of Geophysical Research, 104 (D22), 27421-27440.

Sawaisarje, G. K., Khare, P., Shirke, C. Y., Deepakumar, S., \& Narkhede, N. M. (2014). Study of winter fog over Indian subcontinent: Climatological perspective. Mausam, 65(1), 19-28.

Schmidt, C. (2013). Modernizing artisanal brick kilns: A global need. Environmental Health Perspectives, 121(8), a242-a249. https://doi. org/10.1289/ehp.121-a242.

Schreurs, M. (2011). Transboundary Cooperation to Address Acid Rain. In S. Dinar (Ed.), Beyond resource wars: Scarcity, Environmental degradation, and international cooperation (pp. 90-116). Boston: MIT Press.

Schwartz, J., Coull, B., Laden, F., \& Ryan, L. (2008). The effect of dose and timing of dose on the association between airborne particles and survival. Environmental Health Perspectives, 116(1), 64-69. https://doi.org/10.1289/ehp.9955.

Schwartz, J., Dockery, D. W., Neas, L. M., Wypij, D., Ware, J. H., Spengler, J. D., et al. (1994). Acute effects of summer air pollution on respiratory symptom reporting in children. American Journal of Respiratory and Critical Care Medicine, 150(5, I), 1234-1242. http://doi.org/10.1164/ajrccm.150.5.7952546.

Sellegri, K., Laj, P., Venzac, H., Boulon, J., Picard, D., Villani, P., et al. (2010). Seasonal variations of aerosol size distributions based on long-term measurements at the high altitude Himalayan site of Nepal Climate Observatory-Pyramid (5079 m), Nepal. Atmospheric Chemistry and Physics, 10(21), 10679-10690. https://doi.org/10. 5194/acp-10-10679-2010.

Semple, J. L., \& Moore, G. W. K. (2008). First observations of surface ozone concentration from the summit region of Mount Everest. Geophysical Research Letters, 35(20), L20818. http://doi.org/Artn. https://doi.org/10.1029/2008g1035295.

Shahid, I., Kistler, M., Mukhtar, A., Ghauri, B. M., Cruz, C. R., Bauer, H., et al. (2016). Chemical characterization and mass closure of $\mathrm{PM}_{10}$ and $\mathrm{PM}_{2.5}$ at an urban site in Karachi e Pakistan. Atmospheric Environment, 128, 114-123.

Sharma, A. R., Kharol, S. K., Badarinath, K. V. S., \& Singh, D. (2010). Impact of agriculture crop residue burning on atmospheric aerosol loading-A study over Punjab State, India. Annales Geophysicae: Atmospheres, Hydrospheres and Space Sciences, 28(2), 367.
Sharma, P., Chandra, J., Chand, K., Paul, R., Prasad, P., \& Chauhan, C. (2013). Surface ozone concentration and its behaviour with aerosols in the northwestern Himalaya. India, 71, 44-53.

Shakya, K., Rupakheti, M., Aryal, K., \& Peltier, R. (2016). Respiratory effects of high levels of particulate exposure in a cohort of traffic police in Nepal. Journal of Occupational and Environmental Medicine, 58(6), 218-225.

Shindell, D., Hicks, K., Ramanathan, V., \& Terry, S. (2013). Integrated assessment of black carbon and tropospheric ozone. UNEP and WMO.

Shrestha, I. L., \& Shrestha, S. L. (2005). Indoor air pollution from biomass fuels and respiratory health of the exposed population in Nepalese households. International Journal of Occupational and Environmental Health, 11, 150-160.

Shrestha, P., Barros, A. P., \& Khlystov, A. (2010). Chemical composition and aerosol size distribution of the middle mountain range in the Nepal Himalayas during the 2009 pre-monsoon season. Atmospheric Chemistry and Physics, 10(23), 11605-11621. http:// doi.org/10.5194/acp-10-11605-2010.

Shrestha, S. R., Kim Oanh, N. T., Xu, Q., Rupakheti, M., \& Lawrence, M. G. (2013). Analysis of the vehicle fleet in the Kathmandu Valley for estimation of environment and climate co-benefits of technology intrusions. Atmospheric Environment, 81, 579-590.

Siddique, S., Banerjee, M., Ray, M. R., \& Lahiri, T. (2010). Air pollution and its impact on lung function of children in Delhi, the Capital City of India. Water, Air, and Soil Pollution, 212(1), 89100. https://doi.org/10.1007/s11270-010-0324-1.

Sillman, S. (1999). The relation between ozone, $\mathrm{NO}_{x}$, and hydrocarbons in urban and polluted rural environments. Atmospheric Environment, 33, 1821-1845.

Singh, A., \& Agrawal, M. (2008). Acid rain and its ecological consequences. Journal of Environmental Biology, 29(1), 15-24.

Sinha, V., Kumar, V., \& Sarkar, C. (2014). Chemical composition of pre-monsoon air in the Indo-Gangetic Plain measured using a new air quality facility and PTR-MS: High surface ozone and strong influence of biomass burning. Atmospheric Chemistry and Physics, 14, 5914-5941.

Skamarock, W. C., Klemp, J. B., Dudhia, J., Gill, D. O., Barker, D. M., Duda, M. G., et al. (2008). A description of the advanced research WRF Version 3. Boulder, CO: NCAR.

Smith, K. R., \& Mehta, S. (2003). The burden of disease from indoor air pollution in developing countries: Comparison of estimates. International Journal of Hygiene and Environmental Health, 206 (4-5), 279-289.

Smith, K. R., Samet, J. M., et al. (2000). Indoor air pollution in developing countries and acute lower respiratory infections in children. Thorax, 55(6), 518-532.

Somanathan, E., \& Bluffstone, R. (2015). Biogas: clean energy access with low-cost mitigation of climate change. Environmental \& Resource Economics, 62(2), 265-277. https://doi.org/10.1007/ s10640-015-9961-6.

Starke, L. E. (2007). Cityscape: Rizhao, solar powered city. 2007 State of the world our urban future. New York: W.W. Norton \& Company.

State Council. (2013). Action plan for air pollution prevention and control (edited).

Stern, F. B., Halperin, W. E., Hornung, R. W., Ringenburg, V. L., \& McCammon, C. S. (1988). Heart disease mortality among bridge and tunnel officers exposed to carbon monoxide. American Journal of Epidemiology, 128(6), 1276-1288. Retrieved from http://aje. oxfordjournals.org/content/128/6/1276.abstract.

Stockwell, C. E., Christian, T. J., Goetz, J. D., Jayarathne, T., Bhave, P. V., Praveen, P. S., et al. (2016). Nepal Ambient Monitoring and Source Testing Experiment (NAMaSTE): Emissions of trace gases and light-absorbing carbon from wood and dung cooking fires, 
garbage and crop residue burning, brick kilns, and other sources. Atmospheric Chemistry and Physics, 16(17). https://doi.org/10. 5194/acp-16-11043-2016.

Sud, Y. C., Wilcox, E., Lau, W. K.-M., Walker, G. K., Liu, X.-H., Nenes, A. S. B. (2009). Sensitivity of boreal-summer circulation and precipitation to atmospheric aerosols in selected regions-Part 1: Africa and India. Annals of Geophysics, 27, 3989-4007.

Syed, F. S., Kornich, H., \& Tjernstrom, M. (2012). On the fog variability over south Asia. Climate Dynamics, 39, 2993-3005.

Tare, V., Tripathi, S. N., Chinnam, N., Srivastava, A. K., Dey, S., Manar, M., et al. (2006). Measurements of atmospheric parameters during Indian Space Research Organization Geosphere Biosphere Program Land Campaign II at a typical location in the Ganga Basin 2. Chemical properties. Journal of Geophysical Research: Atmospheres, 111(D23). http://doi.org/10.1029/2006JD007279.

Thompson, L. G., Yao, T., Mosley-Thompson, E., Davis, M. E., Henderson, K. A., \& Liu, P.-N. (2000). A high-resolution millennial record of the South Asian monsoon from Himalayan ice core. Science, 289, 1916-1919.

Tripathee, L., Kang, S. C., Rupakheti, D., Zhang, Q. G., Huang, J., \& Sillanpää, M. (2016). Water-soluble ionic composition of aerosols at urban location in the foothills of Himalaya, Pokhara Valley, Nepal. Atmosphere, 7(8), 102-114. https://doi.org/10.3390/ atmos7080102.

Tripathi, S. N., Dey, S., Tare, V., \& Satheesh, S. K. (2005). Aerosol black carbon radiative forcing at an industrial city in northern India. Geophysical Research Letters, 32, L08802. https://doi.org/10.1029/ $2005 \mathrm{~g} 1022515$.

UNEP. (2002). The Asian Brown Cloud: Climate and Other Environmental Impacts. Bangkok: UNEP Resource Center for Asia and the Pacific.

UNEP. (2011). Near-term climate protection and clean air benefits. Actions for controlling short-lived climate. Nairobi, Kenya: Forcers United Nations Environment Programme (UNEP).

UNEP/WMO. (2011). Integrated assessment of black carbon and tropospheric ozone. United Nations Environment Programme.

Unruh, G. C. (2000). Understanding carbon lock-in. Energy Policy, 28, $817-830$.

Unruh, G. C. (2002). Escaping carbon lock-in. Energy Policy, 30, 317-325.

Upadhyay, A. K., Singh, A., Kumar, K., \& Singh, A. (2015). Impact of indoor air pollution from the use of solid fuels on the incidence of life threatening respiratory illnesses in children in India. $B M C$ Public Health, 15(300), 2015. https://doi.org/10.1186/s12889-0151631-7.

USEPA. (2006). An inventory of sources and environmental releases of dioxin-like compounds in the United States for the years 1987, 1995, and 2000, EPA/600/P-03/002F (677 pp.). Washington, DC, USA: National Center for Environmental Assessment, Office of Research and Development.

Vadrevu, K. P., Ellicott, E., Giglio, L., Badarinath, K. V. S., Vermote, E., Justice, C., et al. (2012). Vegetation fires in the himalayan region -Aerosol load, black carbon emissions and smoke plume heights. Atmospheric Environment, 47, 241-251. https://doi.org/10.1016/j. atmosenv.2011.11.009.

Venkataraman, C., Habib, G., Eiguren-Fernandez, A., Miguel, A. H., \& Friedlander, S. K. (2005). Residential biofuels in South Asia: Carbonaceous aerosol emissions and climate impacts. Science, 307, 1454-1456.

Vinoj, V., Rasch, P. J., Wang, H., Yoon, J.-H., Ma, P.-L., Landu, K., et al. (2014). Short-term modulation of Indian summer monsoon rainfall by West Asian dust. Nature Geoscience, 7(4), 308-313. https://doi.org/10.1038/ngeo2107.

Wan, X., Kang, S., Li, Q., Rupakheti, D., Zhang, Q., Guo, J., et al. (2017). Organic molecular tracers in the atmospheric aerosols from Lumbini, Nepal, in the northern Indo-Gangetic Plain: influence of biomass burning. Atmospheric Chemistry and Physics, 17, 88678885. https://doi.org/10.5194/acp-17-8867-2017.

Wang, C., Kim, D., Ekman, A. M. L., Barth, M. C., \& Rasch, P. J. (2009). Impact of anthropogenic aerosols on Indian summer monsoon. Geophysical Research Letters, 36, 1-6. https://doi.org/ 10.1029/2009GL040114.

Wang, T., Wong, H. L. A., Tang, J., Ding, A., Wu, W. S., \& Zhang, X. C. (2006). On the origin of surface ozone and reactive nitrogen observed at a remote mountain site in the northeastern Qinghai-Tibetan Plateau, western China. Journal of Geophysical Research, 111, D08303. https://doi.org/10.1029/2005jd006527.

Wang, X., Gong, P., Sheng, J., Joswiak, D. R., \& Yao, T. (2015). Long-range atmospheric transport of particulate Polycyclic Aromatic Hydrocarbons and the incursion of aerosols to the southeast Tibetan Plateau. Atmospheric Environment, 115, 124-131.

Wang, Y. (2015). Politically connected polluters under smog. Business and Politics, 17(1), 97-123. https://doi.org/10.1515/bap-2014-0033.

WHO. (2005). Air quality guidelines for particulate matter, ozone, nitrogen dioxide and sulfur dioxide, 22. Retrieved from http://www. euro.who.int/Document/E87950.pdf.

WHO. (2016). Ambient air pollution: A global assessment of exposure and burden of disease.

Wiedinmyer, C., Yokelson, R. J., \& Gullett, B. K. (2014). Global emissions of trace gases, particulate matter, and hazardous air pollutants from open burning of domestic wastE. Environmental Science and Technology, 48(16), 9523-9530. https://doi.org/10. 1021/es502250z.

Wilson, W. E., \& Suh, H. H. (1997). Fine particles and coarse particles: Concentration relationships relevant to epidemiologic studies. Journal of the Air and Waste Management Association, 47(12), $1238-1249$.

Wingfors, H., Hägglund, L., \& Magnusson, R. (2011). Characterization of the size-distribution of aerosols and particle-bound content of oxygenated PAHs, PAHs, and n-alkanes in urban environments in Afghanistan. Atmospheric Environment, 45(26), 4360-4369. https:// doi.org/10.1016/j.atmosenv.2011.05.049.

World Bank. (2007). India: Strengthening institutions for sustainable growth. Washington D.C.: World Bank.

World Bank. (2008). Nepal country environmental analysis: Strengthening institutions and management systems for enhanced environmental governance. Report No. 38984-NP. Environment and Water Resources Management Unit, Sustainable Development Department, South Asia Region. Washington, DC.

World Bank. (2013). China: Accelerating household access to clean cooking and heating, in East Asia and Pacific clean stove initiative series. Washington, DC: World Bank.

World Bank. (2014). Diesel power generation.

World Bank and Institute for Health Metrics and Evaluation. (2016). The cost of air pollution: Strengthening the economic case for action. Washington, DC: World Bank. License: Creative Commons Attribution CC BY 3.0 IGO.

Xia, X., Zong, X., Cong, Z., Chen, H., Kang, S., \& Wang, P. (2011). Baseline continental aerosol over the central Tibetan plateau and a case study of aerosol transport from South Asia. Atmospheric Environment, 45(39), 7370-7378.

Xiao, H., Kang, S., Zhang, Q., Han, W., Loewen, M., Wong, F., et al. (2010). Transport of semivolatile organic compounds to the Tibetan Plateau: Monthly resolved air concentrations at Nam Co. Journal of Geophysical Research Atmospheres, 115(16), 1-9. http://doi.org/ 10.1029/2010JD013972.

Xiao, Q., Saikawa, E., Yokelson, R. J., Chen, P., Li, C., \& Kang, S. (2015). Indoor air pollution from burning yak dung as a household fuel in tibet. Atmospheric Environment, 102, 406-412.

Xu, B., Cao, J., Hansen, J., Yao, T., Joswia, D. R., Wang, N., et al. (2009). Black soot and the survival of Tibetan glaciers. Proceedings 
of the National Academy of Sciences of the United States of America, 106, 22114-22118. https://doi.org/10.1073/pnas. 0910444106.

Yasunari, T. J., Bonasoni, P., Laj, P., Fujita, K., Vuillermoz, E., Marinoni, A., et al. (2010). Estimated impact of black carbon deposition during pre-monsoon season from Nepal Climate Observatory-Pyramid data and snow albedo changes over Himalayan glaciers. Atmospheric Chemistry and Physics, 10(14), 6603-6615. http://doi.org/10.5194/acp-10-6603-2010.

Yin, X., Kang, S., de Foy, B., Cong, Z., Luo, J., Zhang, L., et al. (2017). Surface ozone at Nam Co in the inland Tibetan Plateau: variation, synthesis comparison and regional representativeness.
Atmospheric Chemistry and Physics, 17, 11293-11311. https://doi. org/10.5194/acp-17-11293-2017.

Young, O. R., Guttman, D., Qi, Y., Bachus, K., Belis, D., Cheng, H., et al. (2015). Institutionalized governance processes: Comparing environmental problem solving in China and the United States. Global Environmental Change, 31, 163-173.

Zhao, Z., Cao, J., Shen, Z., Xu, B., Zhu, C., Chen, L. W. A., et al. (2013). Aerosol particles at a high-altitude site on the Southeast Tibetan Plateau, China: Implications for pollution transport from South Asia. Journal of Geophysical Research Atmospheres, 118 (19), 11360-11375. http://doi.org/10.1002/jgrd.50599.
Open Access This chapter is licensed under the terms of the Creative Commons Attribution 4.0 International License (http:// creativecommons.org/licenses/by/4.0/), which permits use, sharing, adaptation, distribution and reproduction in any medium or format, as long as you give appropriate credit to the original author(s) and the source, provide a link to the Creative Commons license and indicate if changes were made.
The images or other third party material in this chapter are included in the chapter's Creative Commons license, unless indicated otherwise in a credit line to the material. If material is not included in the chapter's Creative Commons license and your intended use is not permitted by statutory regulation or exceeds the permitted use, you will need to obtain permission directly from the copyright holder. 